\title{
Entzündliche Erkrankungen
}

C. Warnke, J. Havla, M. Kitzrow, A. Biesalski, S. Knauss

2.1 Multiple Sklerose -53

2.1.1 Definition der MS - 53

2.1.2 Diagnostische Kriterien der MS - 54

2.1.3 Ätiologie der MS - 55

2.1.4 Makroskopische Veränderungen der MS -57

2.1.5 Histopathologische Veränderungen der MS - 58

2.1.6 Pathophysiologische Prinzipien der MS - 58

2.1.7 Therapie -62

2.2 Ambulant erworbene bakterielle Meningitis/ Meningoenzephalitis - 66

2.2.1 Erregerspektrum - 67

2.2.2 Aufbau und Funktion der Blut-Hirn-Schranke - 69

2.2.3 Pathophysiologie der bakteriellen Meningoenzephalitis - 70

2.2.4 Perspektiven -76

2.3 Herpes-Enzephalitis - 77

2.3.1 Herpesviren -78

2.3.2 Pathologie/Histopathologie -79

2.3.3 Klinischer Verlauf und Pathophysiologie $\quad-80$

2.3.4 Sekundäre Autoimmunprozesse -83

2.3.5 Immunsuppressive Therapie bei NMDA-positiver Herpes-Enzephalitis? - 84

2.3.6 Grundprinzipien der Therapie -85 
2.4 Limbische Enzephalitis und Autoimmunenzephalitis - 86

2.4.1 Grundlagen/Nomenklatur -86

2.4.2 Das limbische System - 87

2.4.3 Entstehungsmechanismus immunvermittelter Enzephalitiden -88

2.4.4 Grundprinzipien der Pathophysiologie unterschiedlicher Enzephalitiden - 89

2.4.5 Klinische und therapeutische Implikationen - 94

Literatur $\quad-95$ 


\subsection{Multiple Sklerose}

\section{Warnke, J. Havla}

\section{- - Zum Einstieg}

Die multiple Sklerose (MS) ist eine chronisch-entzündliche, immunvermittelte Erkrankung des zentralen Nervensystems. Während sie in der Frühphase oft von schubförmig auftretenden, häufig reversiblen neurologischen Ausfällen dominiert wird, kommt es mit längerer Erkrankungsdauer zunehmend zu einem progredienten Krankheitsverlauf. Hier steht dann ein nicht mehr reversibler und fortschreitender Verlust von motorischen, sensiblen und kognitiven Fähigkeiten im Zentrum der Erkrankung. Ausgehend von aktuellen Erkenntnissen zur Ätiologie und Pathogenese der MS gibt dieses Kapitel zudem eine Übersicht über die aktuell revidierten Kriterien einer klinischen Diagnosestellung sowie die Grundprinzipien der Wirkungsweise von MS-gerichteter Immuntherapie. Die Herausforderungen und Risiken der immuntherapeutischen Langzeitintervention werden dabei nicht ausgespart.

\section{Multiple Sklerose (MS)}

- Definition: Chronisch-entzündliche, immunvermittelte Erkrankung des zentralen Nervensystems (Gehirn und Rückenmark).

- Epidemiologie:

- Inzidenz: 8/100.000,

- Prävalenz: 200/100.000,

- Mortalität: 1-2/100.000,

- Lebenszeitverkürzung 7-14 Jahre.

- mehr als 2 Millionen MS-Kranke weltweit.

- Ätiologie:

- Unklar, komplexe Interaktion von Genetik und Umweltfaktoren, bei der es zu einer fehlgeleiteten Immunantwort gegen Strukturen von Gehirn und Rückenmark kommt.

- Zielantigen bislang nicht definiert.

- Diagnostik: Ausschlussdiagnose basierend auf klinischen Befunden, Magnetresonanztomographie und Labor

- Therapie:

- Akut (Schubtherapie): Glukokortikosteroide und Plasmaseparation/ Immunadsorption.
- Verlaufsmodifizierend: immunmodulierende oder immunsuppressive Medikamente.

\subsubsection{Definition der MS}

Die MS gehört mit geschätzten 200.000 Erkrankten in Deutschland und über 2 Millionen Betroffenen weltweit zu den häufigsten Erkrankungen in der Neurologie. Das Manifestationsalter liegt typischerweise im jungen Erwachsenenalter (20.-40. Lebensjahr), und Frauen sind 2- bis 3-mal häufiger betroffen (Kip et al. 2016), wie man es oft bei Erkrankungen mit vermuteter Immunpathogenese findet, ohne dass die Ursache hierfür geklärt wäre (Reich et al. 2018).

Der Begriff MS ist zunächst deskriptiv und beschreibt die an verschiedenen Stellen auftretenden („multiple") Vernarbungen („Sklerose“). Der Terminus „Encephalomyelitis disseminata" wird synonym verwendet. Er bringt zum Ausdruck, dass die MS eine entzündliche Erkrankung („... itis“) des zentralen Nervensystems (ZNS: Gehirn und Rückenmark) ist und beinhaltet auch, dass die Erkrankung definitionsgemäß an verschiedenen Stellen (sog. räumliche Dissemination) und zu verschiedenen Zeiten (zeitliche Dissemination) auftritt (Reich et al. 2018) Charakterisiert wird die Erkrankung vor allem in ihrer Frühphase von schubförmig auftretenden, zunächst oft reversiblen neurologischen Störungen (schubförmige MS, RMS).

Schub
Ein Schub ist über eine durch den Patienten
berichtete oder objektiv erfasste Episode
neurologischer Störungen definiert, die
typisch für einen entzündlichen demyelini-
sierenden Prozess im ZNS ist, mindestens
24 Stunden anhält und nicht von Fieber oder
einer Infektion begleitet wird.

Infolge eines Schubes kann es bei unvollständiger Rückbildung zu Behinderung kommen. Eine fortschreitende Behinderung, zumeist gemessen auf der Expanded Disability Status Scale (EDSS) (Kurtzke 1983), kann jedoch auch schubunabhängig eintreten, wobei dies sowohl bei der schubförmigen MS, als auch bei chronisch progredienten Varianten (s. unten) beobachtet wird. 
Ein charakteristisches Frühsymptom der MS ist die sog. Neuritis nervi optici (Entzündung des Sehnervs), die typischerweise mit retrobulbären Augenschmerzen, Rotentsättigung sowie Latenzverzögerung in den visuell evozierten Potenzialen (VEPs) einhergeht. Weitere frühe Symptome sind Sensibilitätsstörungen und Schmerzen sowie neurogene Blasenstörungen, Obstipation und/oder Sexualfunktionsstörungen.

Motorische Störungen (Spastik, Muskelschwäche, Ataxie, Tremor) führen oft erst im weiteren Verlauf zu einer progredienten Gangstörung, die in einem deutschen Kollektiv nach einer durchschnittlichen Krankheitsdauer von knapp 13 Jahren bei $28 \%$ der Patienten zur Abhängigkeit von einer Gehhilfe führte und in 6\% der Fälle zur Rollstuhlpflichtigkeit. Zunehmend werden auch schwerer fassbare Symptome wie kognitive Störungen, neuropsychiatrische Veränderungen und reduzierte Belastbarkeit/Fatigue als wichtige, behindernde Elemente der Erkrankung wahrgenommen (Kip et al. 2016).

Im Verlauf der Erkrankung kommt es häufig zum Übergang in einen progredienten Krankheitsprozess, in dem eine Erholung von einem Schub nicht mehr oder nur noch eingeschränkt stattfindet. Der Übergang in diese als sekundär chronisch-progrediente MS (SPMS) bezeichnete Form tritt im Mittel nach 10-15 Krankheitsjahren ein (Ontaneda et al. 2017). Davon lässt sich eine kleinere Gruppe von etwa 7\% aller Patienten abgrenzen, bei der die Erkrankung primär progredient verläuft (PPMS) (Kip et al. 2016).

( Unabhängig von der Verlaufsform ist die Erkrankung mit einem individuell unterschiedlichen und nur bedingt vorhersagbaren, über die Jahre kumulierenden Risiko einer bleibenden Behinderung, mit einer durchschnittlich um 7-14 Jahre verkürzten Lebenserwartung und einer reduzierten Lebensqualität assoziiert.

\subsubsection{Diagnostische Kriterien der MS}

Für die Diagnose der multiplen Sklerose sind international gegenwärtig die 2001 veröffentlichten (McDonald et al. 2001) und 2017 zuletzt überarbeiteten sogenannten McDonald-Kriterien gültig (Thompson et al. 2018). Die Diagnose MS kann gestellt werden, sofern diese Kriterien erfüllt sind und sich keine Hinweise auf eine konkurrierende, die Beschwerden des Patienten besser erklärende Erkrankung finden. Die McDonald-Kriterien zielen insgesamt auf eine frühere Diagnosestellung $a b$, sodass inzwischen häufig bereits nach dem ersten klinischen Ereignis (Schub) die Diagnose einer MS gestellt werden kann. Wie im Folgenden ausgeführt, erfolgt die Diagnose bei typischer Klinik in der Regel mit Hilfe des MRTs sowie der Liquordiagnostik.

\subsubsection{Magnetresonanztomographie (MRT)}

Die örtliche und zeitliche Dissemination der Erkrankung wird entweder anhand von objektivierbaren klinischen Läsionen in verschiedenen Arealen des ZNS zu verschiedenen Zeiten oder anhand von Kriterien der Ergebnisse der Zusatzdiagnostik nachgewiesen (s. Übersicht). Diese Kriterien ermöglichen dabei die Diagnose der MS bereits nach einem ersten Schub, der in der klinisch-neurologischen Untersuchung, im VEP bei Patienten mit Sehstörung oder in der MRT objektivierbar ist (Thompson et al. 2018).

Kriterien zur Diagnose der schubförmigen MS anhand von MR und Liquor

- Örtliche Dissemination: $\geq 1$ T2-Läsionen in mindestens 2 von 4 der folgenden

Regionen:

- periventrikulär

- juxtakortikal/kortikal

- infratentoriell

- spinal

- Zeitliche Dissemination (eines von

3 Kriterien muss erfüllt sein):

- gleichzeitiger Nachweis von MRTLäsionen mit und ohne Schrankenstörung

- neue oder schrankengestörte T2Läsion in der Verlaufs-MRT, ungeachtet der zeitlichen Abstände

- Nachweis von isolierten oligoklonalen Banden im Liquor

(nach Thompson et al. 2018)

\subsubsection{Liquor}

Der Untersuchung des Liquor cerebrospinalis kommt bei der Sicherung der zeitlichen Dissemi- 
nation (Übersicht s. oben) sowie im Rahmen der Ausschlussdiagnostik eine zentrale Bedeutung zu (Thompson et al. 2018). Als alternative Erkrankungen gilt es beispielsweise, die Neuroborreliose, die Neurosyphilis, eine systemische rheumatische Erkrankung (z. B. den SLE mit ZNS-Beteiligung) oder eine Neurosarkoidose von der MS abzugrenzen.

Üblicherweise erfolgt in Deutschland neben der Bestimmung des IgG-Quotienten im Quotientenschema und der Untersuchung auf oligoklonale Banden (OKB) auch die Analyse auf autochthone, intrathekale Produktion von Antikörpern gegen Masern-, Röteln- und Varizellazoster-Viren (sog. MRZ-Reaktion), die bei moderater Sensitivität (etwa 60\%) die höchste Spezifität für die Diagnose der MS aller Liquorparameter aufweist (Jarius et al. 2017). Zytologisch findet sich häufig eine milde Pleozytose mit lymphomonozytärem Zellbild.

\subsubsection{Weitere Zusatzdiagnostik}

Evozierte Potenziale bei der Diagnosestellung der MS werden zur Objektivierung von berichteten oder auch klinisch untersuchbaren funktionellen Defiziten eingesetzt. Zunehmend wird auch die optische Kohärenztomographie (OCT) eingesetzt, um eine subklinische oder klinisch nachvollziehbare Pathologie zu objektivieren und insbesondere die retinale Nervenfaserschicht (RNFL) in Verlaufsuntersuchungen darzustellen. Noch spielt die OCT keine Rolle in offiziellen Diagnosekriterien der MS, könnte aber perspektivisch an Bedeutung gewinnen, z. B. auch zum nichtinvasiven Monitoring von therapeutischen Effekten (Petzold et al. 2017).

\subsection{3 Ätiologie der MS}

Die Ätiologie der MS ist noch unklar ist (Goodin 2016). Bislang ist nicht einmal bekannt, ob eine oder mehrere Ursachen zur MS führen. Im Allgemeinen geht man jedoch von einer komplexen Erkrankung aus, bei der wahrscheinlich genetische Disposition und Umweltfaktoren mit bislang unzureichend definierten zusätzlichen Einflüssen zusammenwirken, wobei die einzelnen Faktoren auch miteinander interagieren können. Somit kann das Erkrankungsrisiko auch bei der Präsenz einzelner Ursachen bislang nicht zuverlässig vorhergesagt werden. Entsprechend liegt das Wieder- holungsrisiko für dizygote Zwillinge bei etwa 5\% und für monozygoten Zwillinge bei etwa 30\%. Aber auch das Risiko für Kinder eines MSerkrankten Elternteils, eine MS zu bekommen, ist im Vergleich zur allgemeinen Bevölkerung gering erhöht (circa $2-4 \%$ vs. $0,1 \%$ ).

Einen Hinweis auf die Interaktion mit beteiligten Umweltfaktoren geben Ergebnisse der Migrationsstudien. Dabei korreliert das MS-Risiko mit dem Alter bei der Auswanderung. Emigriert ein Mensch erst im Erwachsenenalter, behält er das Erkrankungsrisiko des verlassenen Landes. Wandert er schon als Kind aus, übernimmt er das Erkrankungsrisiko des neuen Ziellandes (Goodin 2016).

\section{Zwillingsstudie}

An der Ludwig-Maximilians-Universität München gibt es aktuell eine deutschlandweite Zwillingsstudie, für die bereits $>50$ monozygote Zwillingspaare rekrutiert wurden (http://www.klinikum.uni-muenchen.de/Institut-fuer-Klinische-Neuroimmunologie/de/aktuelles/neuigkeiten_ MS/20161119_Zwillingsstudie.html), bei denen mindestens ein Zwilling an MS erkrankt ist. Die Studie hat sich zum Ziel gesetzt, die Auslösung und Entstehung der multiplen Sklerose und ganz besonders das komplizierte Zusammenspiel von Umweltfaktoren und Erbfaktoren besser zu verstehen. Anhand von detaillierten Interviews, klinischen und kernspintomographischen Untersuchungen sowie Analysen von Proben (Blut-, Liquor- und Stuhlproben) werden in verschiedenen Projekten zahlreiche Fragestellungen untersucht, u. a. der Einfluss der Darmflora (s. unten: Info "Mikrobiom") und anderer Umweltfaktoren auf die Entstehung der MS sowie der Einfluss möglicher Risikogene auf die Krankheitsentstehung.

Derartige Studien sind von großer Bedeutung für ein besseres Verständnis dafür, warum trotz einer identischen genetischen Prädisposition und ähnlichen Umweltfaktoren in den ersten Lebensphasen nur ein Teil der Zwillingspaare hinsichtlich des klinischen Phänotyps MS-konkordant sind.

\subsubsection{Viren und MS}

Mit der Erstbeschreibung der MS Ende des 19. Jahrhunderts kam der weiterhin nicht vollständig ausgeräumte Verdacht auf, dass es sich bei der MS um eine Viruserkrankung handeln könnte. Jedoch gelang es nicht, pathognomonische histopathologische Befunde zu erheben, die für die MS als spezifische Viruserkrankung sprechen, und auch der direkte Nachweis eines spezifischen krankheitsverursachenden Virus gelang nicht (Mentis et al. 2017). Unter den mit einem erhöhten MS-Risiko einhergehenden Faktoren (s. Übersicht) findet sich aber die Infektion mit dem Epstein-Barr Virus (EBV). 
Definierte MS-Umweltrisikofaktoren

- Infektion mit Epstein-Barr Virus (EBV) bzw. Anamnese einer infektiösen Mononukleose

- Niedriger Vitamin-D-Spiegel/gemäßigte Klimazonen

- Zigarettenrauchen

- Erhöhter Body-Mass-Index (BMI)

Nahezu alle Patienten mit MS haben eine positive EBV-Serologie (im Vergleich zu etwa 90-95\% der Vergleichspopulation), und eine besondere Risikoerhöhung besteht für Individuen, die im Jugendalter eine infektiöse Mononukleose als symptomatische Infektion mit EBV erlitten haben. Somit wird die EBV-Infektion allgemein als Voraussetzung, nicht jedoch als alleinige Ursache für die Entwicklung einer MS betrachtet. Andere Viren der Herpesfamilie (u. a. HHV6, CMV und VZV) wurden ebenfalls als Auslöser der multiplen Sklerose diskutiert, ein möglicher Zusammenhang ließ sich jedoch bislang nicht erhärten (Mentis et al. 2017).

Aufmerksamkeit erlangten zuletzt auch humane endogene Retroviren (HERV), die ihre umgeschriebene RNA in das menschliche Genom integrieren können und unter bestimmten Umständen auch Genprodukte hervorbringen können. Daraus entwickelte sich die Hypothese, dass von HERVs gebildete Eiweiße mögliche Kofaktoren bei der Entstehung der MS darstellen könnten, z. B. durch die Aktivierung von Toll-likeRezeptoren oder durch die Hemmung von zellulären Reparaturvorgängen. Ein rekombinanter monoklonaler Antikörper gegen ein Hüllprotein von HERV-W verfehlte in einer Phase-IIb-Studie allerdings den Studienendpunkt in Bezug auf kontrastmittelaufnehmende Läsionen in der MRT, sodass sich ein möglicher Zusammenhang zwischen HERV-W und MS bislang nicht durch einen innovativen Therapieansatz belegen ließ.

\subsubsection{Immunsystem und multiple Sklerose}

Ab den 1930-er Jahren bildet sich parallel mit der Entwicklung von experimentellen Tiermodellen verstärkt die Immunhypothese der MS heraus. Gestützt wird diese Hypothese durch genetische Assoziationsstudien, die sog. "genome-wide association studies" (GWASs), die zeigten, dass insbe- sondere HLA-Klasse-II-Gene und insgesamt mehr als 200 weitere „Immungene“ das Risiko der Entwicklung einer MS mit beeinflussen (Axisa und Hafler 2016; Beecham et al. 2013; Andlauer et al. 2016). Der Beitrag jeder Genvariante ist jedoch äußerst klein. Am relevantesten ist der HLA DRB1*1501-Haplotyp mit einer „odds ratio“ (QR; Quotenverhältnis) von ungefähr 3. Diese Risikogenvarianten beeinflussen jedoch wahrscheinlich auch nur die Entstehung, nicht aber den Verlauf der MS (Kalincik et al. 2013)

Weitere Argumente für die Immunpathogenese sind nachweisbare Immunzellinfiltrate in MS Läsionen mit zum Teil auch klonal expandierten T-Lymphozyten, entzündliche Veränderungen im Liquor von Patienten mit MS und die weiter unten diskutierte zumindest partielle Wirksamkeit einer Vielzahl von Immuntherapeutika (Hohlfeld und Wekerle 2015; Warnke et al. 2013).

\subsubsection{Weitere definierte Einfluss- faktoren auf die MS}

$\mathrm{Zu}$ den weiteren definierten MS-Risikofaktoren zählen

- die geographische Verteilung mit einer höheren Inzidenz in nördlichen Klimazonen,

- ein erniedrigter Vitamin-D-Spiegel,

- das Zigarettenrauchen sowie

- Übergewicht.

Alle diese Faktoren könnten jeweils über die Beeinflussung von Immunvorgängen wirksam werden, die unten genauer diskutiert werden.

Neben diesen bekannten und gut untersuchten Risikofaktoren geht man davon aus, dass zudem Ernährungsfaktoren wie z. B. der Salzgehalt der Nahrung oder Veränderungen im Stoffwechsel bestimmter Fettsäuren sowie das Mikrobiom über die Beeinflussung von Immunvorgängen für die Entwicklung einer MS von Bedeutung sein könnte (Hohlfeld und Wekerle 2015; Haase et al. 2018).

\section{Mikrobiom}

Man geht gegenwärtig davon aus, dass die individuelle Darmflora, auch „Mikrobiota“ genannt, entscheidenden Einfluss auf die Funktion des Immunsystems ausüben könnte. Im Rahmen der nationalen Zwillingsstudie (s. oben) wurde die Darmflora eineiiger Zwillingspaare, bei denen jeweils nur ein Zwilling an MS erkrankt ist, miteinander verglichen. Als wichtigstes Ergebnis dieser Untersuchung zeigte sich, dass genetisch veränderte (transgene) Mäuse (im Modell der spontanen „experimental autoimmune encepahlomyelitis", EAE), die mit Darmbakterien von MS 
Zwillingen besiedelt wurden, häufiger eine der menschlichen MS sehr ähnliche Hirnentzündung entwickelten als Mäuse, die mit Darmbakterien gesunder Zwillinge besiedelt wurden (Berer et al. 2017).

Dabei bleibt aber noch unklar, wie die unterschiedliche Zusammensetzung der Darmbakterien eine Autoimmunreaktion auslösen kann, die letztlich zu einer entzündlichen ZNS-Erkrankung führt. Zudem ist die mögliche Bedeutung der Darmflora für die MS-Pathologie noch nicht beim Menschen selbst gezeigt.

\subsubsection{Makroskopische Veränderungen der MS}

Das pathologische Korrelat der MS sind multiple Entmarkungsherde (Demyelinisierung) sowie die fortschreitende Zerstörung von Nervenzellfasern im ZNS (axonaler Schaden). Prädilektionsstellen sind:

- der Sehnerv,

- der Hirnstamm,

- das Rückenmark,

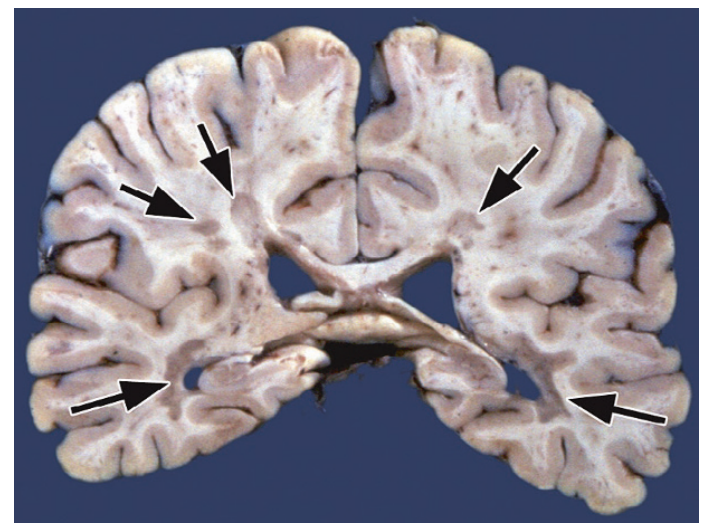

- Abb. 2.1 Makroskopisch nachweisbare MS-typische Läsionen. (Aus: Paulus und Schröder 2012)

- das Kleinhirn sowie

- die balkennahe weiße Substanz.

Demyelinisierende Herde lassen sich direkt im pathologischen Präparat ( $\bullet$ Abb. 2.1) oder indirekt in der MRT (• Abb. 2.2) darstellen.
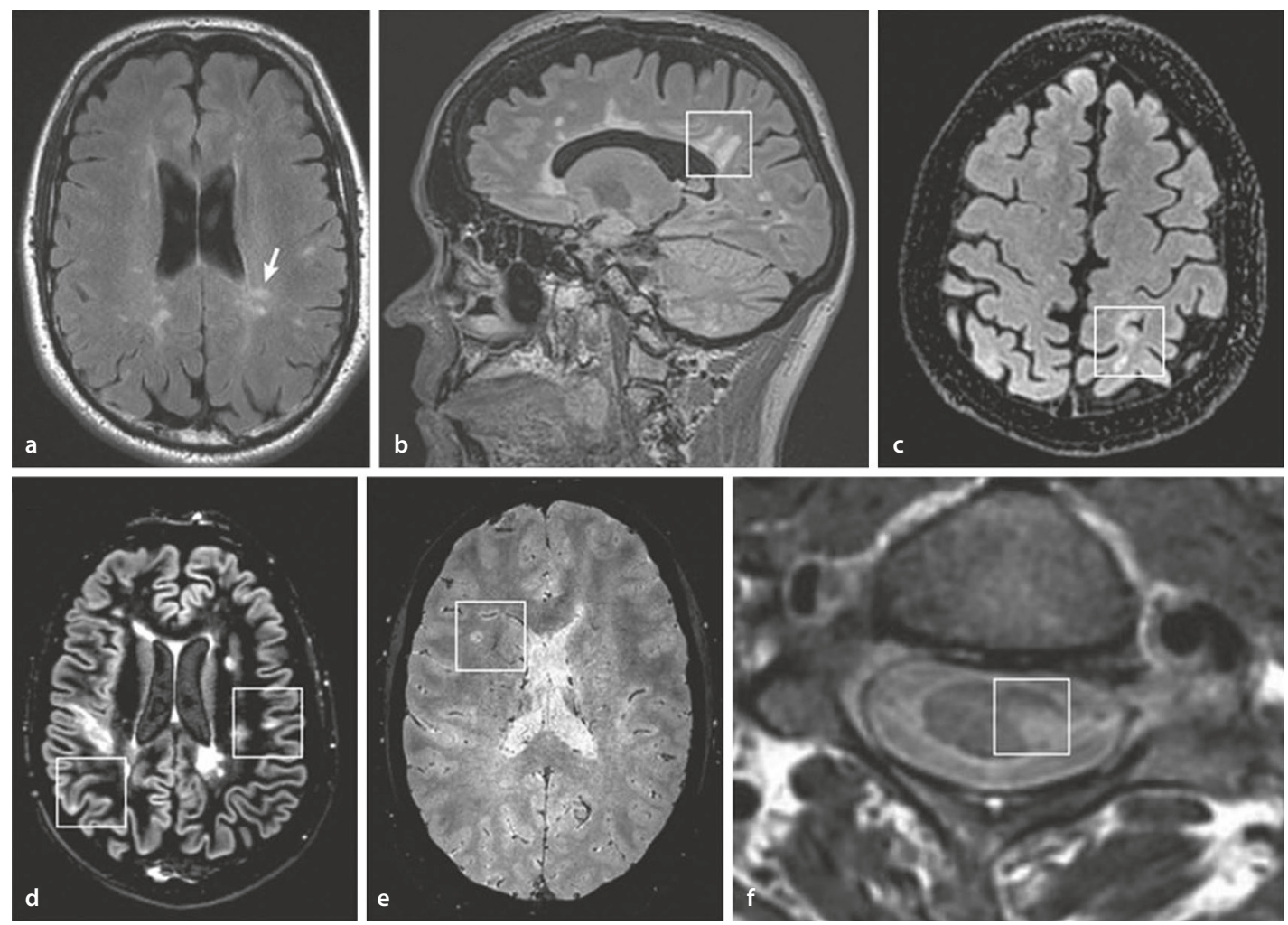

- Abb. 2.2a-f Typische Charakteristika einer multiplen Sklerose in der Magnetresonanztomographie. a Sogenannte Dawson-Finger (Pfeil, axiale FLAIR-Sequenz). b Dawson-Finger (Rahmen, sagittale FLAIR-Sequenz). c Juxtakortikale Läsion (Rahmen, axiale FLAIR-Sequenz). d Kortikale Läsion (Rahmen, axiale DIR-Sequenz). e Zentrales Venenzeichen (Rahmen, axiale T2*-Sequenz). f Exzentrische kurze Myelonläsion (Rahmen, axiale T2Sequenz). (Aus: Geraldes et al. 2018) 


\subsubsection{Histopathologische Verände- rungen der MS}

Die MS gilt historisch als Erkrankung der weißen Substanz. In den „aktiven“ Plaques der schubförmigen MS findet sich ein ausgeprägter Myelinverlust mit Verlust von Oligodendrozyten, jedoch auch Anzeichen einer akuten axonalen Schädigung sowie eine reaktive Astrogliose (Schumacher et al. 2017). Zudem lassen sich in akuten, demyelinisierenden Läsionen deutlich mehr Zellen des Immunsystems (vor allem aktivierte Mikroglia, Makrophagen und T-Lymphozyten) nachweisen als in zellarmen „ausgebrannten Plaques“.

Der Versuch, die durchaus heterogenen histopathologischen Befunde in vier Subtypen einzuteilen, ist weiterhin Gegenstand der wissenschaftlichen Diskussion. Die Subtypen werden neuropathologisch auch in Patterns eingeteilt. Pattern I wird durch eine makrophagenvermittelte, Pattern II durch eine antikörpervermittelte Demyelinisierung definiert. Der Pattern III zeigt neuropathologisch vermehrte Apoptose von Oligodendrozyten, der Pattern IV eine primäre Oligodendropathie (Lucchinetti et al. 2000).

Im Laufe der Erkrankung mit zunehmender klinischer Behinderungsprogression ändert sich auch das histopathologische Erscheinungsbild der weißen Substanz hin zu einer diffusen, zunehmend läsionsunabhängigen Schädigung. Diese Veränderungen entstehen auch in der makroskopisch ansonsten normal erscheinenden weißen Substanz und gelten als Korrelat einer diffusen Mikrogliaaktivierung mit fortscheitendem Axonverlust, einer flächigen Einwanderung von T-Lymphozyten und einer perivaskulären Ansammlung von mononukleären Zellen (Schumacher et al. 2017).

Durch histopathologische Studien ist inzwischen geklärt, dass es bereits frühzeitig bei der MS auch zu einer Schädigung der grauen Substanz kommt. Auch hier kann man fokale Läsionen von einer diffusen Schädigung abgrenzen. Allerdings stellt sich der histopathologische Befund der kortikalen Entzündung mit nur einem vereinzelten Nachweis von Makrophagen oder T-Zellen im Vergleich zu den fokalen Läsionen in der weißen Substanz unterschiedlich dar (Schumacher et al. 2017; - Abb. 2.3). Als Generator der (kortikalen) Entzündung werden hier u. a. auch ektope meningealen Lymphfollikel vermutet, die aus B- oder T-Zellen, Makrophagen sowie Plasmazellen bestehen können (• Abb. 2.4).

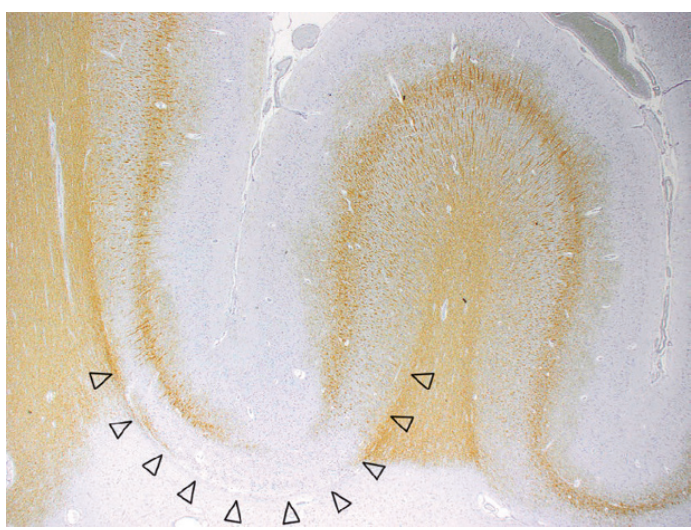

- Abb. 2.3 Kortikale Läsionen sind ein häufiges Phänomen bei MS-Patienten. Die Pfeilköpfe markieren die Grenze zwischen Marklager und Kortex. (Aus: Paulus und Schröder 2012)

Für die klinische Behinderungsprogression bei MS-Patienten ist die Atrophie der grauen Substanz wahrscheinlich von größerer Bedeutung als die fokalen Läsionen der weißen Substanz. Diese Atrophie wird durch neurodegenerative Prozesse angetrieben, $d$. h. beispielsweise durch den Untergang axonaler Verbindungen oder die Abnahme kortikaler Nervenzellen. Welche pathophysiologischen Ursachen der Atrophie zugrunde liegen, wird derzeit in unterschiedlichen Hypothesen überprüft (Schumacher et al. 2017). Als möglicherweise kausal werden unter anderem diskutiert:

- entzündliche oder zytotoxische Mediatoren wie Zytokine, Chemokine oder Komplementfaktoren,

- freie Radikale und oxidativer Stress,

- Störungen des Glutamathaushaltes.

Diese pathomechanistischen Erklärungsmodelle basieren auf der Annahme einer entzündlichen Reaktion als Antrieb der Neurodegeneration bei MS. Ein primär neurodegenerativer Prozess erscheint weniger wahrscheinlich.

\subsubsection{Pathophysiologische Prinzipien der MS}

Die Destruktion des Hirngewebes mit fokalen und diffusen Läsionen der weißen und grauen Subs$\tan z$ wird durch eine fehlgerichtete Immunantwort ausgelöst. Zellen des adaptiven (T-Lymphozyten, B-Lymphozyten) und des angeborenen Immunsystems (z. B. Makrophagen) wirken dabei 


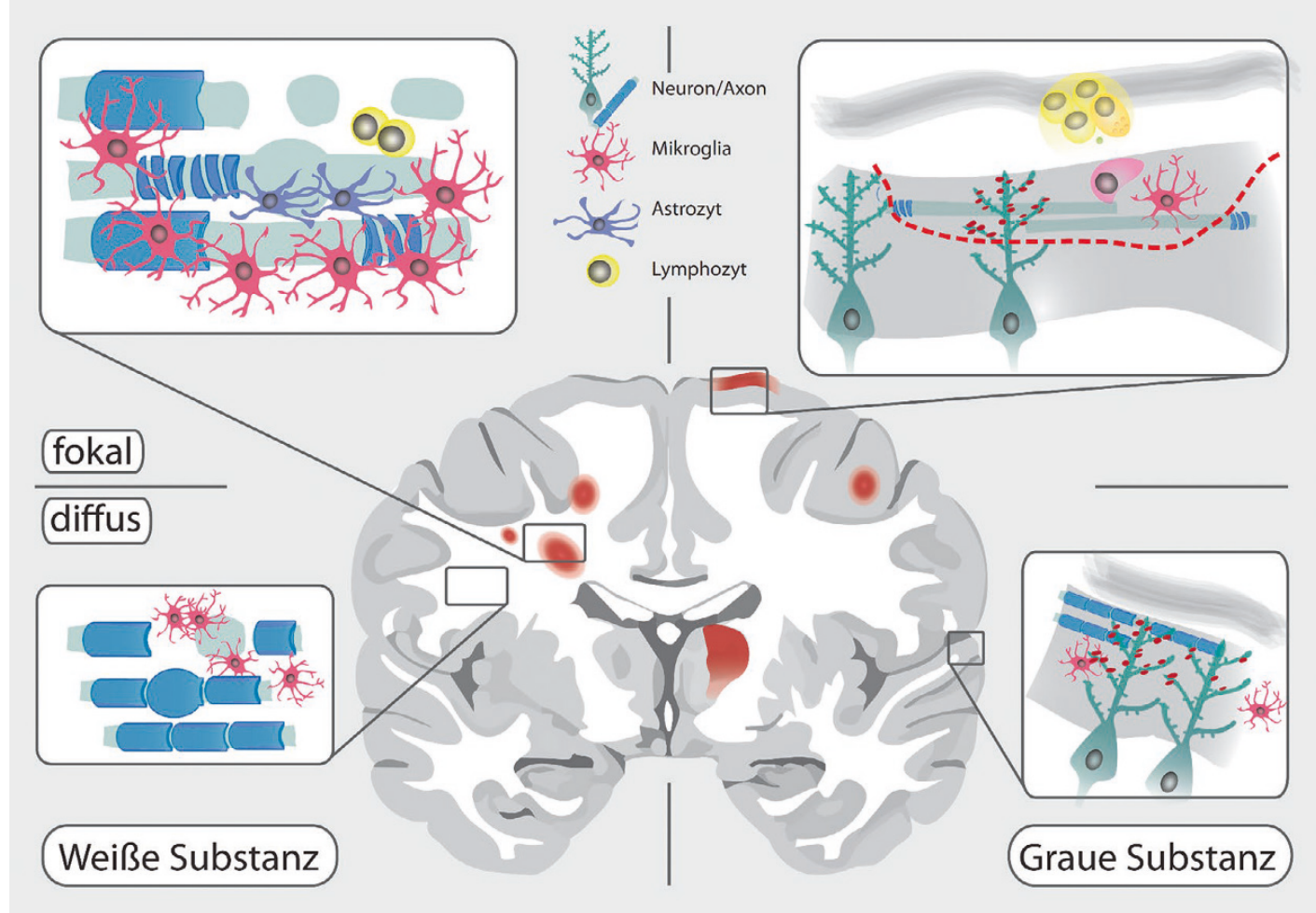

- Abb. 2.4 Fokale und diffuse Schädigung in weißer und grauer Substanz bei der multiplen Sklerose. (Mod. nach Schumacher et al. 2017)

- Abb. 2.5 Vereinfachte Darstellung der Immunpathogenese der MS. In peripheren Organen werden T-Lymphozyten ( $T$, blau) mit Hilfe von Antigen-präsentierenden Zellen (APC, rot) und B-Lymphozyten (B, gelb) aktiviert und moduliert und vice versa. Aktivierte $T$ - ( $T$, orange) und B- (B orange) Lymphozyten können im Gehirn Nervenstrukturen angreifen, wenn sie klonal expandieren und sich der Kontrolle von regulatorischen T-Zellen ( $T$, grün) entziehen. (Mod. nach Warnke et al. 2013)

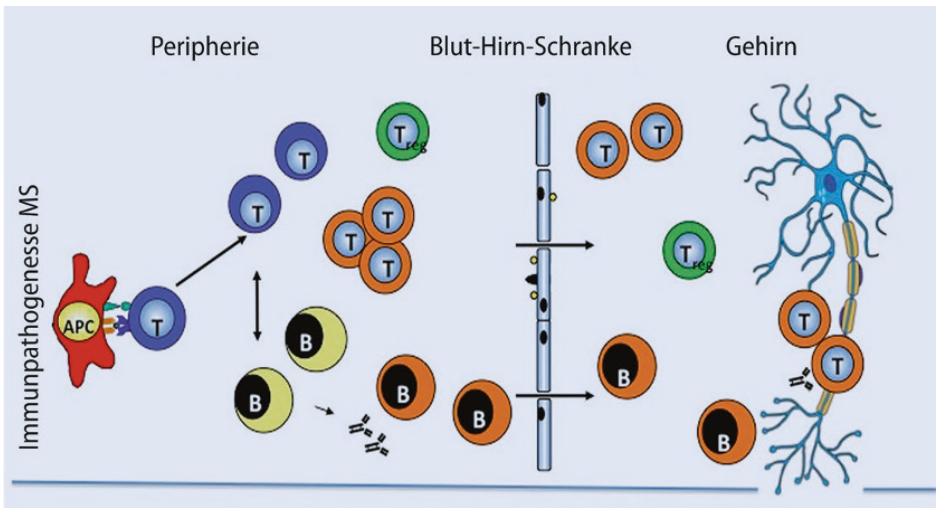

u. a. mit humoralen Faktoren zusammen, sodass schließlich myelinbildende Oligodendrozyten des ZNS ebenso wie Nervenfasern indirekt und direkt geschädigt werden.

Wie in Abb. 2.5 illustriert, wird das Gehirn durch die Blut-Hirn-Schranke vom peripheren, systemischen Immunkompartiment relativ abgetrennt. Zellen des adaptiven Immunsystems, unter anderem T-Lymphozyten, befinden sich in der Peripherie und werden über die Interaktion mit
Antigen-präsentierenden Zellen aktiviert. B-Lymphozyten werden wiederum durch T-Zellen moduliert und vice versa. Aktivierte, potenziell auch gegen das ZNS gerichtete T- und B-Lymphozyten gehören auch zum physiologischen Immunrepertoire, werden aber durch regulatorische T-Zellen kontrolliert.

Über diese aktivierten Lymphozyten, die die Blut-Hirn-Schranke überwinden können, ist eine lokale Immunüberwachung des ZNS gewährleis- 
tet. Diese Zellen dienen u. a. der Abwehr von Infektionen und der Verhinderung von Neoplasien. Bei der MS werden derartige T- und B-Lymphozyten jedoch so aktiviert, dass sie klonal expandieren und sich der Kontrolle der regulatorischen Zellen entziehen.

\subsubsection{Zielstrukturen in der Immun- pathogenese der MS}

In autoimmunen Tiermodellen der MS werden MS-ähnliche Krankheitsbilder zumeist bei Nagern durch bestimmte definierte Autoantigene induziert. Bei der MS selbst ist dagegen das Antigen nicht eindeutig definiert (Hohlfeld et al. 2016a). Hierin unterscheidet sich die MS von anderen immunvermittelten Erkrankungen, so z. B. der antikörperpositiven Myasthenia gravis (s. Kapitel 7.1) oder auch der Gruppe der Antikörper-assoziierten Enzephalitiden (z. B. der anti-NMDA RezeptorEnzephalitis, - Abschn. 2.4). Lediglich bei einer Subgruppe von Patienten, die an einer Autoantikörper-positiven Neuromyelitis-optica-Spektrum-Erkrankung (NMOSD) leiden, ist das Antigen bekannt.

Bei der NMOSD handelt es sich um eine primär die Sehnerven und das Rückenmark betreffende entzündliche Erkrankung des ZNS mit Gemeinsamkeiten zur MS, bei der dem Nachweis von Anti-Aquaporin4-Autoantikörpern (Lennon et al. 2004) und zunehmend auch Anti-MyelinOligodendrocyte-Glycoprotein (MOG)-Antikörpern (Jarius et al. 2016) ein hoher diagnostischer Wert wie auch eine pathophysiologische Relevanz zugeschrieben werden.

\section{NationMS und NationNMO des KKNMS (Krankheits- bezogenes Kompetenznetz Multiple Sklerose)}

Das Krankheitsbezogene Kompetenznetz Multiple Sklerose (KKNMS) ist ein interdisziplinäres, deutschlandweites Forschungsnetzwerk (www.kompetenznetz-multiplesklerose. de). Es ist eines von 21 Kompetenznetzen in der Medizin, die vom Bundesministerium für Bildung und Forschung (BMBF) initiiert wurden. Sie alle verfolgen das Ziel, Forscher zusammenzubringen, um die Patientenversorgung zu verbessern.

Eines der Kernprojekte des KKNMS ist die Kohortenstudie NationMS, die seit der ersten Förderperiode besteht und auf eine Gesamtlaufzeit von mindestens 10 Jahren angelegt ist. Der MS-Kohortenstudie wird mit Beginn der dritten Förderperiode eine NMO-Kohorte (NationNMO) zur Seite gestellt. Ziel ist es unter anderen, die Patienten beider Kohorten zu vergleichen und so auch die Diagnosekriterien der NMOSD zu verfeinern.

Große Sichtbarkeit hat inzwischen das Qualitätshandbuch des KKNMS erlangt, das ein wichtiger Ratgaber für Neurologen bei der Verschreibung von Immuntherapeutika dar- stellt und frei im Internet abgerufen werden kann (http:// www.kompetenznetz-multiplesklerose.de/fachinformationen/qualitaetshandbuch/).

Die Rolle von CD4+-T-Lymphozyten, CD8+-TZellen, B-Zellen und Antikörpern in der Pathogenese der MS wurden in den letzten Jahren detailliert erforscht. Dabei wurden die Erkenntnisse zum einen aus dem autoimmunen Tiermodell der MS (EAE) wie auch aus humanen Studien gewonnen (Hohlfeld et al. 2016a). T- und B-Zellen exprimieren Antigen-spezifische Oberflächenrezeptoren, die sogenannten T-Zell- (TCRs) und B-Zell-Rezeptoren (BCRs), die eine sehr hohe Vielfalt aufweisen. Durch genetische Rekombination und auch zufällige Prozesse können beispielsweise bis $\mathrm{zu} 10^{15}$ verschiedene TCRs gebildet werden, wobei das menschliche Immunsystem hieraus mehr als 25 Millionen verschiedene T-Zell-Klone selektiert.

Die Vielfalt der BCRs ist sogar noch höher, bedingt durch die Fähigkeit von B-Zellen, sich im Rahmen der Affinitätsreifung noch weiter anzupassen (Hohlfeld et al. 2016a). Für das Verständnis der Autoimmunpathogenese ist es wichtig zu wissen, dass TCRs viele verschiedene Antigene erkennen können, die allerdings häufig strukturverwandt sind. Diese Polyspezifität erklärt, weshalb Immunantworten, z. B. gegen bestimmte Pathogene, in einigen Fällen Autoimmunerkrankungen triggern können. Zudem ist inzwischen bekannt, dass Autoimmunität zu einem gewissen Grad physiologisch ist und B- und T-Zellen vor allem dann zerstört werden, wenn sie eine hohe Bindungsstärke zu Autoantigenen aufweisen. B- und T-Zellen mit geringerer Bindungsstärke hingegen können überleben und werden von den sogenannten regulatorischen $\mathrm{B}$ - und T-Zellen kontrolliert.

\section{- CD4+-T-Zellen in der MS}

Lange Zeit galt diese Zellpopulation („T-Helferzellen") als Schlüsselelement in der Pathogenese der MS. Die Annahme beruhte auf der Tatsache, dass genetische Studien starke Assoziationen mit HLAKlasse-II-Genen zeigten, deren Proteinprodukte Antigenfragmente spezifisch gegenüber CD4+Zellen, nicht jedoch gegenüber CD8+-T-Zellen präsentieren.

Auf der Suche nach Ziel-Antigenen in der Pathogenese der MS wurden im Tiermodell zahlreiche Immunisierungsexperimente durchgeführt, die zeigten, dass Gewebe des ZNS, aber auch ver- 
schiedene isolierte Myelinproteine („myelin basic protein" [MBP], MOG oder „proteolipid protein“ [PLP]) wie auch der Transfer von aufgereinigten MBP-spezifischen CD4+-T-Zellen eine EAE hervorrufen können (Hohlfeld et al. 2016a). Anschließend konnte auch bei MS-Patienten gezeigt werden, dass z. B. MBP- oder auch MOG-spezifische T-Zellen aus dem Blut kultiviert werden können, und dass das Hauptrisikoallel, HLA$\mathrm{DRB}^{\star} 1501$, unter anderen zu den MBP-präsentierenden HLA-Molekülen zählt.

Da allerdings Myelin-Antigen-spezifische CD4+-T-Zellen auch aus dem Blut von Gesunden isoliert werden können (und Transferexperimente bei Menschen unethisch wären), gibt es bisher keinen direkten Beweis für deren pathogenetische Relevanz für die MS. Indirekte Hinweis für deren Relevanz sind jedoch beispielsweise eine höhere Frequenz dieser Zellen bei Patienten mit MS sowie Ergebnisse aus humanisierten Mausmodellen, wobei diese Mäuse Myelin-Antigen-spezifische humane TCRs zusammen mit humanen HLA Klasse II Molekülen exprimierten und spontan eine EAE entwickeln konnten.

Zusammenfassend kann festgehalten werden, dass Myelin-Antigen-spezifische CD4+-T-Zellen wahrscheinlich eine bedeutende Rolle in der Pathogenese der MS spielen. Da jedoch eine Vielzahl von Antigenen relevant zu sein scheinen und die Antigenprofile sogar beim einzelnen Patienten über die Zeit fluktuieren können, lassen sich bislang nicht ein oder mehrere "MS-Antigene“ definieren, was wiederum die Entwicklung von Immunisierungen gegen die MS oder auch die Personalisierung der Therapie der MS erschwert (Hohlfeld et al. 2016a).

\section{- CD8+-T-Zellen in der MS}

CD8+-T-Zellen („zytotoxische T-Zellen“) finden sich in aktiven MS-Läsionen häufig in größerer Zahl als CD4+-T-Zellen, und Untersuchungen des TCR-Repertoires zeigen an, dass diese Zellen lokal im ZNS expandieren. Diese Erkenntnisse implizieren eine hohe Relevanz dieser Zellpopulation in der MS-Pathogenese. Der experimentelle Beweis hierfür gestaltet sich jedoch schwieriger als für CD4+-T-Zellen, unter anderem weil die Isolation und Kultur von Antigen-spezifischen CD8+-T-Zellen eine Herausforderung darstellt.

Zudem können CD8+-T-Zellen auch vor autoimmuner Erkrankung schützen, indem sie enzephalogene CD4+-T-Zellen eliminieren. Entsprechend entwickeln beispielsweise CD8+-depletierte Mäuse eine schwerere Form der EAE als der Wild-Typ. Zusammenfassend bleibt daher bislang unklar, ob CD8+-T-Zellen primär pathogene Effektorzellen sind, regulatorische Zellen oder nur nicht-kausale Bystander-Infiltrate (Hohlfeld et al. 2016b).

\section{- B-Zellen und Antikörper-Antworten in der MS}

Insbesondere auch durch die Publikation einer ersten positiven Studie zur Therapie auch primär progredienter Formen der MS mit einem B-Zellgerichteten Therapeutikum, dem Anti-CD20Antikörper Ocrelizumab (Montalban et al. 2017), schreibt man den B-Zellen eine zunehmend größere Bedeutung in der MS-Pathogenese zu. B-Zellen sind dabei nicht nur die Antikörper-produzierende Zellpopulation, sondern sie haben auch wichtige Antigen-präsentierende und regulatorische Funktionen. Schon lange ist bekannt, dass sich bei etwa $90 \%$ der Patienten mit MS eine intrathekale polyspezifische AntikörperAntwort im Sinne von OKB finden. Dabei handelt es sich in der Regel um Antikörperantworten der IgG-Klasse.

Bei etwa 40\% der Patienten finden sich jedoch auch IgM-Banden. Diese Banden sind im einzelnen Individuum oft über die Zeit stabil. Trotz intensiver Forschung ist es bislang nicht gelungen, die Zielstrukturen dieser Banden eindeutig zu identifizieren.

Ein weiteres Charakteristikum von Patienten mit MS ist der Nachweis der intrathekalen Produktion von Antikörpern gegen häufig vorkommende Virusinfektionen, insbesondere gegen Masern, Röteln und Zoster (sog. MRZ-Reaktion). Diese Reaktion wird jedoch allgemein als Zeichen einer polyspezifischen Immunaktivierung im ZNS gewertet, und eine pathogenetische Relevanz wird dieser Antwort nicht zugeschrieben.

In EAE-Experimenten richten sich Antikörperantworten häufig gegen das an der MyelinOberfläche befindliche MOG. Der alleinige Transfer von Anti-MOG-Antikörpern im EAE-Modell ist nicht krankheitsverursachend, da diese Antikörper nicht in hinreichender Konzentration das ZNS erreichen (Hohlfeld et al. 2016b). Allerdings verstärken beispielsweise MOG-spezifische Antikörper die durch MBP-spezifische CD4+-T-Zellen induzierte EAE. Im Blut von Patienten mit MS 
konnte gezeigt werden, dass sich eine starke antiMOG-Antikörperantwort bei etwa $20-40 \%$ der Kinder mit akuter disseminierter Enzephalomyelitis (ADEM) oder auch kindlicher MS findet. Longitudinale Untersuchungen deuten darauf hin, dass Anti-MOG-Antikörper-Antworten bei Kindern mit einer monophasischen ADEM-Erkrankung im Verlauf nicht mehr, dagegen bei Kindern mit MS länger nachweisbar sind. Bei Erwachsenen mit MS finden sich diese Antikörper in der Regel nicht mehr, wohl aber, wie oben bereits erwähnt, bei einer Subgruppe von etwa 20\% aller Patienten mit NMOSD und fehlendem Nachweis von AntiAquaporin 4-Antikörpern.

Mittels zahlreicher unterschiedlicher Screeningmethoden wurde auch nach anderen Zielstrukturen von Antikörper-Antworten gesucht, wobei u. a. Antikörper gegen Neurofascin, KIR4.1 und Anotamin 2 beschrieben wurden. Die Datenlage ist hier jedoch uneinheitlich, sodass weitere Studien erforderlich bleiben (Hohlfeld et al. 2016 b).

Im Kontext mit der Erforschung der Rolle von B-Zellen in der MS werden zunehmend Analysen des Immunrepertoires mittels „Next-Generation Sequencing" (NGS) durchgeführt, um nachzuvollziehen, wo die Affinitätsreifung stattfindet. Dabei gelten aktuell die zervikalen Lymphknoten, die über durale Lymphgefäße mit dem ZNS-Kompartiment kommunizieren können, ebenso als Kandidaten wie ektopes meningeales lymphatisches Gewebe (Lehmann-Horn et al. 2016).

\subsubsection{Therapie}

$(2$ Gegenwärtig gibt es keine Heilung der MS. Somit ist das Ziel der Behandlung die Unterdrückung der Krankheitsaktivität.

Dabei ist die Akutbehandlung im Falle eines klinischen Schubereignisses von der verlaufsmodifizierenden Therapie abzugrenzen.

\subsubsection{Schubtherapie}

Die Schubtherapie erfolgt mittels Glukokortikosteroiden (GKS). Dabei sind die Effekte der intravenösen Pulstherapie auf eine raschere Symptomrückbildung im Rahmen des MS-Schubes besser belegt als die Wirkung auf die funktionelle Erholung/das residuelle Defizit nach einem längeren Beobachtungszeitraum. Im Allgemeinen kommt
Methylprednisolon in einer Dosierung von 500-1000 mg/d über 3-5 Tage zum Einsatz.

GKS wirken über verschiedene Mechanismen. Die Effekte werden zum überwiegenden Teil über einen spezifischen Glukokortikoid-Rezeptor vermittelt. Dieser befindet sich ohne die Anwesenheit von GKS inaktiv im Zytosol und wandert nach Substratbindung in den Zellkern, wo er durch Bindung an bestimmten DNA-Sequenzen unter anderem die Expression verschiedener (häufig proinflammatorischer) Zytokine reguliert.

Darüber hinaus beeinflussen GKS über nicht genomische Mechanismen verschiedene zelluläre

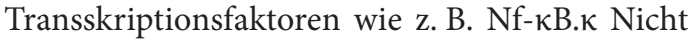
zuletzt stärken GKS die Integrität der Blut-HirnSchranke und verhindern so eine Migration weiterer Immunzellen in das ZNS. Auch proapoptotische Effekte auf T-Lymphozyten (im Besonderen $\mathrm{CD}^{+}$-Zellen) sind bekannt (Tischner und Reichhardt 2007).

Bei unzureichender Symptomrückbildung innerhalb von 14 Tagen nach Steroidpulstherapie kommen neben der erneuten, ultrahochdosierten i.v. Glukokortikosteroidgabe $(2 \mathrm{~g} / \mathrm{Tag}$ über 3-5 Tage) die Plasmapherese bzw. Immunadsorption in Frage.

\subsubsection{Verlaufmodifizierende Therapie}

Seit Mitte der 1990-er Jahre wurde eine Vielzahl neuer Medikamente für die Behandlung der MS entwickelt und zugelassen. Dabei haben sich parallel auch die Therapieziele weiterentwickelt. Während zunächst die Reduktion der Schubrate und Verzögerung des Eintritts bzw. Verlangsamung oder Stopp der bestätigten Behinderungsprogression das Therapieziel waren, wird zunehmend ein zusammenfassendes Erfolgskriterium der Therapie („fehlende Evidenz für Krankheitsaktivität“, „No Evidence of Disease Activity“; NEDA) als Therapieziel ausgegeben.

Neben Schub- und Progressionsfreiheit wird dabei auch eine fehlende MRT-Aktivität (d. h. keine neuen Gadolinium-anreichernden T1-, keine neuen oder sich vergrößernden T2-Läsionen, keine beschleunigte Hirnvolumenminderung) angestrebt, wobei dieser kombinierte Endpunkt bislang - auch aufgrund praktischer Hürden in der MS-Versorgung (standardisierte MRT-Untersuchungen) - unter Alltagsbedingungen noch keine klinische Relevanz erlangt hat (Havla et al. 2016). 


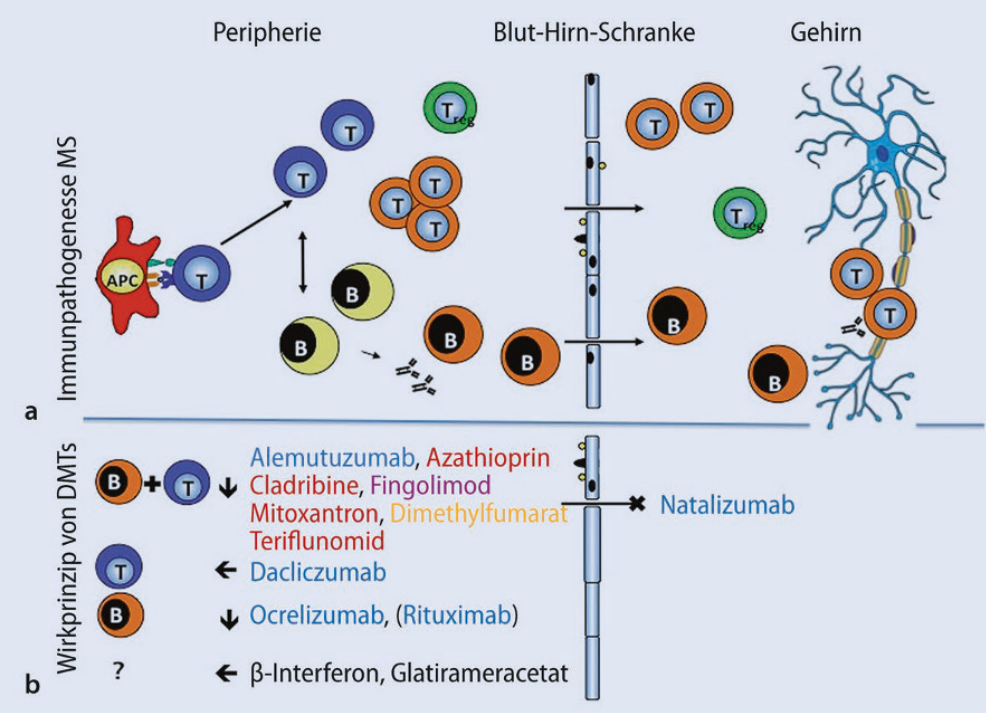

Verschiedene Interferon- $\beta$-Formulierungen und Glatirameracetat sind Immunmodulatoren ohne gut definierte Zielstruktur (schwarz), die kein bekanntes immunsuppressives Potenzial besitzen. Die immunmodulatorische und teils auch immunsuppressive Wirksamkeit von Dimethylfumarat mit Nachweis einer Lymphopenie bei einem Teil der Patienten ist bislang nur teilweise verstanden (orangefarben), $u$. a. wird eine Beinflussung des Nrf2-Signalwegs diskutiert. Substanzen, die mit der DNA- und Zellsynthese interferieren (rot) sind Mitoxantron, Azathioprin, Cladribin und Teriflunomid.

Das kleine Molekül Fingolimod moduliert Sphingosin-1-Phosphat-Rezeptoren und hält darüber Lymphozyten in peripheren lymphatischen Organen zurück (lilafarben), was zu einer ausgeprägten Lymphopenie im peripheren Blut führt. Monoklonale Antikörper (blau) haben selektive Angriffspunkte mit unterschiedlichen zell- oder kompartmentspezifischen Effekten.

Die Depletion von Zellen, die CD52 tragen (Alemtuzumab), führt zu einer temporären Reduktion von T- und B-Zellen. Die Depletion von CD20-positiven Zellen betrifft einen großen Teil der B-Zell-Reihe (Ocrelizumab, Rituximab). Daclizumab wirkt über die Bindung an CD25, eine Untereinheit des IL-2-Rezeptors von T-Zellen, und moduliert darüber deren Funktion. Natalizumab dagegen bindet an eine Untereinheit von Integrinmolekülen, die an der Transmigration von aktivierten Immunzellen über die Blut-Hirn-Schranke beteiligt sind, und führt darüber zu einer Depletion dieser Zellen im Gehirn, nicht jedoch im peripheren Blut.

- Abb. 2.6 Vereinfachte Darstellung der Wirkprinzipien der verlaufsmodifizierenden Therapeutika (sog. .,disease modifying drugs", DMTs)

$(7$ Grundprinzip der verlaufmodifizierenden Therapeutika ist es, durch Modulation oder Suppression von fehlgeleiteter Immunantwort, gerichtet gegen Gehirn und Rückenmark, MS-Krankheitsaktivität zu unterdrücken.

Inzwischen gibt es eine Vielzahl von Therapeutika mit unterschiedlichen Wirkprinzipien (• Abb. 2.6. - Tab. 2.1).

Interferon- $\beta$ liegt in unterschiedlichen Formulierungen vor, muss jedoch ebenso wie Glatirameracetat subkutan oder intramuskulär verabreicht werden (-Tab. 2.1). Diese bereits seit den 1990-er Jahren verfügbaren Präparate sind vielfach noch heute Erstlinientherapeutika, obgleich für einige der Nachfolgesubstanzen eine Überlegenheit in
Bezug auf die klinische Wirksamkeit gezeigt wurde. Dies begründet sich in dem guten Langzeitsicherheitsprofil.

Mit der Zulassung des ersten monoklonalen Antikörpers für die MS-Therapie (Natalizumab) wurde rasch erkennbar, dass eine erhöhte Wirksamkeit in Bezug auf die MS-Krankheitsaktivität erreichbar ist. Diese erhöhte Wirksamkeit geht jedoch auch mit einem erhöhten therapeutischen Risiko einher (Warnke et al. 2013). Der vermeidlich selektive Eingriff in das Immunsystem durch Natalizumab, z. B. ohne Absinken der Lymphozytenzahl im peripheren Blut, birgt dennoch ein klinisch relevantes Risiko, da die Immunüberwachung des Gehirns verändert wird (Warnke et al. 2010). Das in Studien erstbeobachtete und nach Zulassung weiter gestiegene Risiko, unter 
- Tab. 2.1 Wirkstoffe und deren Nebenwirkungsprofil (mod. nach Havla et al. 2016, mit Erweiterung um neue Therapeutika) - alphabetische Reihung

\begin{tabular}{|c|c|c|}
\hline Wirkstoff & $\begin{array}{l}\text { Administrationsweg/- } \\
\text { häufigkeit }\end{array}$ & $\begin{array}{l}\text { Nebenwirkungen (unsystematische Auswahl nach } \\
\text { Häufigkeit oder Schwere) }\end{array}$ \\
\hline Alemtuzumab & $\begin{array}{l}\text { intravenös, jährlich } \\
\text { oder: } \\
\text { - } 5 \text { Tage i.v. (1. Jahr) } \\
\text { - } 3 \text { Tage i.v. (2. Jahr) }\end{array}$ & $\begin{array}{l}\text { Infusionsreaktionen, sekundäre Autoimmunerkrankun- } \\
\text { gen (z. B. der Schilddrüse, des blutbildenden Systems, } \\
\text { der Niere), Herpesreaktivierung, Listerienmeningitis }\end{array}$ \\
\hline Cladribin & $\begin{array}{l}\text { Oral, Behandlungsphasen über } \\
4-5 \text { Tage in Monat } 1 \text { und } 2 \text { in } 2 \\
\text { Behandlungsjahren } \\
\text { oder oder alternativ: } \\
2 \times 5 \text { Tage / Jahr p.o. } \\
\text { über insgesamt } 2 \text { Jahre }\end{array}$ & $\begin{array}{l}\text { Kopf- und Extremitätenschmerz, Lymphopenie, Malig- } \\
\text { nomrisiko?, Herpesreaktivierung }\end{array}$ \\
\hline Dimethylfumarat & Oral, $2 \times$ täglich & $\begin{array}{l}\text { Flushing, Diarrhö, Oberbauchschmerzen, Lympho-/ } \\
\text { Leukopenien, sehr selten PML }\end{array}$ \\
\hline Fingolimod & Oral, täglich & $\begin{array}{l}\text { Transaminasenerhöhung, Bradyarrhythmie, Makula- } \\
\text { ödem, selten opportunistische Infektionen (Krypto- } \\
\text { kokkose, PML), Basalzellkarzinom, Lymphom }\end{array}$ \\
\hline Glatiramerazetat & $\begin{array}{l}\text { Subkutan, täglich bzw. } \\
3 \times \text { wöchentlich }\end{array}$ & Injektionsstellenreaktionen \\
\hline Interferon- $\beta-1 \mathrm{a}$ & Intramuskulär, 1× wöchentlich & \multirow{4}{*}{$\begin{array}{l}\text { Grippeartige Symptome, Transaminasenerhöhung, } \\
\text { Injektionsstellenreaktionen, neutralisierende Antikörper, } \\
\text { Auftreten oder Verschlechterung depressiver Symptome }\end{array}$} \\
\hline Interferon- $\beta-1 a$ & Subkutan, $3 \times$ wöchentlich & \\
\hline $\begin{array}{l}\text { Interferon- } \beta-1 a \\
\text { pegyliert }\end{array}$ & Subkutan, 14-tägig & \\
\hline Interferon- $\beta-1 b$ & Subkutan, jeden 2. Tag & \\
\hline Mitoxantron & Intravenös, alle 3 Monate & $\begin{array}{l}\text { Transaminasenerhöhung, kumulative Kardiotoxizität, } \\
\text { (promyelozytische) Leukämie }\end{array}$ \\
\hline Natalizumab & Intravenös, monatlich & PML, Hepatotoxizität, Herpesreaktivierung \\
\hline Ocrelizumab & Intravenös, alle 6 Monate & $\begin{array}{l}\text { Infusionsreaktionen, Reaktivierung viraler und bakteriel- } \\
\text { ler Infektionen, Mammakarzinom, Basalzellkarzinom }\end{array}$ \\
\hline Teriflunomid & Oral, täglich & Lebertoxizität, Teratogenität \\
\hline
\end{tabular}

Therapie mit Natalizumab eine JC-Polyomavirusassoziierte, progressive multifokale Leukenzephalopathie (PML) zu entwickeln, begrenzt dessen klinischen Einsatz (Warnke et al. 2015, 2016), auch vor dem Hintergrund, dass inzwischen zahlreiche Alternativpräparate zugelassen wurden.

Aber auch diese alternativen Substanzen haben jeweils ein spezifisches Risikoprofil. So ist kürzlich die Zulassung von Daclizumab zurückgenommen worden, nachdem es trotz Notfalltransplantation zu einem tödlichen Fall von Autoimmunhepatitis kam und in der Folge neben wei- teren Fällen von Autoimmunhepatitis auch mindestens 8 Fälle von Autoimmunenzephalitiden bekannt wurden.

Die Kontraindikationen zum Einsatz von Fingolimod wurden kürzlich um „kardiale Vorerkrankungen" erweitert. Zudem wurde auf ein mögliches Neoplasierisiko bei der Behandlung mit Figolimod hingewiesen, und ähnliche mögliche Risiken werden für kürzlich zugelassene Präparate wie Cladribin und Ocrelizumab erwartet.

Unter dem Einsatz von Alemtuzumab kam es bereits in Studien zu tödlichen Komplikationen, 
u. a. aufgrund von häufig beobachteter sekundärer Autoimmunität, die insbesondere dann bedrohlich werden kann, wenn sie das blutbildende System oder die Niere betrifft (Havla et al. 2016).

( Cave

Da es durch den Einsatz ", moderner" MSTherapeutika zu mitunter letalen Nebenwirkungen kommen kann, ist eine genaue Kenntnis über den Nutzen und die möglichen Risiken der eingesetzten Präparate obligat.

Zusammenfassend kann festgehalten werden, dass die moderne Immuntherapie einen Durchbruch für die Behandlung von Patientinnen und Patienten mit MS bedeutet. Sie macht jedoch umfangreiche Kenntnisse über die eingesetzten Präparate notwendig und häufig ein langfristiges Konzept zum Risikomanagement (bei Alemtuzumab z. B. eine Überwachung über mindestens 5 Jahre nach der letzten Infusion). Dies stellt eine zunehmende Herausforderung für Beteiligte des Gesundheitssystems dar. Als hilfreich für die Praxis erweisen sich in diesem Zusammenhang die Aufklärungsbögen sowie das Qualitätshandbuch zur Therapie der MS sowie der NMOSD (http://www.kompetenznetzmultiplesklerose.de/fachinformationen/ qualitaetshandbuch/).

\subsubsection{Risiko und Nutzen der MS-Therapie}

Die Zulassung von Immuntherapeutika zur Behandlung erfolgt in Deutschland nach sorgfältiger Prüfung von Nutzen und Risiken in zulassungsrelevanten Phase-III-Studien durch die europäische Zulassungsbehörde. Auch nach der Zulassung eines Präparates müssen Risiko und Nutzen gegeneinander abgewogen werden, was - Abb. 2.7 verdeutlicht.

Ein schwarzer Punkt in $\bullet$ Abb. 2.7 steht in dieser schematischen Darstellung für 1\% aller Patienten, die in der jeweiligen Gruppe (Placebo oder Natalizumab) keine neue Krankheitsaktivität in der MRT (hier gemessen als neue oder sich vergrößernde T2-Läsion über 2 Jahre) zeigten. Ein grauer Punkt steht dagegen für jeweils $1 \%$ der $\mathrm{Pa}-$ tienten, die weiterhin neue oder sich vergrößernde T2-Läsionen in der MRT zeigten.

Die absolute Risikoreduktion durch die Therapie liegt also - bezogen auf den hier illustrierten MRT-Endpunkt für eine Behandlung über 2 Jahre - bei 42\% (Polman et al. 2006), eine Zahl, die im
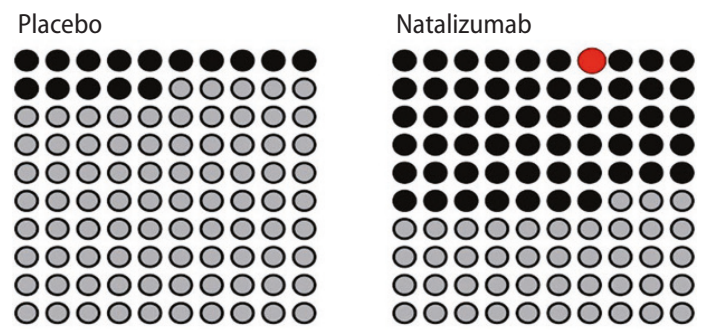

Absolute Risikorduktion $42 \%$

PML

- Abb. 2.7 Risiko und Nutzen der MS-Therapie am Beispiel von Natalizumab (Details s. Text)

Vergleich zu zugelassenen Therapien in anderen Indikationen hoch ist. Allerdings korreliert die Kontrolle der Krankheitsaktivität in der MRT nicht zwingend mit klinischen Parametern der Erkrankung wie beispielsweise der Schubaktivität oder einem Stillstand der Behinderungsprogression, weshalb klinische Größen für die Zulassung einer Therapie der MS als Endpunkte primär zu erfassen sind. Dennoch suggerieren die hier dargestellten MRT-Daten, dass ein großer Anteil beispielsweise auch von schub- oder über 2 Jahre progressionsfreien Patienten langfristig einen Nutzen von der Therapie haben könnte, da subklinische MR-Aktivität limitiert wird und weniger „Narben“ im Gehirn und Rückenmark entstehen. Dem gegenüber stehen jedoch die möglichen unerwünschten Arzneimittelwirkungen; bei der Natalizumab-Therapie insbesondere das Risiko der Entwicklung einer PML.

Wie also ist der Nettonutzen der Behandlung einzuschätzen unter der Annahme, dass 1 Patient von 100 behandelten Patienten langfristig infolge der Behandlung an einer PML verstirbt oder eine hochgradige neue Behinderung erleidet? Eindeutig kann diese Frage nicht beantwortet werden. Dies liegt unter anderem auch darin begründet, dass der individuelle Nutzen einer Therapie bei zugleich schlecht abzuschätzendem Verlauf bisher nicht ausreichend vorhergesagt werden kann. Wie weiter oben erläutert, ist die unbehandelte MS mit schwerer Behinderung und reduzierter Lebenserwartung assoziiert, sodass es in vielen Fällen unausweichlich ist, dieses Risiko gegen das therapeutische Risiko abzuwägen. Damit ist zu erklären, weshalb eine Behandlung, die per definitionem „gelegentlich bis häufig“" mit einer potenziell lebensbedrohlichen Nebenwirkung einhergeht, weiterhin eine - wenn auch eingeschränkte - Zulassung zur Behandlung der MS besitzt. 
$?$

en zur Lernkontrolle

- Welche Umweltfaktoren tragen zum Risiko der Entwicklung einer MS bei?

- Welche Rolle spielt die Genetik bei der MS?

- Welche Viren werden mit der Pathogenese der MS in Verbindung gebracht?

- Für welche "Variante" der MS wurde ein spezifisches Antigen definiert und um welches Antigen handelt es sich?

\subsection{Ambulant erworbene bakterielle Meningitis/ Meningoenzephalitis}

\section{Kitzrow}

\section{- Zum Einstieg}

Bei der bakteriellen oder auch eitrig (= purulent) genannten Meningitis/Meningoenzephalitis handelt es sich immer um eine potenziell lebensbedrohliche entzündliche Erkrankung des zentralen Nervensystems bzw. seiner Hüllen, verursacht durch Bakterien. Die Virulenz des Erregers und die Immunkompetenz des Wirtsorganismus sind dabei sowohl für die Krankheitsmanifestation als auch für die Prognose entscheidend. Im vorliegenden Beitrag werden zunächst die Charakteristika einiger wichtiger ZNS-pathogener Bakterien und Maßnahmen des Infektionsschutzes zu deren Eindämmung dargestellt. Danach folgt eine Beschreibung der Mechanismen, die die Mikroorganismen zur Überwindung der Blut-Hirn-Schranke befähigen, und schließlich wird die Entstehung und Ausbreitung der Entzündung im Hirngewebe erläutert.

Bakterielle Meningitis/Meningoenzephalitis

- Epidemiologie:

- Aktuelle Inzidenz in den westlichen Industrienationen bei ca. 1/100.000 pro Jahr, mit teils erheblichen Unterschieden im internationalen Vergleich.

- Höchstes Erkrankungsrisiko während der ersten 2 Lebensjahre und in der Altersgruppe der über 65-Jährigen.

- Nationale Impfprogramme führen zu abnehmender Erkrankungsinzidenz und Verschiebung des Erregerspektrums.
- Nachweis vieler potenziell ZNS-pathogener Erreger auf Haut und/oder Schleimhäuten asymptomatischer Träger.

- Diagnostik:

- Bei begründetem Verdacht (ggf. nach Ausschluss eines relevanten Hirndrucks) schnellstmögliche Liquordiagnostik zur Diagnosesicherung und zum Erregernachweis.

\section{- Therapie:}

- Bereits bei begründetem Verdacht sofort und noch vor definitiver Diagnosesicherung Beginn einer empirischen systemischen Antibiotikabehandlung.

- Nach erfolgtem Erregernachweis respektive in Kenntnis des jeweiligen Antibiogramms ist ggf. eine Anpassung der antimikrobiellen Therapie erforderlich.

8 In der Literatur werden die Begriffe „Meningitis" und "Meningoenzephalitis" vielfach synonym benutzt, wobei letzterer die bereits eingetretene Ausbreitung der Entzündung über die Pia mater hinaus ins Hirnparenchym umfasst und deshalb im folgenden Text Verwendung finden soll. Eine anatomische Barriere zwischen weicher Hirnhaut und dem darunterliegenden Gewebe existiert zudem auch nicht.

Die bakterielle Meningoenzephalitis ist eine der bedrohlichsten Erkrankungen in der Neurologie. Einer raschen (liquorchemischen) Diagnostik und dem zügigen Beginn einer antimikrobiellen Therapie kommt daher ein hoher Stellenwert zu. Dieser Beitrag rekapituliert zunächst die wichtigsten Erreger einer bakteriellen Meningoenzephalitis. Nachfolgend werden der physiologische Aufbau der Blut-Hirn-Schranke sowie die im Rahmen einer Meningoenzephalitis ablaufenden Pathomechanismen dargestellt.

(8) Cave

Eine bakterielle Meningitis/Meningoenzephalitis ist immer eine invasive und lebensbedrohliche Erkrankung. Die Infektion erfolgt meist hämatogen, seltener per continuitatem. 


\subsubsection{Erregerspektrum}

Das bakterielle Erregerspektrum variiert in den unterschiedlichen Altersgruppen. So wird eine bakterielle Meningoenzephalitis bei Kindern und Erwachsenen überwiegend durch Streptococcus pneumoniae („Pneumokokken“) und Neisseria meningitidis („Meningokokken“) hervorgerufen. Insbesondere mit zunehmendem Lebensalter (>50 Jahre) und bei herabgesetzter Immunkompetenz sind in abnehmender Häufigkeit auch Listeria monocytogenes $(<5 \%)$, Staphylokokken (19\%), gramnegative Enterobakterien und Pseudomonas aeroginosa $(<10 \%)$ sowie Haemophilus influenzae (1-3\%) ursächlich.

Im Säuglingsalter werden innerhalb der ersten 3 Lebensmonate insbesondere Gruppe-B-Streptokokken (Streptococcus agalactiae) und Listeria monocytogenes, seltener auch E. coli als pathogene Erreger nachgewiesen (Al Bekairy et al. 2014; Brouwer et al. 2010)

- Tab. 2.2 fasst die wichtigsten Erreger einer eitrigen Meningoenzephalitis zusammen.

\section{Epidemiologische Surveillance (Überwachung) und Auswirkungen nationaler Immunisierungs- programme}

Seit Beginn dieses Jahrtausends hat sich die Häufigkeit der bakteriellen Meningitis/Meningoenzephalitis in den westlichen Industrienationen nahezu halbiert (Castelblanco et al. 2014; European Centre for Disease Prevention and Control 2014). Diese Entwicklung ist das Resultat der konsequenten Durchführung nationaler Immunisierungsprogramme, der prophylaktischen Antibiotikagaben während der Schwangerschaft nach positivem Screeningbefund (Streptokokken der Gruppe B) und, in begrenztem Umfang, auch der Implementierung suffizienter Hygienerichtlinien im Umgang mit potenziell erkrankten Personen. Allerdings sind die publizierten Erkrankungszahlen wegen der in den meisten Ländern (darunter auch Deutschland) nur für die invasive Meningokokkenerkrankung (IME) bestehenden, generellen gesetzlichen ärztlichen Meldepflicht (Krankheitsverdacht, Erkrankung, Tod) nur bedingt reliabel.

Nachfolgend werden Aspekte der Immunisierungsprogramme in Bezug auf die in • Tab. 2.2 genannten Erreger aufgeführt:

Streptococcus pneumoniae: Die im Rahmen der nationalen europäischen Immunisierungsprogrammen eingesetzten Impfstoffe sind gegen 10, 13 oder 23 der über 90 bekannten Serotypen gerichtet. In Deutschland empfiehlt die ständige Impfkommission (STIKO) für Kinder im 1. und 2. Lebensjahr generell die Vakzination mit einem Pneumokokkenkonjugatimpfstoff (13-valenter Impfstoff), anschlieBend sollen nur noch Angehörige einer Risikogruppe eine entsprechende Immunisierung erhalten (Stand: 2017) (Htar et al. 2015).
Neisseria meningitidis: Schon 2006 wurde von der STIKO die Empfehlung zur generellen Durchführung einer Meningitis-C (MenC)-Impfung für Kinder im 2. Lebensjahr ausgesprochen. Daraufhin ist vom Robert Koch-Institut (RKI) bereits für den Berichtszeitraum 2012 bis 2015 gegenüber 2009 bis 2011 eine Abnahme der jährlichen IME-Inzidenz von 0,51 auf 0,40 Erkrankungen/100.000 Einwohner dokumentiert worden. 2014 ließ sich bei den 14 europäischen Staaten, die die MenC-Impfung mit einem Konjugatimpfstoff fest in ihre nationalen Immunisierungsprogramme für Kinder implementiert hatten, eine Halbierung der Rate entsprechender Erkrankungsfällen gegenüber dem Rest Europas beobachten (14\% vs. $27 \%$ ). Allerdings kommt es bereits innerhalb der ersten 12-18 Monate nach erfolgter einmaliger Vakzination im Säuglings- oder Kleinkindesalter (u. a. Deutschland) meist bereits wieder zu einem deutlichen Abfall des individuellen Antikörpertiters, sodass im Falle einer Exposition kein effektiver Schutz mehr gegeben ist. Endemisch betrachtet beruht der protektive Effekt für die Gesamtbevölkerung also darin, durch eine möglichst flächendeckende Immunisierung die Anzahl der (asymptomatischen) Meningokokken-C-Träger weitestgehend zu reduzieren und damit auch das Infektionsrisiko für Risikogruppen.

2013 erhielt ein oberflächenproteinbasierter Impfstoff $\left.{ }_{4} \mathrm{CMenB}\right)$ gegen Meningokokken der Serogruppe $B$ in Europa seine Zulassung. Die enthaltenen insgesamt $4 \mathrm{im}$ munogenen Epitope werden jedoch nur auf ca. $80 \%$ der betreffenden Krankheitserreger exprimiert. Gegenwärtig liegen noch keine Daten zur Wirksamkeit bezüglich klinischer Endpunkte vor. Die Ergebnisse der Zulassungsstudien legen bei Impfungen von Säuglingen und Kleinkindern eine anfänglich sehr gute Wirksamkeit der induzierten Immunantwort gegenüber den abgedeckten Stämmen nahe. Aber auch hier kommt es bereits nach einem Jahr wieder zu einem deutlichen Abfall des Antikörpertiters. Bei Jugendlichen ließ sich eine stabile Persistenz beobachten.

Für Deutschland kommt die STIKO zu dem Schluss, dass aus der rezenten Studienlage (2016) noch keine ausreichende Evidenz resultiert, die eine generelle Impfempfehlung zulässt. Allerdings sollten Menschen mit spezifischen Grunderkrankungen zusätzlich zu einer Vakzination mit einem quadrivalenten Konjugatimpfstoff gegen Meningokokken der Serogruppen $A, C, W_{135}$ und $Y$ auch gegen Meningokokken der Serogruppe B immunisiert werden (Cohn et al. 2013; Borrow et al. 2013; Vogel et al. 2013).

Haemophilus influenzae: Haemophilus influenzae zählte vor Einführung des entsprechenden Konjugatimpfstoffes gegen den Serotyp B (Hib) Anfang der 1990-er Jahre zu den 3 häufigsten Erregern der Meningoenzephalitis bei Kleinkindern und Kindern bis zum Alter von 5 Jahren. Heutzutage kommen invasive Haemophilus-influenzaeErkrankungen (IHIE) in den wirtschaftsstarken Nationen nur noch selten vor. Im Jahr 2014 wurde für Europa eine durchschnittliche Inzidenzrate von nur noch 0,6/100.000 Einwohner dokumentiert. Diese Entwicklung veranschaulicht eindrücklich Sinnhaftigkeit und Nutzen der flächendeckenden Implementierung von Standardimpfungen in die medizinische Grundversorgung der Bevölkerung. Unbekapselte Stämme von Haemophilus influenzae sind nach Einführung dieser nationalen Hib-Vakzinationspro- 
- Tab. 2.2 Wichtige bakterieller Erreger einer eitrigen Meningoenzephalitis mit spezifischen Charakteristika der einzelnen Erreger*. (Nach Brouwer et al. 2010; RKI Epidemiologisches Bulletin 2016; European Center for Disease Prevention and Control 2016)

\begin{tabular}{|c|c|c|}
\hline Erreger & \multicolumn{2}{|l|}{ Charakteristika } \\
\hline \multirow{8}{*}{$\begin{array}{l}\text { Streptococcus } \\
\text { pneumomiae: } \\
\text { (grampositive } \\
\text { Kokken) }\end{array}$} & Infektionsweg & $\begin{array}{l}\text { I. d. R. endogene Infektionen, ausgehend von den Schleimhäuten des } \\
\text { oberen Respirationstraktes (natürliches Habitat!) }\end{array}$ \\
\hline & Unterteilung & 90 unterschiedliche Serovare, nur ein Teil ist pathogen \\
\hline & Inzidenz/Jahr & $\begin{array}{l}\text { IPE: 4,8/100.000, ca. } 1 / 3 \text { davon mit Meningoenzephalitis mit steigender } \\
\text { Tendenz seit Einführung der Konjugat-Impfstoffe }\end{array}$ \\
\hline & Risikogruppe & $\begin{array}{l}\text { V. a. } \geq 65 \text {-Jährige }(13,8 / 100.000) \text {, gefolgt von Säuglingen } \leq 1 \text { Jahr } \\
(11,3 / 100.000)\end{array}$ \\
\hline & Verhältnis m:w & Leichtes Überwiegen des männlichen Geschlechtes \\
\hline & $\begin{array}{l}\text { Saisonales } \\
\text { Auftreten }\end{array}$ & $\begin{array}{l}\text { Anstieg der Erkrankungsrate im Herbst, Gipfel im Dezember (wie bei respi- } \\
\text { ratorischen Infektionserkrankungen typisch) }\end{array}$ \\
\hline & Letalität der IPE & Bis zu $20 \%$ \\
\hline & Besonderheiten & $\begin{array}{l}\text { Häufigster Erreger der bakteriellen Meningoenzephalitis in Europa und } \\
\text { Nordamerika; in Deutschland Meldepflicht für IPE nur in den neuen Bun- } \\
\text { desländern (Stand 2017) }\end{array}$ \\
\hline \multirow{8}{*}{$\begin{array}{l}\text { Neisseria } \\
\text { meningitidis: } \\
\text { (gramnegative } \\
\text { Kokken) }\end{array}$} & Infektionsweg & $\begin{array}{l}\text { Über Nasopharynx, entweder als endogene Infektion (ca. 10\% der } \\
\text { Gesunden sind kolonisiert) oder als „Tröpfcheninfektion“ }\end{array}$ \\
\hline & Unterteilung & $\begin{array}{l}13 \text { unterschiedliche Serogruppen: B (64\%, fallende Tendenz) > C (16\%) } \\
>>\text { Y (cave: bei > 65-Jährigen aber ca. } 30 \%) \text { und W (steigende Tendenz!) }\end{array}$ \\
\hline & Inzidenz/Jahr & IME: 0,5/100.000, davon ca. $40 \%$ mit Meningoenzephalitis \\
\hline & Risikogruppe & $\begin{array}{l}\text { Säuglinge } \leq 1 \text { Jahr }(10,1 / 100.000)>\text { Kinder von } 1-4 \text { Jahren }(2,5 / 100.000)> \\
\text { Adoleszenz }(16-24 \text { Jahre })(0,7 / 100.000)\end{array}$ \\
\hline & Verhältnis m:w & Annähernd ausgeglichen \\
\hline & $\begin{array}{l}\text { Saisonales } \\
\text { Auftreten }\end{array}$ & $\begin{array}{l}\text { Maximum der Erkrankungen in den Wintermonaten mit beständigem } \\
\text { Rückgang bis Juli/August }\end{array}$ \\
\hline & Letalität der IME & Insgesamt bis $10 \%$ \\
\hline & Besonderheiten & $\begin{array}{l}\text { Generelle ärztliche Meldepflicht } \\
\text { In 10-20\% der Fälle verbleiben relevante neurologisch Langzeitfolgen } \\
\text { Haupterregerreservoir: Altersgruppe der Adoleszenten }\end{array}$ \\
\hline \multirow{8}{*}{$\begin{array}{l}\text { Listeria mono- } \\
\text { cytogenes: } \\
\text { (grampositive, } \\
\text { begeißelte } \\
\text { Stäbchen) }\end{array}$} & Infektionsweg & $\begin{array}{l}\text { I. d. R. oral durch Inkorporation kontaminierte Lebensmittel (Rohmilch- } \\
\text { käse, rohe und gekochte Fleischwaren, Speiseeis u. a.) } \\
\text { Seltener als Weichteilinfektion }\end{array}$ \\
\hline & Unterteilung & 13 unterschiedliche Serovare \\
\hline & Inzidenz/Jahr & $\begin{array}{l}\text { ILE: 0,6/100.000, allerdings werden nur schwere Verläufe erfasst, in } 15-30 \% \\
\text { liegt eine Meningoenzephalitis vor }\end{array}$ \\
\hline & Risikogruppe & $\begin{array}{l}\text { Säuglinge } \leq 1 \text { Jahr (2,8/100.000), gefolgt von den } \geq 65 \text {-Jährigen } \\
(1,9 / 100.000 \text { mit steigender Tendenz), immunkompromittierte Personen }\end{array}$ \\
\hline & Verhältnis m:w & Männer: Frauen = 1,2:1 \\
\hline & $\begin{array}{l}\text { Saisonales } \\
\text { Auftreten }\end{array}$ & $\begin{array}{l}\text { Höchste Erkrankungsinzidenz im Januar, allerdings zweiter Gipfel im Juli } \\
\text { bis September }\end{array}$ \\
\hline & Letalität der ILE & $\begin{array}{l}\text { 9,5\%, (20-30\% bei Listerien-Meningoenzephalitis), erhebliche Schwan- } \\
\text { kungen in Abhängigkeit von der individuellen Immunkompetenz }\end{array}$ \\
\hline & Besonderheiten & $\begin{array}{l}\text { Häufig subakute Verläufe mit viral/apurulent anmutendem Liquorbefund } \\
\text { Resistent gegenüber Cephalosporinen („Listerienlücke“) }\end{array}$ \\
\hline
\end{tabular}


- Tab. 2.2 (Fortsetzung)

\begin{tabular}{|c|c|c|}
\hline Erreger & \multicolumn{2}{|l|}{ Charakteristika } \\
\hline \multirow{8}{*}{$\begin{array}{l}\text { Haemophilus } \\
\text { influenzae } \\
\text { (gramnegative } \\
\text { Stäbchen) }\end{array}$} & Infektionsweg & $\begin{array}{l}\text { Meist „Tröpfcheninfektion“ über den Nasopharynx, selten endogene Infek- } \\
\text { tion (bei } 30-50 \% \text { der Gesunden Bestandteil der Schleimhautflora der } \\
\text { oberen Atemwege) }\end{array}$ \\
\hline & Unterteilung & $\begin{array}{l}6 \text { unterschiedliche Serovare, allerdings auch kapsellose und somit nicht } \\
\text { typisierbare Stämme }\end{array}$ \\
\hline & Inzidenz/Jahr & IHIE: $0,6 / 100.000$, davon ca. $11 \%$ mit Meningoenzephalitis \\
\hline & Risikogruppe & $\begin{array}{l}\text { Säuglinge } \leq 1 \text { Jahr }(4,0 / 100.000) \text {, gefolgt von den } \geq 65 \text {-Jährigen } \\
(1,7 / 100.000)\end{array}$ \\
\hline & Verhältnis m:w & Annähernd ausgeglichen \\
\hline & $\begin{array}{l}\text { Saisonales } \\
\text { Auftreten }\end{array}$ & $\begin{array}{l}\text { Maximum der Erkrankungen während der Wintermonate mit Abnahme der } \\
\text { Fallzahl zum Sommer hin (Minimum im August) }\end{array}$ \\
\hline & Letalität & $3-8 \%$ \\
\hline & Besonderheiten & $\begin{array}{l}\text { Erheblicher Rückgang der Inzidenz, v. a. im Säuglingsalter seit Implemen- } \\
\text { tierung der Hib-Schutzimpfung }\end{array}$ \\
\hline \multicolumn{3}{|c|}{$\begin{array}{l}\text { * Die Angaben entsprechen jeweils den ermittelten (Durchschnitts-) Werten für Gesamteuropa. } \\
\text { Abkürzungen: IPE = invasive Pneumokokkenerkrankung (Pneumonie und Bakteriäme/Sepsis oder Meningitis/ } \\
\text { Meningoenzephalitis und/oder Bakteriämie/Sepsis), IME = invasive Meningokokkenerkrankung (Meningitis/ } \\
\text { Meningoenzephalitis und/oder Bakteriämie/Sepsis), ILE = invasive Listerienerkrankungen, IHIE = invasive Haemo- } \\
\text { philus-influenzae-Erkrankung. Hib = Haemophilus influenzae Typ B }\end{array}$} \\
\hline
\end{tabular}

gramme gegenwärtig für ca. 80\% aller IHIE (mit vorliegendem Ergebnis eines Typisierungsverfahrens) in Europa verantwortlich. Ihre Quote nahm dabei während der letzten 5 Jahre einen beständig ansteigenden Verlauf. Auf den am stärksten humanpathogenen Serotyp B (bekapselt) entfallen hingegen nur noch $6 \%$ aller Erkrankungen, auf den ebenfalls bekapselten Serotyp F 9\%. Liegt das Patientenalter allerdings über 25 Jahre, findet sich mit 57\% der Fälle weiterhin vorrangig der Serotyp B (Puig et al. 2014; Collins et al. 2016).

Gegen Listeria monocytogenes existiert zurzeit keine Impfung.

\subsubsection{Aufbau und Funktion der Blut-Hirn-Schranke}

Die Blut-Hirn-Schranke (BHS) ist eine physiologische Barriere zwischen dem Gefäßsystem und dem zentralen Nervensystem (ZNS). Ihre Aufgabe ist es, das Hirngewebe vor Krankheitserregern und Toxinen zu schützen.

Im Bereich der Kapillaren des ZNS bilden spezifische Endothelzellen, eine Basallamina (bestehend aus extrazellulären Matrixproteinen), die Perizyten sowie fußartige Fortsätze der Astrozyten gemeinsam die Blut-Hirn-Schranke, die auch „neurovaskuläre Einheit" genannt wird (Daneman
2012; Armulik et al. 2005; Carmignoto et al. 2010) (- Abb. 2.8). Diese sowohl strukturelle als auch funktionelle Barriere verhindert die Passage nahezu aller Moleküle, mit Ausnahme sehr kleiner und lipophiler Teilchen, und gewährleistet so ein neutrales Mikromilieu innerhalb des zentralen Kompartimentes. Zwischen den Ausläufern der Astrozyten befindliche, perivaskuläre Makrophagen gewährleisten die erste Stufe der ortsständigen Immunabwehr nach Überwindung der BHS (Carmignoto et al. 2010).

\section{Neurovaskuläre Einheit \\ Eine neurovaskuläre Einheit besteht aus einer Kapillare im Bereich des ZNS und der sie umgebenden Strukturen (Endothel, Basal- lamina, Perizyten und Astrozyten).}

Die Endothelzellen des ZNS unterscheiden sich grundlegend von denen aller anderen Gewebe. Einerseits sind diese mitochondrienreichen Zellen hoch polarisiert, wodurch in Kombination mit den in großer Zahl vorhandenen, durch transmembranöse Proteine gebildeten "tight junctions" (TJ) der parazelluläre Transfer selbst für Ionen erheblich begrenzt wird, andererseits fehlen 
Kapillaren (neurovaskuläre Einheit)

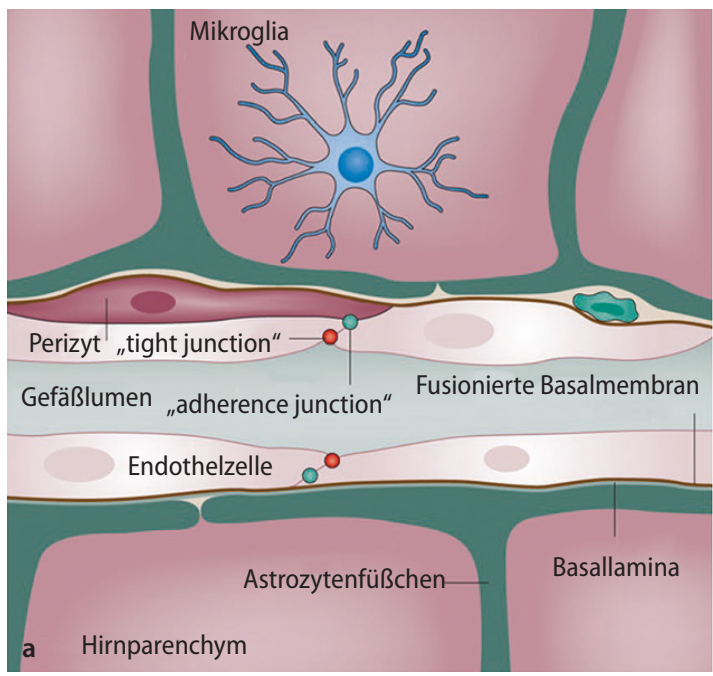

- Abb. 2.8a, b Schematischer Aufbau der Blut-HirnSchranke: a im Bereich der Kapillaren (neurovaskuläre Ein-

Fensterungen im Endothel, und die niedrige Anzahl zytoplasmatischer Vesikel führt zu einer geringen Pino- und Transzytoserate.

Der elektrische Gradient ermöglicht zudem die Ausbildung spezieller transmembranöser Transporteigenschaften; darunter sogenannte Efflux-Carrier für niedermolekulare lipophile Toxine, die zuvor passiv die BHS überwunden haben, sowie Transportmoleküle zur Versorgung des Gehirns mit essenziellen Nährstoffen.

Wie in anderen Bereichen des Körpers verfügen auch die Endothelien des ZNS über „adherence junctions" (AJ), die, ähnlich den TJ, über ein Transmembranprotein die Zell-Zell-Adhäsion bewirken. An der Membraninnenseite sind diese Makromoleküle mit den Aktinfilamenten des Zytoskeletts vernetzt und/oder haben Verbindung $\mathrm{zu}$ intrazellulären Signalproteinen. Somit sind AJ und TJ in eine Vielzahl von Endothelfunktionen wie der Aufrechterhaltung der Membranpolarität, der Membranstabilität und auch der Permeabilität der BHS involviert. Auch eine direkte Interaktion zwischen diesen beiden Kontaktstrukturen selbst wurde mittlerweile belegt (Daneman 2012; Armulik et al. 2005).

Lumenwärts ist das Endothel von einer Polysaccharidschicht, der Glykokalyx, überzogen. Diese innerste Barriere spielt eine entscheidende Rolle beim Aufbau des kolloidosmotischen Druckgradienten und behindert die Interaktion zwischen Blutbestandteilen und der Endotheloberfläche.
Post-kapilläre Venolen und Venen

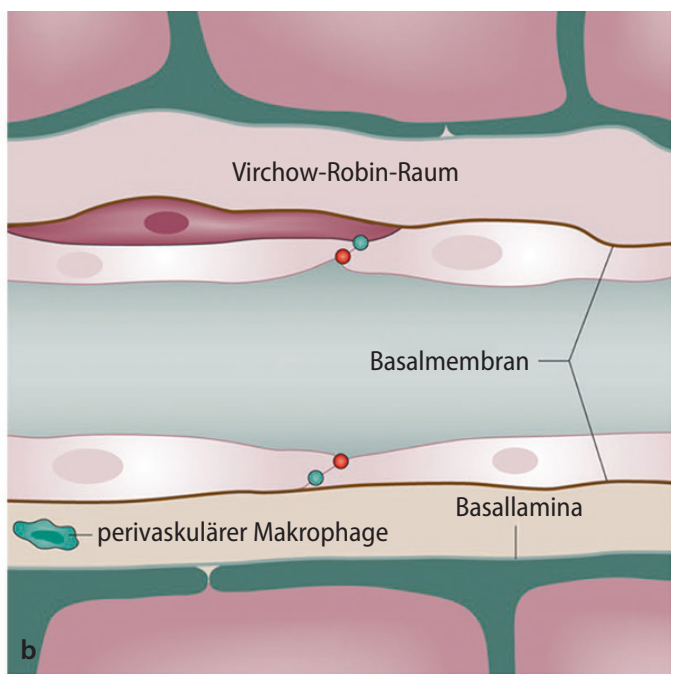

heit), b Im Bereich postkapillärer Venolen und Venen. (Aus: Coureuil et al. 2017)

Auch Astrozyten und Perizyten beeinflussen die Funktion der BHS direkt. Zudem sind beide Zelltypen in die Regulierung des Muskeltonus der muralen glatten Muskelzellen involviert und somit auch an der Kontrolle des zerebralen Blutflusses beteiligt (Carmignoto et al. 2010). Ihr Beitrag zur Verhinderung des Eindringens von Mikroorganismen ins ZNS ist jedoch nur ansatzweise bekannt.

Eine besondere Bedeutung bei der Regulation der Wasserhomöostase des Gehirns kommt den Astrozyten zu, deren lumenwärts gerichtete Fortsätze die Aquaporin-4-Wasserkanäle exprimieren (Haj-Yasein et al. 2011).

\subsubsection{Pathophysiologie der bakteriellen Meningo- enzephalitis}

Die an der Entstehung und Entwicklung einer Meningoenzephalitis beteiligten Mechanismen sind äußerst umfangreich. Sie umfassen u. a. Funktionsstörungen der BHS sowie immunologische und erregerinduzierte Reaktionen der neurovaskulären Einheit, direkte und indirekte toxische Wirkungen der ZNS-pathogenen Mikroorganismen selbst, Konsequenzen der Aktivierung der körpereigenen Infektabwehr, Effekte exzitatorischer Neurotransmitter und sekundäre Erkrankungsfolgen wie zerebrale Ischämien oder Gewebehypoxien. 
Eine Vielzahl der potenziell Meningoenzephalitis verursachenden Keime, darunter auch N. meningitidis, S. pneumoniae und $\mathrm{H}$. influenzae, besiedeln die Haut, den Nasooropharynx, den oberen Respirationstrakt, den Gastrointestinaltrakt oder auch die vaginale Schleimhaut gesunder Menschen. Die Kolonisation kann permanent, vorübergehend oder intermittierend sein.

In der Regel kommt es nur unter besonderen Umständen (Verletzungen, Immunschwäche) zu einer Penetration der Bakterien durch die äußeren Zellbarrieren und zu einer lokalen Entzündung. Hiervon ausgehend ist eine systemische Aussaat über den Blutkreislauf, in selteneren Fällen auch eine Ausbreitung per continuitatem (z. B. bei Mittelohrprozessen), Voraussetzung für den Befall des ZNS. Für einige Erreger (u. a. Hib und S. pneumoniae) existieren Hinweise auf eine positive Korrelation zwischen dem Ausmaß der Bakteriämie und der Wahrscheinlichkeit, an einer Meningoenzephalitis zu erkranken. Ob hingegen auch für (hochvirulente) Keime wie N. meningitidis eine solche Beziehung mit einem krankheitsauslösenden Schwellenwert existiert, ist bislang ungeklärt.

Das Überleben im Blutstrom des Wirtes - trotz der körpereigenen Immunabwehr (wesentlich in Form von komplement- und antikörpervermittelter Phagozytose) - ist daher ein grundlegendes Virulenzmerkmal solcher ZNS-pathogener Bakterien. Diese Resistenzeigenschaft beruht z. T. darauf, dass schlagartig nach Erreichen des Intravasalraumes bei den Erregern eine Modifikation des (bakteriellen) genomischen Transkriptionsprofils einsetzt und damit eine Veränderung der Zellwandbeschaffenheit, eine gesteigerte Expression von komplementregulierenden Proteinen sowie eine vermehrte Eisenaufnahme bewirkt wird. Andere Mikroorganismen (z. B. E. coli) entziehen sich der Körperabwehr durch die Aufnahme in antigenpräsentierende Zellen (APC, wie Makrophagen, dendritische Zellen) und in neutrophile Granulozyten. Nach der rezeptorvermittelten Phagozytose vermehren sich diese Bakterien dann intrazellulär und damit geschützt vor den Einflüssen des Immunsystems (Van Sorge und Doran 2012).

Die Erreger, die in ausreichender Anzahl im Blutstrom überlebt haben, gelangen schlussendlich mit dem Kreislauf ins Gehirn. Die Mechanismen, über die ZNS-pathogene Keime die zunächst noch intakte BHS überwinden, sind unterschiedlich und zum Teil komplex. Eine genauere Beschreibung folgt im nächsten Abschnitt.
Zunächst kann die bakterielle Entzündung auf die Meningen begrenzt bleiben, häufig folgt jedoch eine Invasion in das angrenzende Hirnparenchym mit daraus resultierender zusätzlicher diffuser oder lokaler Enzephalitis. Als Konsequenz der inflammatorischen Prozesse kommt es zu einer zunehmenden Störung der BHS-Funktion mit erhöhter Permeabilität. Im Zuge des graduellen $\mathrm{Zu}$ sammenbruchs dieser Barriere gelingt weiteren Bakterien, aber auch zellulären und humoralen Bestandteilen des Immunsystems, nun die Passage aus der Blutbahn ins Gehirn, woraus sich eine Akzeleration und Ausdehnung der Entzündung ergibt. Im Liquor cerebrospinalis bilden sich diese Vorgänge als (granulozytäre) Pleozytose mit $>1000$ Zellen/ $\mu$ l, begleitet von einer mitunter exzessiven Eiweißvermehrung ab.

\subsubsection{Eigenschaften pathogener Bakterien zur Überwindung der Blut-Hirn-Schranke}

Prinzipiell stellt die Blut-Hirn-Schranke ein unüberwindbares Hindernis für Makromoleküle und damit auch für alle körperfremden Zellen dar. Daher sind ein ausreichendes Ausmaß der Bakteriämie und die Bindung der Erreger an die mikrovaskuläre ZNS-Endothelzell-Schicht sowie deren anschließende Invasion unabdingbare Voraussetzungen für die Entstehung einer Meningoenzephalitis.

Bereits eine intakte zerebrale Mikrozirkulation hat direkte Auswirkungen auf das Erkrankungsrisiko. Ein physiologischer Blutfluss verursacht Scherkräfte, die wiederum die endotheliale Funktion in den Kapillaren und Arteriolen des ZNS verbessern. So ist für N. meningitidis eine schlechtere luminale Adhäsion bei guter lokaler Perfusion belegt (Van Sorge und Doran 2012).

Viele potenzielle Meningoenzephalitis-Erreger weisen Gemeinsamkeiten bei der initialen Interaktion mit der ZNS-Endothelschicht auf:

Zunächst verfügt ein Großteil der entsprechenden Bakterien über Pili (Härchen) oder kleine Fibrillen, über die der erste Kontakt zustande kommt. Im Weiteren erfolgt eine Downregulation der Expression bestimmter bakterieller KapselPolysaccharide, die während des Transports im Blutstrom eine gewisse immunologische Resistenz bewirkt haben, nun aber die Passage der BHS behindern würden. Schließlich schütten diverse Erreger spezifische Toxine aus, die die Endothelzellen schädigen und so die Permeabilität der 
Barriere erhöhen (Van Sorge und Doran 2012; Kim 2008).

Eine Vielzahl von Liganden auf der Oberfläche von Bakterien und lumenwärts ausgerichtete Rezeptoren des Endothels, die überwiegend durch Kopplung an ein G-Protein intrazelluläre Signalwege aktivieren, wurden bereits identifiziert und ausgiebig untersucht. Trotz einer erheblichen Diversität im Detail zwischen den unterschiedlichen Spezies finden sich doch prinzipielle Übereinstimmungen in Bezug auf die bei der Überwindung der BHS stattfindenden Prozesse (Kim 2008).

\section{- Bindung ZNS-pathogener Bakterien an die neurovaskuläre Einheit}

Die Invasion eines Bakteriums ins ZNS beginnt mit der Bindung zwischen sogenannten mikrobiellen Adhäsinen und Rezeptoren der Endothelzelle. Der Laminin-Rezeptor (LR) und der „platelet activating factor receptor" (PAFr) sind dabei die für die wichtigsten ZNS-pathogenen Keime (N. meningitidis, S. pneumomiae, H. influenzae) gemeinsamen Bindungsstellen.

Die Interaktion mit der BHS erfolgt dabei nicht immer direkt, z. T. sind auch „BridgingMoleküle" der Extrazellularmatrix involviert (z. B. Fibronectin) (Banerjee et al. 2011; Kim et al. 2011; Kim 2006).

Die sequenzielle Bindung an Rezeptoren setzt endothelial unterschiedliche intrazelluläre Signalwege in Gang. Dies ist eine wesentliche Voraussetzung für den Transfer des Bakteriums durch die BHS (• Abb. 2.9).
Die Ausschüttung von inflammatorischen Zytokinen bewirkt eine vermehrte Expression von bakterienbindenden Rezeptoren auf Wirtszellen und/oder von intrazellulären Botenstoffen. Einige Spezies, darunter auch S. pneumoniae, nutzen diesen Mechanismus, indem sie selbst die Chemokinliberation induzieren und so ihre Aufnahme in Endothelzellen forcieren. Wichtig ist in diesem Kontext, dass sich diese durch Mikroorganismen gezielt hervorgerufene Freisetzung von Mediatoren hinsichtlich ihrer Zusammensetzung an Zytokinen von der generellen Immunantwort des Wirtes auf potenzielle Krankheitserreger wesentlich unterscheidet (Kim 2008).

Abgesehen von Infektionen mit N. meningitidis und Hib wird die Ausschüttung der stark proinflammatorisch wirkenden Zytokine TNF- $\alpha$ und Interleukin-1 (IL-1) typischerweise nicht induziert. Hierin ist möglicherweise die Erklärung zu sehen, weshalb die beiden genannten Spezies durch eine außergewöhnlich hohe Virulenz und sehr fulminante Krankheitsverläufe gekennzeichnet sind (Van Sorge und Doran 2012).

\section{- Passage ZNS-pathogener Bakterien durch die neurovaskuläre Einheit}

Grundsätzlich existieren drei Möglichkeiten der Passage durch die BHS: Im Einzelnen handelt es sich um

\section{- I - den transzellulären Transfer (u. a.}

S. pneumoniae, N. meningitidis, E. coli) ohne Zerstörung der "tight junctions“ und ohne Bakterienvermehrung in der Endothelzelle,

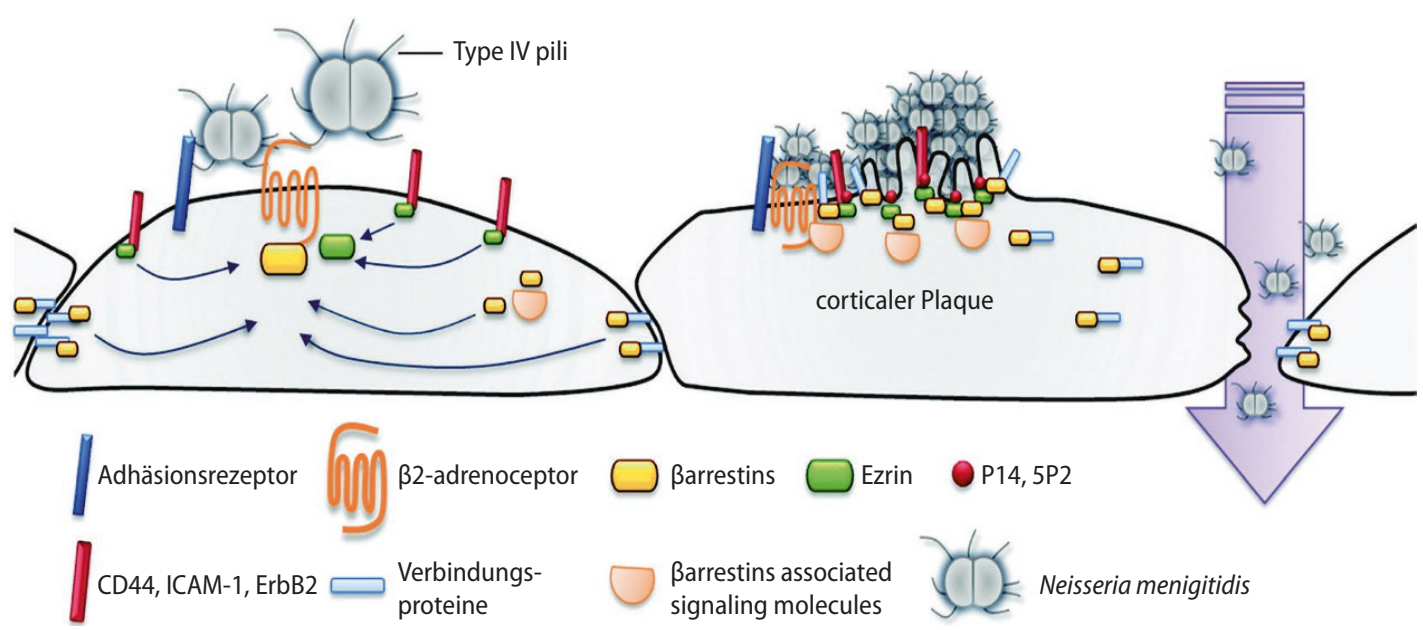

- Abb. 2.9a-c Liganden-Rezeptor-Bindung, Induktion intrazellulärer Signalwege und deren Effekte auf die BHS-
Permeabilität am Beispiel von N. meningitidis. Weitere Details s. Text. (Aus Coureuil et al. 2012) 
- II - den parazellulären Transfer (u. a. Borrelia spp.) mit oder ohne Zerstörung der „tight junctions" und

- III - das „Trojanisches-Pferd-Prinzip“ (unter anderem L. monocytogenes), wobei die Transmigration pathogener Mikroorganismen innerhalb einer infizierten phagozytierenden Zelle des Immunsystems erfolgt (• Abb. 2.10).

8 Die Passage eines Bakteriums durch die BHS kann auf drei unterschiedliche Arten erfolgen:

- als Transfer direkt durch die Endothelzellen selbst (I)

- zwischen den Zellen der neurovaskulären Einheit hindurch (II) oder

- nach dem Prinzip des „Trojanischen Pferdes" (III), wie (I) ebenfalls über einen transzellulären Transportweg.

Einige Spezies gelangen auf mehr als eine dieser Arten ins Hirngewebe.

Beim transzellulären Transfer (siehe I) muss zunächst rezeptorvermittelt eine Reorganisation des Aktinzytoskeletts (Aktinpolymerisation) der Endothelzelle induziert werden. Beim sogenannten "Zipper-Mechanismus" wird das Bakterium passiv über eine Membranausstülpung inkorporiert. Beim „Trigger-Mechanismus“ sind zusätzlich in die Wirtzelle injizierte Mediatoren für die Einschleusung erforderlich (Kim 2008). Nach der Internalisierung in eine Vakuole, bestehend aus einem Abschnitt der Zellmembran, passieren die Erreger die BHS und verlassen auf der lumenabgewandten Seite wieder die Endothelzelle. Einige Spezies sind in der Lage, während des Transfers zusätzlich intrazelluläre Signalwege zu modulieren. Beispielsweise verhindern Bakterien wie E. coli auf diese Weise ihre eigene Zersetzung während der Passage, indem sie die Fusion der Vakuolen mit Lysosomen unterbinden (Kim 2006, 2008).

\subsubsection{Zusammenbruch der Blut- Hirn-Schranke}

Mit der Progression des Entzündungsprozesses kommt es zu einer zunehmenden Zerstörung der Integrität der BHS. Daran sind eine Vielzahl von Faktoren beteiligt.

Neben der transzellulären Passage gewinnt insbesondere mit fortschreitender Erkrankungsdauer die parazelluläre Translokation ins Hirnpa-
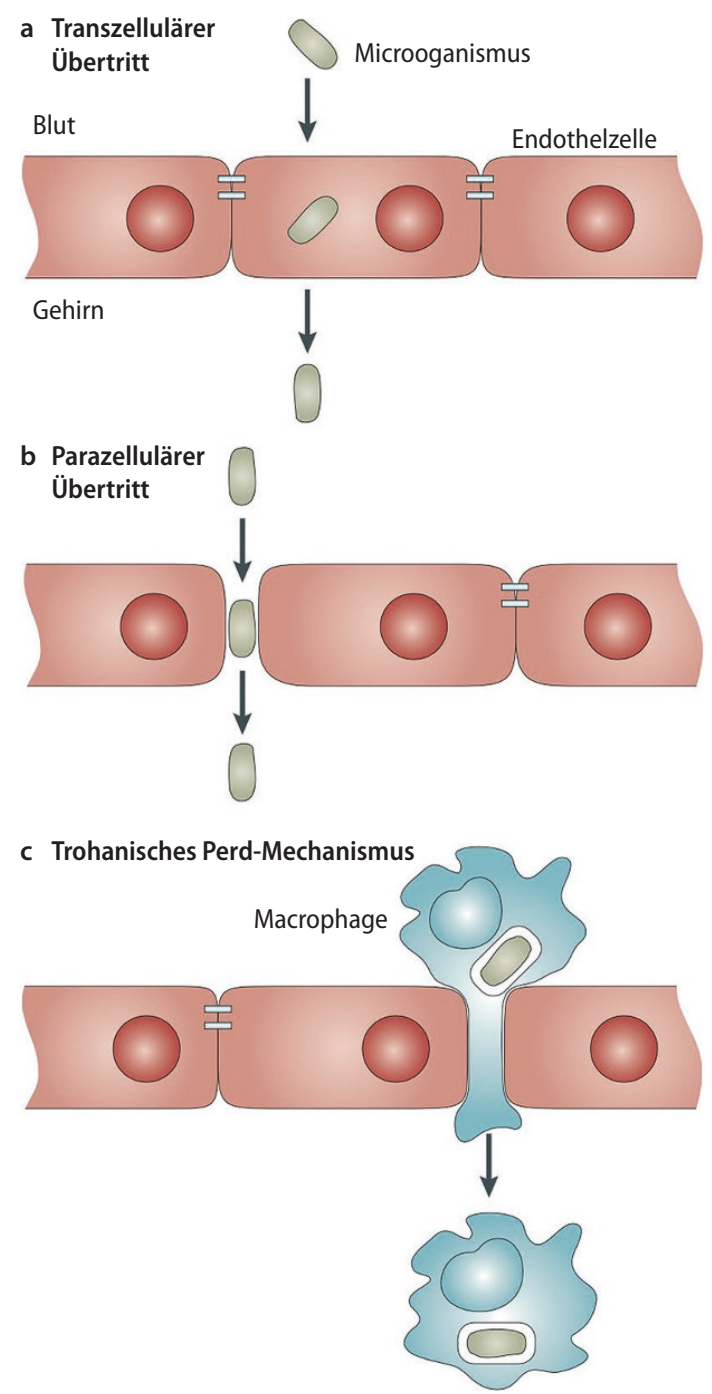

- Abb. 2.10 Passage der Bakterien durch die Blut-HirnSchranke (BHS). (Aus: Kim 2008)

renchym an Bedeutung. Hierfür ist entweder eine Zerstörung der TJ und AJ, überwiegend durch direkte Einwirkung sezernierter Bakterientoxine, erforderlich, oder es bedarf einer spezifischen Interaktion zwischen diesen Strukturen und dem eindringenden Mikroorganismus, sodass die „Schranke“ quasi vorübergehend geöffnet wird (Van Sorge und Doran 2012).

Unter anderem schüttet S. pneumoniae Giftstoffe aus, die eine regelrechte "Durchlöcherung“ der BHS verursachen. Darüber hinaus bewirken die freigesetzten Toxine eine Verstärkung der Immunantwort des Körpers mit gesteigerter Zytokin-/Chemokin-Ausschüttung, die, wie oben bereits erwähnt, ihrerseits selbst die Schranken- 
funktion negativ beeinflussen können. Beispielsweise ist für bestimmte Erreger (s. oben) eine gesteigerte systemische Expression von TNF- $\alpha$ mit einer erhöhten Permeabilität der BHS vergesellschaftet, für andere hingegen nicht (Barichello et al. 2011).

Daneben induzieren einige Bakterien (u. a. E. coli, S. pneumoniae) die Bildung von Stickstoffmonoxid-Synthase (iNOS) in ZNS-Endothelzellen, wodurch ebenfalls die Migration der Erreger ins Hirngewebe erleichtert wird.

Neben diesen eher unspezifischen Methoden zur Störung der BHS-Integrität greifen einige Spezies zum Verlassen der Blutbahn auch auf komplexere Strategien zurück. N. meningitidis und E. coli benutzen ihre Oberflächenadhäsionsmoleküle (Typ-IV-Pili bei N. menigitidis, OmpA bei E. coli), um über die Aktivierung intrazellulärer Signalwege schlussendlich eine Konformitätsänderung im Bereich bestimmter AJ-Proteine (u. a. „vascular endothelial cadherin“) zu bewirken, wodurch die parazelluläre Translokation ermöglicht wird. $\mathrm{Zu}$ sätzlich induziert N. meningitidis die Freisetzung von Matrix-Metalloproteinase 8 (MMP 8) aus neutrophilen Granulozyten des Wirtes, die eine spezifische Spaltung des TJ-Proteins Occludin verursacht und zu einer weiteren Schwächung der Barrierestruktur beiträgt.

Andere Mikroorganismen (z. B. Bacillus anthracis) wiederum injizieren Proteasen und/oder Toxinkomplexe in die Endothelzellen und bewirken dadurch eine weitgehende Unterbindung des endosomalen Proteintransportes. Dadurch kommt nicht nur das Recycling von Konnektivitätsstrukturen der AJs und TJs zum Erliegen, sondern mit weiterreichenden Folgen auch die Zell-zu-Zell-Kommunikation (Van Sorge und Doran 2012).

Schlussendlich tragen auch diverse Faktoren der Immunantwort des Wirtsorganismus zum Zusammenbruch der BHS bei. Zwar sind neutrophile Granulozyten entscheidend für die Verhinderung und Eindämmung einer bakteriellen Sepsis, jedoch ist in unterschiedlichen Tiermodellen zur Pneumokokken- und Hib-Meningoenzephalitis die Prävention der Leukozytenmigration ins ZNS mittels Anti-CD18-Antikörpern mit einer signifikant verringerten Letalität vergesellschaftet (Banarjee et al. 2011).

Die o.g. Vorgänge können sich auch im Bereich des die Ventrikel auskleidenden Ependyms abspielen.

\subsubsection{Aufrechterhaltung und Expansion der Meningo- enzephalitis}

Die von den Komponenten der BHS vermittelte Immunantwort auf die Bakteriämie und den initialen Kontakt eines pathogenen Agens mit dem ZNS-Endothel ist essenziell für eine effektive Beseitigung des entsprechenden Mikroorganismus, bevor es diesem gelingt, in das Hirnparenchym einzudringen. Zeitpunkt und Ausmaß der Bereitstellung neutrophiler Granulozyten sind entscheidend für den Erkrankungsverlauf (Van Sorge und Doran 2012).

Andererseits verursacht eine anhaltende Exposition gegenüber neurotropen Erregern in vielen Fällen eine inadäquat starke Aktivierung der neurovaskulären Einheit mit konsekutiv überschießender Inflammation, wodurch sowohl die Schrankenfunktion weiter kompromittiert wird, als auch unmittelbar eine neuronale Schädigung hervorgerufen werden kann (Banarjee et al. 2011).

Es gibt jedoch auch konträre Krankheitsverläufe mit einer Down-Regulation der physiologischen Abwehrmechanismen. Die Proliferation und Ausbreitung von B. anthracis im Gehirn wird beispielsweise durch die induzierte Suppression der Chemotaxis neutrophiler Granulozyten begünstigt.

Die Untersuchungen zu den komplexen Abläufen, die der veränderten Regulation der genomischen Transkription in Zellen der neurovaskulären Einheit unter dem Einfluss bakterieller Entzündungsvorgänge zugrunde liegen, stehen erst am Anfang.

Viele Bakterien bewirken nicht erst durch die Invasion der Endothelzellen, sondern bereits durch ihren Kontakt mit lumenseitigen Strukturen der neurovaskulären Einheit die Auslösung der Immunantwort des Wirtsorganismus mit zum Teil exzessiver Zytokinfreisetzung. Daher liegt in der gezielten Blockade spezifischer Ligand-Rezeptor-Bindungen ein erfolgversprechender Ansatz zur Abschwächung insbesondere inflammatorischer Prozesse im Rahmen der Pathogenese der Meningoenzephalitis (Van Sorge und Doran 2012).

\section{- Zusammenbruch des physiologischen ZNS-Milieus}

Die durch ZNS-pathogene Mikroorganismen hervorgerufene Permeabilitätssteigerung der BHS 
betrifft nicht nur die jeweiligen Krankheitserreger, sondern auch immunkompetente Zellen des peripheren Blutes wie Monozyten und Granulozyten sowie aus dem Blutplasma stammende Mediatoren und Proteine. Hierdurch kommt es zu einer gravierenden Veränderung gegenüber dem physiologischen ZNS-Milieu bei intakter Schrankenfunktion mit der Folge einer Verstärkung und Beschleunigung der Inflammation und damit auch des neuronalen Schadens (Kim 2008). Ein bedeutsamer Faktor ist in diesem Zusammenhang die Freisetzung proteolytischer Enzyme und Entzündungsmediatoren (einschließlich freier Radikale) aus den eingewanderten Leukozyten.

\section{- - Direkte Gewebetoxizität ZNS-pathogener Bakterien}

Meningoenzephalitiserreger selbst verursachen ebenfalls Gewebeschädigungen im ZNS. Nach der Passage der BHS proliferieren die Bakterien im Subarachnoidalraum und können von dort weiter in das Gehirn vordringen (Nau und Gerber 2003). Unterschiedlichste Substanzen pathogener Mikroorganismen besitzen eine direkt neurotoxische Wirkung. Pneumolysin (aus S. pneumoniae) beispielsweise ist ein porenbildendes Toxin, das u. a. Neurone durch den so vermittelten ungehemmten Einstrom von extrazellulärem Kalzium schädigt.

Neben den im Rahmen des Entzündungsgeschehens aktivierten Granulozyten, Makrophagen, Mikroglia- und Endothelzellen sind auch einige Bakterien selbst in der Lage, freie Radikale zu produzieren, die dann eine Oxidation von Membranlipiden und DNA-Aberrationen bewirken. Der durch den oxidativen Stress hervorgerufene Verlust der Membranintegrität geht mit einem exzessiv hohen Energieverbrauch einher, der schließlich die Apoptose betroffener Zellen einleitet (Koedel und Pfister 1999). Des Weiteren können freie Radikale auch durch Aktivierung des Transkriptionsfaktores NF- $\kappa$ B die Transkription verschiedener Entzündungsmediatoren forcieren.

Auch diverse Bakterienbestandteile (v. a. der subkapsulären Zellwand) wie Lipopolysaccharide, Teichonsäure u. a. $\mathrm{m}$. besitzen eine unmittelbare Toxizität gegenüber Nervengewebe und/oder Gliazellen.

\section{- Energiedepletion, Gewebeischämie und Apoptose}

Glutamat und andere exzitatorische Aminosäuren sind im Rahmen bakterieller Meningoenzephali- tiden deutlich erhöht. Dies führt insbesondere an Nervenzellen zu einer verstärkten Depolarisation der Zellmembran durch Induktion eines Kalziumeinstroms, der seinerseits einen unphysiologisch hohen Energieverbrauch verursacht und damit schlussendlich zur neuronalen Schädigung beiträgt (Nau und Gerber 2003).

Die Effekte unterschiedlicher bereits oben genannter Noxen wie Pneumolysin und exzitatorische Neurotransmitter sowie oxidativer Stress konvergieren u. a. in der Freisetzung von Cytochrom $\mathrm{C}$ aus den Mitochondrien. In der weiteren Abfolge der Signalkaskade kommt es dann zur Aktivierung von Caspasen, die ihrerseits maßgeblich apoptotische Abläufe in Gang setzten und unterhalten (Koedel und Pfister 1999).

Ischämische respektive hypoxische Läsionen des Hirngewebes sind bei bakteriell verursachten ZNS-Infektionen verbreitet und überwiegend multifaktoriell bedingt. Ursächlich können - jeweils alleine, meist jedoch in Kombination (Nau und Gerber 2003; Pfister et al. 1992) - sein:

- Vasospasmen oder Vaskulitiden bis hin zum konsekutiven Verschluss arterieller Gefäße,

- ein Hirnödem mit Anstieg des intrakraniellen Drucks, Abfall des zerebralen Perfusionsdrucks und/oder transtentorieller bzw. transforaminaler Herniation und

- eine Kompromittierung der zerebralen Autoregulation

\subsubsection{Zerebrale Komplikationen der bakteriellen Meningoenze- phalitis}

In absteigender Häufigkeit erleiden betroffene Patienten im akuten Erkrankungsstadium die nachstehenden, das ZNS einschließlich seiner Gefäße sowie einzelne Nervi craniales betreffende Komplikationen. Anzuführen sind im Einzelnen zerebrovaskuläre Mitbeteiligungen in Form von Vaskulitiden, Vasospasmen und Störungen der zerebralen Autoregulation, daneben aber auch septische Sinus- und Hirnvenenthrombosen, ferner vestibulocochleäre Defekte (Hörstörungen, Schwindel), die Ausbildung eines Hydrozephalus und/oder eines Hirnödems mit der Gefahr der Herniation, Hirnnervenausfälle, symptomatische epileptische (Früh-) Anfälle bis hin zur Manifestation einer sekundären Epilepsie, eine diffuse Zerebritis (Hirnphlegmone) und selten Hirnabszesse oder subdurale Empyeme (Pfister et al. 1992). 
Die assoziierten Schäden können im individuellen Fall prognosebestimmend sein.

\section{- Frühe systemische Komplikationen der bakteriellen Meningoenzephalitis und der Septikämie}

In der Akutphase der Erkrankung liegt, je nach Virulenz des Krankheitserregers und immunologischer Kompetenz des Wirtsorganismus, eine hinsichtlich des Schweregrades variabel ausgeprägte Septikämie vor. Die in diesem Rahmen fakultativ auftretenden extrakraniellen Organmanifestationen weisen z.T. ein speziesspezifisches Verteilungsmuster auf. $\mathrm{Zu}$ den Erkrankungsbildern zählen der septische Schock, die Verbrauchskoagulopathie (= disseminierte intravasaler Gerinnung, DIC), das „adult respiratory distress syndrome“ (ARDS), Arthritiden v. a. großer Gelenke (septisch oder auch reaktiv verursacht), Rhabdomyolysen, Pankreatitiden, die septische einseitige (selten beidseitige) Endophthalmitis oder Panophthalmitis sowie spinale Komplikationen aufgrund einer Myelitis oder Ischämie bei Vaskulitis der rückenmarkversorgenden Arterien.

Im Sinne einer Fernwirkung der durch die entzündlichen Prozesse im Gehirn hervorgerufenen Schäden können sich - unter anderem infolge des Syndroms der inadäquaten $\mathrm{ADH}$-Sekretion (SIADH), des zerebralen Salzverlustsyndroms oder auch eines zentralen Diabetes insipidus - zentralbedingte Elektrolytstörungen, überwiegend in Form der Hyponatriämie, entwickeln (Koedel und Pfister 1999; Pfister et al. 1992).

Bei Nachweis einer Sinusitis, Mastoiditis oder Otitis media handelt es sich nicht um septische Absiedelung, sondern in der Regel um den extrameningealen Infektfokus, den es konsequent $\mathrm{zu}$ sanieren gilt.

\section{Cave}

Im Rahmen einer bakteriellen Meningoenzephalitis kann es zu schwerwiegenden systemischen Komplikationen kommen. Hierzu gehören die Verbrauchskoagulapathie ebenso wie der septische Schock oder zentralbedingte Elektrolytstörungen. Eine intensivmedizinische Überwachung ist deshalb obligat!

\subsubsection{Perspektiven}

Auch zukünftig wird infolge der nun verfügbaren Impfstoffe gegen die beiden häufigsten Auslöser der bakteriellen Meningoenzephalitis (S. pneumoniae, N. meningitidis) sowie gegen $\mathrm{H}$. influenzae eine weitere Änderung des Erregerspektrums zu beobachten sein. Insbesondere ist dabei aber von einem Shift hin zu anderen Serogruppen/ Serovaren innerhalb der einzelnen Spezies auszugehen, die nicht von den jeweils eingesetzten, meist polyvalenten Impfstoffen mit abgedeckt werden (Htar et al. 2015). Dies unterstreicht die Sinnhaftigkeit einer nationalen epidemiologischen Surveillance, einschließlich der Dokumentation des jeweiligen klinischen Syndroms als obligates Instrument für die zeitnahe dynamische Anpassung der Impfstoffe und anderer präventiver Maßnahmen.

Für die Entwicklung maßgeschneiderter Therapien der Zukunft ist zudem eine profunde Kenntnis über die genauen Abläufe der immunologischen Antwort der neurovaskulären Einheit auf die Exposition gegenüber potenziell ZNSpathogenen Bakterien wichtig. Genaue Kenntnisse über die Aktivierung von Signalwegen und die intrazelluläre Informationsweitergabe nehmen dabei eine Schlüsselposition ein. Die Herausforderung besteht darin, durch eine gezielte Modulation der Immunantwort protektive Effekte gegenüber eingedrungenen Krankheitserregern zu fördern und negative Folgen, wie beispielsweise den Verlust der BHS-Integrität und die überschießende Inflammation bis hin zur Generierung eines neuronalen Schadens, zu minimieren.

Dass dieses Konzept prinzipiell anwendbar ist, zeigen die klinischen Studien zum Einsatz von Dexamethason bei der bakteriellen Meningoenzephalitis. Zwar konnte ein signifikanter Nutzen bisher nur für Erkrankungen infolge einer S. pneumoniae-Infektion belegt werden, allerdings lässt sich auch für andere hochvirulente Erreger wie N. meningitidis zumindest ein tendenzieller Vorteil hinsichtlich des Outcomes erkennen (De Gans und van de Beek 2002; Brouwer et al. 2015; Heckenberg et al. 2012). Gegenüber der nur unspezifischen Immunsuppression mit Steroiden ist zukünftig von einer gezielten Blockade oder auch Aktivierung pathophysiologisch bedeutsamer Signalwege der Zellen der neurovaskulären Einheit eine höhere Effektivität bei der Behandlung der bakteriellen Meningoenzephalitis zu erwarten. 


\section{Gabe von Dexamethason bei bakterieller Meningo- enzephalitis}

Die bakterizide Wirkung gängiger Antibiotika zur Behandlung der septischen Meningoenzephalitis hat die Lyse der ursächlichen Bakterien zufolge. Damit ist eine Ausschüttung proinflammatorischer Mediatoren (z. B. Pneumolysin), insbesondere in den Subarachnoidalraum, mit prognostisch ungünstigen Auswirkungen vergesellschaftet. Eine aktuelle Cochrane-Analyse unter Einschluss von 25 Studien belegt für den Einsatz von Dexamethason bei Nachweis von Pneumokokken eine signifikante Reduktion der Letalität und von Hörschäden. Dieser Effekt ist bisher für andere Erreger, darunter auch Meningokokken, weniger eindrücklich oder gar nicht nachzuweisen. Allerdings war bei keiner der Untersuchungen die Steroidbehandlung mit relevanten klinischen Komplikationen vergesellschaftet; vielmehr zeigte sich sogar zusätzlich eine (tendenzielle) Reduktion anderer neurologischer Folgeschäden.

Therapeutische Konsequenzen: Daher wird gegenwärtig beim Verdacht auf das Vorliegen einer bakteriellen Meningoenzephalitis die Gabe von Dexamethason in einer Dosierung von $10 \mathrm{mg}$ alle 6 Stunden, jeweils unmittelbar vor oder mit der antimikrobiellen Therapie empfohlen. Bei positivem Nachweis von S. pneumoniae ist das Regime über 4 Tage so beizubehalten, in allen anderen Fällen sollte die Behandlung beendet werden (De Gans und van de Beek 2002).

\section{?}

- Welches sind die häufigsten ZNS-pathogenen Keime, die im Erwachsenenalter eine bakterielle Meningoenzephalitis verursachen?

- Auf welche drei Arten gelangen pathogene Bakterien prinzipiell durch die BlutHirn-Schranke?

- Welche zerebralen und systemischen Komplikationen können im Zuge einer bakteriellen Meningoenzephalitis auftreten?

- Was ist die Rationale für den Einsatz von Dexamethason in Kombination mit Antibiotika zur Behandlung der bakteriellen Meningoenzephalitis?

\subsection{Herpes-Enzephalitis}

\section{A. Biesalski}

\section{- Zum Einstieg}

Verschiedene Virusinfektionen können sich im ZNS manifestieren. Klinisch häufig und zumeist unkompliziert ist die virale, lymphozytäre Meningitis, die mit Kopfschmerz, (mäßigem) Fieber und Nackensteifigkeit einhergeht und innerhalb einiger Tage von alleine wieder abklingt. Treten zu- sätzlich Bewusstseinsstörungen oder fokal-neurologische Symptome auf, sind sie ein wichtiger Hinweis auf das Übergreifen der Entzündung auf das Hirnparenchym und somit die Entwicklung einer (Meningo-)Enzephalitis. Zu den Viren, die das Nervensystem befallen, gehören - neben einigen Vertretern der Herpesviren - auch Enteroviren (z. B. Poliovirus), Paramyxoviren (z. B. Masern-, Mumpsviren) oder Arboviren (z. B. FSME).

Die Herpes-Enzephalitis, als häufigste sporadisch auftretende Virusenzephalitis in unseren Breiten, stellt eine hochakute und lebensbedrohliche Erkrankung dar, die im Folgenden vorgestellt werden soll.

\section{Herpes-Enzephalitis}

- Sporadisch auftretende, viral ausgelöste Entzündung des Hirnparenchyms, die unbehandelt in mindestens $70 \%$ der Fälle tödlich verläuft.

- Inzidenz: 1-4/1.000.000 Einwohner/Jahr.

- Erreger:

- Herpes-simplex-Virus Typ 1 (HSV 1): $>90 \%$, akuter Beginn, zumeist schwerwiegender Verlauf.

- Herpes-simplex-Virus Typ 2 (HSV 2): 5-10\%, schleichender Beginn, milder Verlauf, "Mollaret-Meningitis".

- Verlauf:

- Bei HSV 1 Prodromalphase über mehrere Tage mit Kopfschmerz, (sub-)febriler Temperatur und Unwohlsein. Dann akutes Auftreten von Bewusstseinsstörung (Somnolenz bis Psychose), fokalneurologischen Symptomen (Aphasie, Hemiparese, epileptische Anfälle), Temperaturanstieg, Meningismus, Koma.

- Bei HSV 2 oft schleichender Beginn, Kopfschmerz, ggf. Kaudaradikulitis oder -myelitis.

- Therapie: Frühestmögliche virustatische Therapie mit Aciclovir i.v. (in Sonderfällen Foscarnet); ggf. ergänzende Kortison-Gabe.

- Prognose: Die Mortalität der HSV 1-Enzephalitiden liegt auch bei rechtzeitiger Therapie bei $20-30 \%$, in fast allen Fällen verbleiben bei Überlebenden neurologische Defizite wie Gedächtnisstörungen. Bei HSV 2-Enzephalitis bzw. -Meningitis ist die Prognose gut. 
- Tab. 2.3 Übersicht über die humanpathogenen Herpesviren. Die mit * gekennzeichneten Viren können generell das ZNS befallen.

\begin{tabular}{|c|c|c|c|}
\hline Gruppe & Vertreter & Übertragungsweg & Assoziierte Erkrankungen \\
\hline \multirow[t]{2}{*}{$\begin{array}{l}\text { a-Herpes- } \\
\text { viren }\end{array}$} & $\begin{array}{l}\text { Herpes-simplex-Virus } \\
\text { Typ } 1 \text { und } 2 \text { (HSV 1, } \\
\text { HSV 2)* }\end{array}$ & $\begin{array}{l}\text { HSV 1: vorwiegend oral über } \\
\text { Speichel und Haut/Schleim- } \\
\text { hautkontakt } \\
\text { HSV 2: sexuelle Übertragung, } \\
\text { perinatal }\end{array}$ & $\begin{array}{l}\text { Herpes labialis (HSV 1), Herpes genitalis } \\
\text { (HSV 2), Herpes-Enzephalitis (HSV 1), } \\
\text { Herpes neonatorum (zumeist HSV 2), } \\
\text { Keratokunjunctivitis herpetica }\end{array}$ \\
\hline & $\begin{array}{l}\text { Varicella-zoster-Virus } \\
(\text { VZV) }\end{array}$ & $\begin{array}{l}\text { Tröpfcheninfektion, Übertra- } \\
\text { gung aerogen oder durch } \\
\text { Kontakt mit Bläscheninhalt }\end{array}$ & $\begin{array}{l}\text { Primärinfektion (meist Kinder): „Wind- } \\
\text { pocken“ } \\
\text { Rezidiv: „Gürtelrose“ (Zoster) }\end{array}$ \\
\hline \multirow[t]{3}{*}{$\begin{array}{l}\beta \text {-Herpes- } \\
\text { viren }\end{array}$} & $\begin{array}{l}\text { Zytomegalievirus } \\
(\mathrm{CMV})^{*}\end{array}$ & $\begin{array}{l}\text { Übertragung über } \\
\text { Körperflüssigkeiten (Speichel, } \\
\text { Urin, Muttermilch) über } \\
\text { direkten Schleimhautkontakt, } \\
\text { sexuell, iatrogen }\end{array}$ & $\begin{array}{l}\text { Zumeist inapparenter Verlauf mit } \\
\text { "grippalen“ Symptomen } \\
\text { Bei intrauteriner Übertragung oder } \\
\text { Immunsuppression schwere, z. T. } \\
\text { lebensbedrohliche Verläufe oder Spät- } \\
\text { schäden möglich }\end{array}$ \\
\hline & $\begin{array}{l}\text { Humanes Herpesvirus } 6 \\
\text { (HHV 6) }\end{array}$ & $\begin{array}{l}\text { Speichel, enger Haut-/ } \\
\text { Schleimhautkontakt }\end{array}$ & $\begin{array}{l}\text { Exanthema subitum („Dreitagefieber“), } \\
\text { selten Meningoenzephalitis }\end{array}$ \\
\hline & $\begin{array}{l}\text { Humanes Herpesvirus } 7 \\
\text { (HHV 7) }\end{array}$ & $\begin{array}{l}\text { Speichel, enger Haut-/ } \\
\text { Schleimhautkontakt }\end{array}$ & $\begin{array}{l}\text { Häufig inapparenter Verlauf, Exanthema } \\
\text { subitum }\end{array}$ \\
\hline \multirow[t]{2}{*}{$\begin{array}{l}\mathrm{\gamma} \text {-Herpes- } \\
\text { viren }\end{array}$} & $\begin{array}{l}\text { Epstein-Barr-Virus } \\
(\text { EBV)* }\end{array}$ & $\begin{array}{l}\text { Orale Übertragung „ „kissing } \\
\text { disease“ }\end{array}$ & $\begin{array}{l}\text { Infektiöse Mononukleose in unter- } \\
\text { schiedlicher Ausprägung („Pfeiffer'sches } \\
\text { Drüsenfieber“), maligne Tumorerkran- } \\
\text { kungen (Magenkarzinom, unterschied- } \\
\text { liche Lymphome) }\end{array}$ \\
\hline & $\begin{array}{l}\text { Kaposi-Sarkom-Herpes- } \\
\text { virus (KSHV/HHV 8) }\end{array}$ & $\begin{array}{l}\text { Speichel, sexuelle Übertra- } \\
\text { gung }\end{array}$ & $\begin{array}{l}\text { Kaposi-Sarkom, KSHV/HHV8-assoziierte } \\
\text { Lymphome }\end{array}$ \\
\hline
\end{tabular}

\subsubsection{Herpesviren}

Es sind neun verschiedene humane Herpesviren bekannt, die in unterschiedlicher Weise pathogen wirken können (•Tab. 2.3).

\subsubsection{Lebenszyklus der Herpes- simplex-Viren}

Einige Merkmale sind vielen Viren gemein: Sie nutzen den Stoffwechsel infizierter Wirtszellen zur eigenen Replikation, können vorübergehend in eine Art „Ruhezustand“ treten, durch Reaktivierung eine erneute Virusaussaat verursachen und zur Infektion anderer Individuen führen. Je nach Art des Virus werden unterschiedliche Wirtszellen befallen.

Herpesviren sind große, doppelsträngige DNA-Viren, die gut an den Menschen angepasst sind: Sie verursachen eine lebenslange Infektion, führen in der Mehrzahl der Fälle nicht zum Tod ihres Wirtes und können leicht auf andere Menschen übertragen werden.

Der Lebenszyklus der Herpes-simplex-Viren ist in - Abb. 2.11 dargestellt: Sie treten über die Schleimhäute des Mund- und Nasen-RachenRaumes (HSV 1) oder genital (HSV 2) in den Organismus ein. Im Epithel der Haut oder Schleimhaut erfolgt die Virusreplikation, die sich über Bläschenbildung (HSV 1, Herpes labialis) im Bereich der Mundschleimhaut äußern kann, häufig aber unbemerkt bleibt. Das Virus infiziert sensorische Neurone und kann über retrograden axonalen Transport in den Nervenzellkörper sensibler Ganglien vordringen, wo es eine Latenz etabliert (bei oraler Infektion zumeist in Ganglien des N. trigeminus, bei genitaler Infektion in lumbosakralen Ganglien).

Während der Latenzphase ist die Virusinfektion asymptomatisch. Die viralen DNA-Genome persistieren hierbei im Nukleus der Nervenzellen 
- Abb. 2.11a, b Lebenszyklus der Herpesviren: Primärinfektion, Latenz, Reaktivierung. (Aus: Suerbaum et al. 2016)

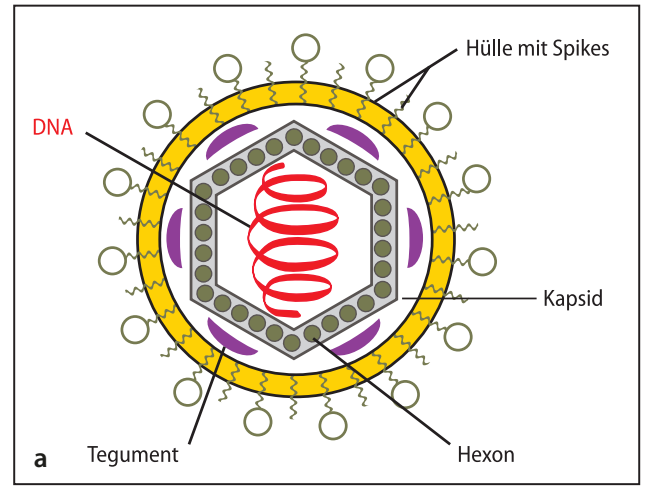

b

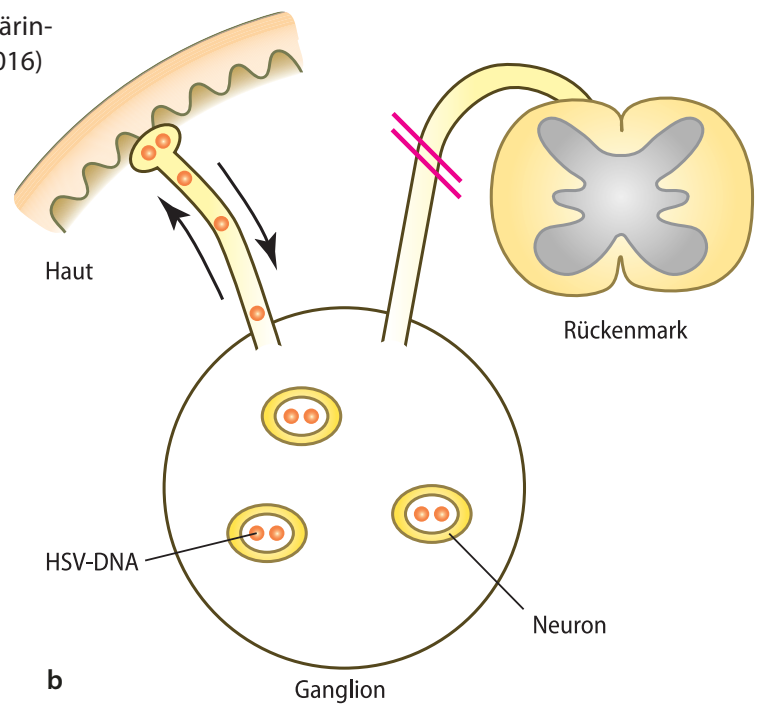

und sind während dieser Phase serologisch nicht nachweisbar. Es kann zu einer Reaktivierung und Replikation der Viren kommen, die über anterograden axonalen Transport zurück in die Peripherie gelangen und dort erneut zur Infektion innervierter Hautareale führen. Treten dann klinische Symptome auf, spricht man von Rekurrenz oder Rezidiv. Rezidive treten in der Regel spontan auf, können jedoch durch unterschiedliche Faktoren beeinflusst werden. Hierzu gehören unter anderem emotionaler Stress, Fieber, Gewebeschäden oder Immunsuppression (Whitley et al. 2007).

\subsubsection{HSV 1}

Mit HSV 1, auch bekannt als „orales“ Herpessimplex-Virus, sind weltweit mehr als 90\% der Erwachsenen infiziert. In der Mehrzahl der Fälle verläuft die Infektion inapparent, bleibt jedoch ein Leben lang als latente Infektion bestehen. Herpes labialis stellt die mit Abstand häufigste Manifestation eines HSV 1-Rezidivs dar und tritt bei bis zu $30 \%$ der erwachsenen Bevölkerung ein- oder mehrfach im Leben auf.

Die Herpes-Enzephalitis tritt überwiegend im Rahmen einer Primärinfektion mit HSV 1 auf. Es bestehen Hinweise darauf, dass bei den betroffenen Patienten ein milder Immundefekt vorliegt, der das Erkennen und adäquate Reagieren auf das
Virusantigen erschwert (genetische Mutation von TLR3, s.unten). Patienten, die regelmäßig an Herpes labialis leiden, sind nicht häufiger von HerpesEnzephalitis betroffen. In mindestens der Hälfte der Fälle unterscheidet sich der virale Stamm, der für die Enzephalitis verantwortlich ist, von dem Stamm, der bei demselben Patienten herpetische Hautläsionen verursacht (Bradshaw und Venkatesan 2016). Nach aktuellem Kenntnisstand bestehen keine beeinflussbaren Risikofaktoren, die für die Erkrankung prädisponieren.

\subsubsection{HSV 2}

Infektionen mit HSV 2, das als "genitales“ Herpessimplex-Virus gilt, gehören zu den sexuell übertragbaren Erkrankungen. Eine Primärinfektion kann zum Herpes genitalis führen, der mit Bläschenbildung am weiblichen Genital oder dem Penis einhergeht. Eine Herpes Mening(oencephal) itis mit HSV 2 ist sehr selten, verläuft meist milde und hat eine gute Prognose.

\subsubsection{Pathologie/Histopathologie}

Die Herpes-Enzephalitis geht beim Erwachsenen mit Entzündungen, Stauungszeichen der lokalen Gefäße und/oder Blutungen einher, die anfangs asymmetrisch (zumeist links beginnend) im Be- 


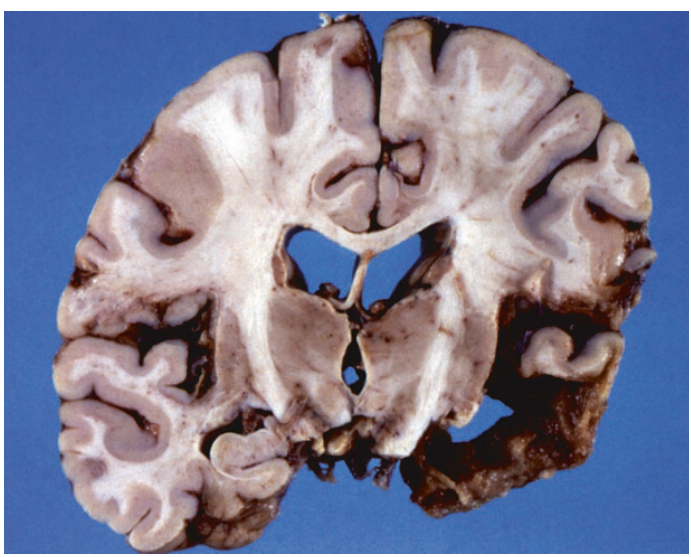

- Abb. 2.12 Präparat eines Patienten, der in seinem Leben eine HSV 1-Enzephalitis überlebt hatte. Im Temporallappen besteht eine große Defekthöhle mit bräunlich verfärbten Wänden. (Aus: Paulus und Schröder 2012)

reich der Temporallappen auftreten und sich im Verlauf bitemporal und bifrontal ausbreiten. Limbische Strukturen sind ebenso betroffen wie die angrenzenden Meningen.

Bei unzureichender Therapie entstehen innerhalb von zwei Wochen umfangreiche Nekrosen und Hämorrhagien, die (beim Überleben der Erkrankung) resorbiert werden und mit verbleibenden Defekten verheilen (• Abb. 2.12).

Histologisch zeigen sich bereits früh im Krankheitsverlauf unspezifische Veränderungen. Es bestehen Stauungen von Kapillaren und kleinen Gefäßen sowie kortikale und subkortikale Petechien. In den Meningen sind Makrophagen und Lymphozyten in mäßiger Zahl nachweisbar. In etwa der Hälfte der Fälle lassen sich zu Beginn der Erkrankung typische intranukleäre Einschlüsse, sogenannte Cowdry-Typ A nachweisen, die sich bei unterschiedlichen Herpesinfektionen (auch HSV 2, VZV) zeigen.

Innerhalb der zweiten und dritten Woche entwickeln sich hämorrhagische Nekrosen und eine ausgedehnte Entzündungsreaktion, die weit über das makroskopisch sichtbare Areal hinausgeht und den „wahren“ Infektionsbereich widerspiegelt (- Abb. 2.13). Ab Ende der zweiten Woche treten Mikrogliaknötchen sowie perineuronale leukozytäre Satellitosen auf. Spät im Krankheitsverlauf entwickelt sich eine gliale Nekrose.

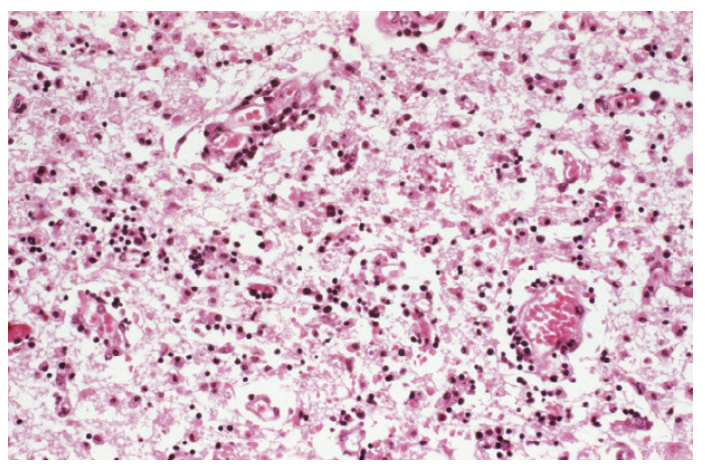

- Abb. 2.13 Floride HSV-Enzephalitis des Temporallappens mit hämorrhagischer Nekrose und perivaskulären, diffus das zerfallende Gehirnparenchym durchsetzenden lymphozytären Infiltraten. (Aus: Paulus und Schröder 2012)

\subsubsection{Klinischer Verlauf und Pathophysiologie}

Die HSV-Enzephalitis zeigt einen meist typischen klinischen Verlauf, der die pathophysiologischen Prozesse der Erkrankung widerspiegelt. Aus diesem Grund werden im Folgenden die klinischen Erkrankungsstadien, die typischen diagnostischen Beobachtungen sowie die pathophysiologischen Mechanismen dargestellt. Einen Überblick über die zeitlichen Zusammenhänge gibt • Abb. 2.16.

\subsubsection{Klinischer Verlauf der Herpes- Enzephalitis}

Die Herpes-Enzephalitis beginnt mit einem Prodromalstadium aus unspezifischen Symptomen wie allgemeinem Krankheitsgefühl und Fieber (sehr häufig, 90-100\% der Fälle), Bewusstseinsstörungen (recht häufig, 70-90\%), epileptischen Anfällen (häufig, 40-70\%) Kopfschmerz, Wesensänderung sowie fokalneurologischen Defiziten (z. B. Aphasie, Hemiparese), das mehrere Tage andauern kann. Während dieser Frühphase zeigen sich unauffällige cCT- sowie anfangs auch cMRTBefunde, ggf. bilden sich im EEG unspezifische Allgemeinveränderungen sowie ein temporaler Herdbefund ab.

Im Liquor besteht anfangs häufig eine gemischtzellige Pleozytose, die sich innerhalb der ersten Tage zu einer lymphozytären Pleozytose entwickelt (bis 500 Zellen/ $\mu$ l, in $<5 \%$ der Fälle ist auch eine normale Zellzahl möglich). Typischerweise bestehen eine mäßige bis ausgeprägte Eiweißerhöhung (Gesamteiweiß 1,0-1,5 g/l) sowie 

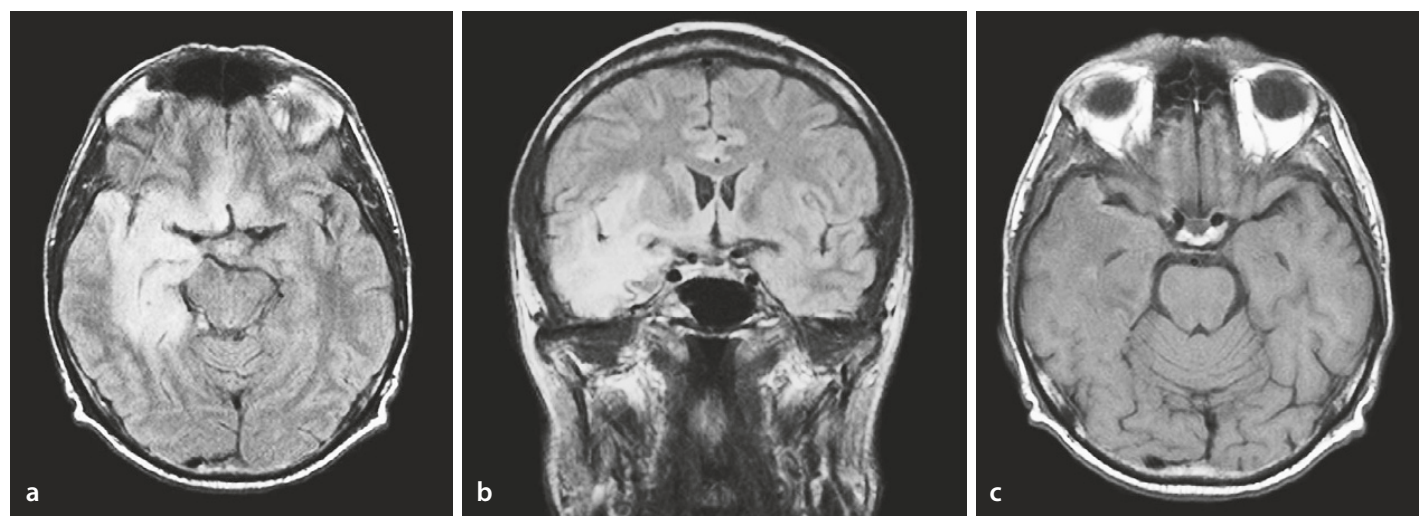

- Abb. 2.14a-c Rechtsseitige Herpes-Enzephalitis. Die Frontobasis links ist beginnend mitbetroffen. a, b FLAIR, c T1 nativ. (Aus: Linn et al. 2011)

- Abb. 2.15a, b Herpes-Enzephalitis bilateral, links ausgedehnter als rechts. a FLAIR, b T2. (Aus: Linn et al. 2011)
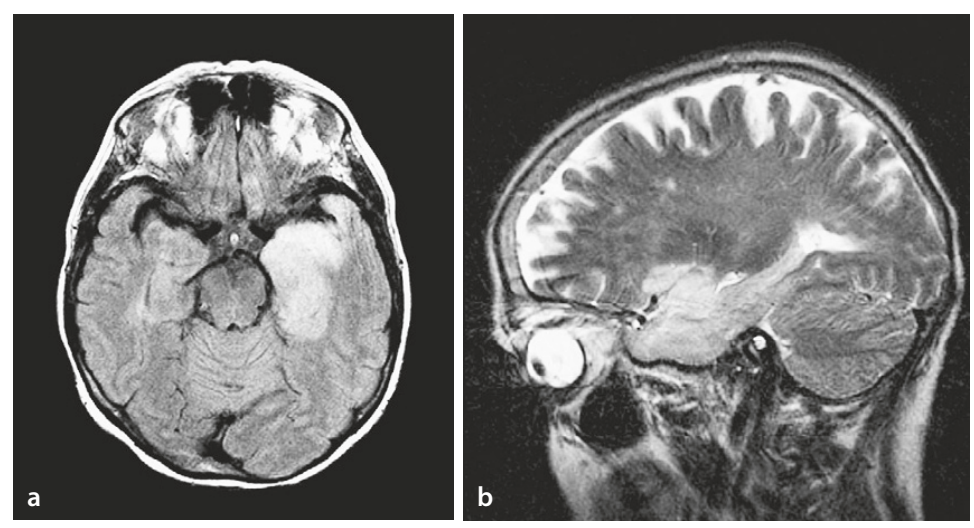

ein leichter Laktatanstieg (bis 4,0 $\mathrm{mmol} / \mathrm{l}$ ). In der Liquor-PCR kann die HSV-Infektion bereits innerhalb der ersten 5 Tage mit hoher Sensitivität nachgewiesen werden, ein Nachweis spezifischer IgG-Antikörper ist jedoch frühestens ab dem 10. Tag möglich.

Im Anschluss an das Prodromalstadium entwickeln sich Fieber und Nackensteifigkeit, es treten manifeste neurologische und/oder neuropsychologische/-psychiatrische Störungen auf, die von einer allgemeinen Verwirrtheit oder Bewusstseinstrübung bin hin zu psychoseähnlichen $\mathrm{Zu}$ ständen reichen können. Fokale neurologische Symptome (Aphasie, Hemiparese) und insbesondere epileptische Anfälle treten häufig entsprechend der Lokalisation des Virusbefalles auf. Im cCT/cMRT zeigen sich einseitig temporale hypodense Läsionen ( Abb. 2.14), im EEG bestehen bereits schwerwiegende diffuse Hirnfunktionsstörungen.

\section{Cave}

Die CT-Bildgebung ist in den ersten Tagen der Erkrankung häufig unauffällig. Entscheidend ist die frühe MRT-Diagnostik!

Unbehandelt nehmen die Symptome innerhalb von Stunden oder wenigen Tagen fulminant $\mathrm{zu}$, klinisch entwickelt sich dann in der Regel zusätzlich eine schwere quantitative Bewusstseinsstörung. Die Entzündung breitet sich nach kontralateral aus, es entstehen bitemporale und bifrontobasale hämorrhagische Nekrosen (-Abb. 2.15), die zu einem massiven Anstieg des intrakraniellen Druckes mit nachfolgender Herniation führen können. Während dieser Phase zeigen sich im EEG charakteristische „periodische lateralisierte Komplexe" (PLEDs), auch Sharp Waves oder SharpSlow-Waves können sichtbar werden.

Mehr als zwei Drittel der unbehandelten Patienten versterben während dieser Phase. 
$(8$ Die Herpes-Enzephalitis hat einen typischen rasch-progredienten Verlauf, stellt sich aber in der Frühphase häufig unspezifisch dar. Bereits im Verdachtsfall ist - auch bei unauffälliger Bildgebung - frühestmöglich eine virustatische i.v.-Therapie einzuleiten, um verheerende Spätfolgen zu verhindern.

\subsubsection{Hirnnerven als Leitstruktur des Virenbefalles}

Der Grund für die Lokalisation der charakteristischen mesiotemporalen Hirnläsionen bei der Herpes-Enzephalitis liegt vermutlich in der Neuroanatomie. Es wird angenommen, dass der Virusbefall entweder den N. trigeminus oder den N. olfactorius betrifft und das Virus über retrograden axonalen Transport das Gehirn erreichen kann. Für den N. olfactorius als Leitstruktur der Virusinfektion spricht insbesondere seine direkte Verbindung $\mathrm{zu}$ frontalen und mesiotemporalen Gehirnstrukturen sowie dem limbischen System, dessen Schädigung das bereits frühe Auftreten von Bewusstseinsstörungen erklären könnte. Der $\mathrm{N}$. trigeminus andererseits innerviert die Meningen und erreicht den Lobus orbitofrontalis als auch den Lobus temporalis, was ebenfalls eine Eintrittspforte für das Virus sein könnte. Die Ausbreitung des Virusbefalls auf die kontralaterale Seite läuft vermutlich entlang der vorderen Kommissur. Bei Neugeborenen ist die Infektion hingegen üblicherweise nicht auf rhinenzephale Strukturen begrenzt, sondern zeigt eine diffuse Verteilung.

In sehr seltenen Fällen kann auch der Hirnstamm von der Virusinfektion betroffen sein.

\subsubsection{Mutationen des TLR3-Signalweges}

Untersuchungen der vergangenen Jahre konnten Faktoren identifizieren, die für eine Herpes-Enzephalitis prädisponieren. Hierzu gehören unterschiedliche Mutationen in für den Toll-likeRezeptor-3 (TLR3)-Signalweg kodierenden Genen. TLR3 gehört zu den „Muster-Erkennungsrezeptoren" und wird im zentralen Nervensystem, in epithelialen sowie in dendritischen Zellen exprimiert. Es ist wichtiger Protagonist im Rahmen der angeborenen (unspezifischen) Immunantwort.

Bei einer HSV-Infektion wird die virale DNA durch TLR3 erkannt und löst eine Signalkaskade aus, die (unter anderem) die Produktion proin- flammatorischer Zytokine (insbesondere IFN- $\alpha$, $-\beta$ und/oder IFN- $\lambda$ ) anregt und die Immunantwort initiiert. Zum gegenwärtigen Zeitpunkt sind 6 Gene bekannt, die am TLR3-Signalweg beteiligt sind (TLR3, UNC93B1, TRIF, TRAF3, TBK1 und IRF3). Die Mutation in einem dieser Gene verursacht eine Störung des TLR3-Signalweges und führt zu einer verminderten Interferonproduktion und damit zu einer inadäquaten Immunantwort. Zugleich ließ sich in mehreren In-vitro-Untersuchungen zeigen, dass die Virusreplikation in genetisch prädisponierten Zellen deutlich schneller verläuft als in Zellpopulationen ohne genetische Mutation. Von unterschiedlichen Gruppen wurde deshalb bereits eine ergänzende Interferonbehandlung von an Herpes-Enzephalitis erkrankten Patienten vorgeschlagen.

Zusammengenommen weisen diese Beobachtungen auf eine genetisch bedingte - möglicherweise erbliche - Immundefizienz hin (Bradshaw und Venkatesan 2016; Zhang und Casanova 2015). Bislang handelt es sich hierbei jedoch insgesamt um Erkenntnisse aus experimentell-wissenschaftlichen Studien, die im klinischen Setting weiterer Überprüfung bedürfen.

\subsubsection{Pathophysiologie der Herpes- Enzephalitis}

Die schwerwiegenden Schäden der HSV 1-Enzephalitis sind auf mindestens zwei Mechanismen zurückzuführen. Einerseits die direkten Auswirkungen des Virus auf das infizierte Gewebe, andererseits die Schädigung, die durch die Immunantwort des Wirtes hervorgerufen wird.

\section{- Direkte Auswirkung des Virus}

Herpes simplex gehört zu den lytischen Viren, die die infizierte Wirtszelle zerstören bzw. ihre Apoptose, also den programmierten Zelltod herbeiführen. Zu Beginn der Erkrankung gelangt das Virus über axonalen Transport (s. oben) in das zentrale Nervensystem. Aufgrund einer angeborenen oder erworbenen Immundefizienz erfolgt in dieser frühen Krankheitsphase allenfalls eine inadäquate Immunantwort - selbst bei beginnendem Zelluntergang von Neuronen und Gliazellen. Während dieser Phase zeigen sich bereits Allgemeinveränderungen im EEG als Ausdruck der schweren Zellschädigung, wohingegen die cCT-Bildgebung - möglicherweise aufgrund der fehlenden Immunreaktion und Ausbleiben eines perifokalen Ödems - noch unauffällig ist. 
Interessanterweise korreliert die Viruslast im Liquor nicht mit der Schwere der Erkrankung oder den zerebralen Läsionen in der MRT-Bildgebung. Diese Beobachtung gab bereits früh Hinweise auf einen zusätzlichen, die Krankheit erschwerenden, Immunprozess (Wildemann et al. 1997).

\section{Der zytopathische Effekt (" cytopathic} effect", CPE) beschreibt typische morphologische Veränderungen virusinfizierter Wirtszellen, die sich in vitro nachweisen lassen. Hierzu gehören u. a. eine Abkugelung und Lyse der betroffenen Zelle, die Bildung von Riesenzellen (Synzytien) sowie das Auftreten klassischer nukleärer Einschlüsse

(z. B. Cowdry-Typ A bei HSV-Infektion). Der zytopathische Effekt ist auch im Falle der HSV-Enzephalitis für den Zelltod der betroffenen Neuronen verantwortlich.

\section{- Auswirkungen der (überschießenden) Immunantwort}

In unterschiedlichen, sowohl klinischen, als auch tierexperimentellen Studien konnte gezeigt werden, dass es bei der HSV-Enzephalitis zu sekundären, Virus-unabhängigen Schädigungen des Hirnparenchyms kommt (Martinez-Torres et al. 2008). Einer der Gründe hierfür ist offenbar die (letztlich) überschießende Immunantwort des Wirtes.

Neben den Effekten der angeborenen und der erworbenen Immunantwort könnten auch sekundäre Autoimmunmechanismen eine Rolle spielen ( Abschn. 2.3.4).

Denkbar wäre eine - in erster Instanz - beeinträchtigte angeborene Immunreaktion (genetische Störung des TLR3-Signalweges mit verminderter Ausschüttung proinflammatorischer Zytokine, s. oben), die das Erkennen und adäquate Bekämpfen des eingedrungenen Virus erschwert. Nach Infiltration und Ausbreiten des Virus kommt es vermutlich zu einem Überschießen der spezifischen Immunantwort, die den verheerenden Entzündungsprozess der Akutphase verursacht.

Verschiedene Hinweise sprechen für eine derartig fehlgeleitete, ausufernde Immunreaktion (Martinez-Torres et al. 2008): Hierzu gehört die Beobachtung eines deutlich schwerwiegenderen Krankheitsverlaufes der Herpes-Enzephalitis bei immunkompetenten gegenüber immungeschwächten Patienten. Hinzu kommen Studien, die den Nutzen einer ergänzenden KortisonTherapie bei ähnlichen Erkrankungen mit überschießender Entzündungsreaktion (z. B. bakterielle Meningitis, herpetische Keratitis) darstellen konnten. Auch die erfolgreiche alleinige Anwendung von Kortison - bevor Aciclovir zur Verfügung stand - gibt Hinweis auf den positiven Effekt einer ergänzenden immunsuppressiven Behandlung der HSV-Enzephalitis.

Vor diesem Hintergrund kann eine KortisonGabe aktuell als Ultima Ratio (z. B. bei kritischem Anstieg des Hirndruckes) in Erwägung gezogen werden (s. auch DGN Leitlinie 2015).

Zusammenfassend scheinen der zytopathische Effekt der Virusinfektion und die Folgen der überschießenden Immunantwort gemeinsam für den rasanten und hochdramatischen Verlauf der Erkrankung verantwortlich zu sein (• Abb. 2.16).

Die Bedeutung eines sekundären Autoimmunprozesses soll im Folgenden dargestellt werden.

\subsubsection{Sekundäre Autoimmun- prozesse}

Obwohl die HSV-Enzephalitis als monophasische Erkrankung gilt, treten in bis zu 27\% der Fälle innerhalb der ersten 4 Monate nach Abklingen der Symptome Rezidive auf (Armangue et al. 2014). Oft zeigt sich hierbei klinisch ein etwas anderes Bild als zuvor: Die Patienten werden auffällig durch Bewegungsstörungen oder psychiatrische Symptome, wohingegen epileptische Anfälle oder fokal-neurologische Störungen in den Hintergrund rücken. Diese Beobachtung, die zumeist negative Virus-PCR in erneuten Liquoruntersuchungen, ein schlechtes Ansprechen auf die wiederholte Aciclovir-Gabe und fehlende $\mathrm{Zu}$ nahme der MR-tomographischen Läsionen lenkten den Verdacht auf ein autoimmunvermitteltes Geschehen.

Hinzu kommen mehrere Fallberichte der vergangenen Jahre über biphasische Verläufe von HSV-Enzephalitiden, bei denen NMDA-Rezeptor-Antikörper nachgewiesen werden konnten und das erneute Auftreten enzephalitischer Symptome als Autoimmunenzephalitis gewertet - und so therapiert werden konnte.

Ein zufälliges Zusammentreffen von viraler und autoimmuner Enzephalitis erscheint - ob der Seltenheit beider Entitäten - eher unwahrscheinlich, sodass man von einer durch die Virusinfek- 
Unspezifische Allgemeinsymptome: Kopfschmerz, Unwohlsein

Subfebrile Temperatur

Leichte Allgemeinveränderung

Temporaler Herdbefund

Unauffällige Bildgebung
Zunehmende Bewusstseinstrübung, fokalneurologische Symptomatik

(Aphasie, Hemiparese, Anfälle)
Koma

Mittelschwere bis schwere Allgemeinveränderung

Periodische Komplexe über beiden Temporalregionen

$$
\begin{aligned}
& \text { Hypodensität temporal } \underset{\text { bitemporal }}{ } \longrightarrow \text { Hämorrhagische Imbibierung } \\
& \text { Temporal gyriforme KM-Aufnahme }
\end{aligned}
$$

Ödembildung temporal $\longrightarrow$ Zunahme des Ödems, bitemporale Läsionen KM-Aufnahme, zytotoxisches Ödem

Virus-PCR positiv

Pleozytose, Eiweißerhöhung $\longrightarrow$

\begin{tabular}{|c|c|c|c|}
\hline INFEKTION & PRODROMALPHASE / Stadium 1 & 2. WOCHE / Stadium 2 & 3. WOCHE / Stadium 3 \\
\hline
\end{tabular}

HSV-spezifische Antikörper

\begin{tabular}{|c|c|}
\hline 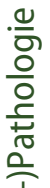 & $\begin{array}{l}\text { Unspezifische Veränderungen: } \\
\text { - } \quad \text { Stauung von kleinen Gefäßen } \\
\text { - } \quad \text { (sub-)kortikale Petechien } \\
\text { - } \quad \text { Makrophagen + Lymphozyten im } \\
\quad \text { Bereich der Meningen } \\
\text { - } \quad \text { Cowdry-Typ-A-Einschlüsse }\end{array}$ \\
\hline
\end{tabular}

Lokale Produktion von $\lg M, \lg A$, IgG

Mikrogliaknötchen

Perineurale Satellitosen

Zunehmende Entwicklung hämorrhagischer Nekrosen mit perivaskulären Infiltraten

Ausgedehnte Entzündungsreaktion und Ödembildung

Astrogliose

Immunhistochemischer Nachweis von Virus-Antigen positiv

HSV gelangt über

retrograden, axonalen

Transport in das ZNS

(N. olfactorius/trigeminus)

TLR3-Mutation: inadäquate unspez. Immunantwort (?)

Viral vermittelter Zelluntergang von

Neuronen und Gliazellen "Zell-Lyse”
Zunehmende Nekrose temporal

Ausbreitung des Prozesses auf die Gegenseite

Überschießende spez. Immunantwort mit schwerer Entzündungsreaktion, Ödembildung, Anstieg des Hirndruckes

Autoimmunreaktion (?)

- Abb. 2.16 Klinischer Verlauf, Diagnostik und Pathophysiologie der HSV-Enzephalitis

tion getriggerten Antikörperbildung ausgehen kann. Als Ursachen hierfür wurden unterschiedliche Hypothesen aufgestellt. Hierzu gehören beispielsweise eine gemeinsame genetische Prädisposition oder eine durch die virusinduzierte neuronale Schädigung (mit Freisetzung neuronaler Antigene) angestoßene Autoimmunreaktion. Daneben wurden von verschiedenen Autoren eine unspezifische B-Zell-Aktivierung und/oder ein molekulares Mimikri durch strukturelle Ähnlichkeiten zwischen Virus und Autoantigen in Betracht gezogen.

Bemerkenswerterweise ließen sich NMDARezeptor-Antikörper auch bei einigen Patienten nachweisen, die keine erneute Enzephalitis durch- lebten. Welche Rolle die pathologischen Antikörper in diesem Falle spielten, ist gegenwärtig nicht geklärt (Prüss et al. 2012).

\subsubsection{Immunsuppressive Therapie bei NMDA-positiver Herpes- Enzephalitis?}

In der Mehrzahl der beschriebenen NMDA-Enzephalitis-Fälle infolge einer HSV-Enzephalitis wurde die Therapie um Immunsuppressiva ergänzt oder damit weitergeführt (s. auch $>$ Abschn. 2.4).

Die Beobachtung der zusätzlichen Autoimmunreaktion gibt Hinweise darauf, dass die 
schwere Hirnschädigung im Rahmen der HSVEnzephalitis nicht alleine auf die Virusinfektion mit konsekutivem Zelluntergang sowie die überschießende Immunantwort zurückzuführen ist, sondern auch durch Autoimmunmechanismen verstärkt wird. Vor diesem Hintergrund könnte eine Therapie mit immunsuppressiven Substanzen - allen voran Kortikosteroiden, in manchen Fallberichten aber auch Cyclophosphamid oder Rituximab - eine mögliche zusätzliche Option darstellen. Entgegen der Befürchtung, eine derartige Therapie könnte die HSV-Infektion verstärken, konnte dies weder im Tiermodell noch in einzelnen Fallstudien nachgewiesen werden (Nosadini et al. 2017).

$(8$ Bei erneutem Auftreten oder anhaltenden/ zunehmenden enzephalitischen Symptomen einer Herpes-Enzephalitis sollte sowohl an eine unzureichende Primärtherapie gedacht als auch eine autoimmun vermittelte Genese in Betracht gezogen werden. Eine Untersuchung auf NMDA-Rezeptor-Antikörper sowie auf andere potenzielle Antikörper (gegen Zelloberflächen/synaptische Antigene) sollte durchgeführt werden, um ggf. eine Immuntherapie einleiten zu können.

\subsubsection{Grundprinzipien der Therapie}

Bereits beim klinisch begründeten Verdacht auf eine Herpes-Enzephalitis sollte unverzüglich eine virustatische Therapie mit Aciclovir eingeleitet werden, da der pathologische Prozess ansonsten nicht aufgehalten werden kann.

Aciclovir wurde bereits in den 1970-er Jahren entwickelt und ist seither in unterschiedlicher Form (Suspension, Tabletten, Infusion) verfügbar. Es ist ein Prodrug, das zunächst in die virusinfizierten (Wirts-)Zellen aufgenommen und dort phosphoryliert - und damit aktiviert - wird. Die erste Phosphorylierung (zu Aciclovir-Monophosphat) erfolgt durch die viruskodierte Thymidinkinase, die weiteren (zu Aciclovir-Triphosphat) durch körpereigene Enzyme.

Nach seiner Aktivierung wird Aciclovir-Triphosphat anstelle von Guanin-Nukleotid in die Virus-DNA eingebaut. Dies hat letztlich einen Kettenabbruch der Virus-DNA zur Folge, da keine weiteren Nukleotide angeknüpft werden können und die virale DNA-Polymerase am Aciclovir fi- xiert bleibt. Da weder Eppstein-Barr- noch Zytomegalieviren eine Thymidinkinase besitzen, ist Aciclovir bei diesen Erkrankungen nicht wirksam.

\section{(. Cave}

Die Aciclovir-Gabe sollte stets mit Bedacht erfolgen: Durch seine geringe Wasserlöslichkeit und zugleich niedrige Bioverfügbarkeit von unter $50 \%$ bei i.v.-Gabe (Plasmahalbwertszeit ca. 2,5-3 Stunden) ist eine hochdosierte Gabe notwendig. Zugleich werden etwa $70 \%$ des Pharmakons unverändert renal ausgeschieden. Hier können hohe und zu schnell applizierte Dosierungen auskristallisieren und nephrotoxisch wirken. Es gilt deshalb: strenge Indikationsstellung, langsame i.v.-Gabe, ausreichende Flüssigkeitszufuhr und regelmäßige Kreatinin-Kontrollen!

Sollte eine Aciclovir-Unverträglichkeit oder -Resistenz bestehen, kann auf das Virustatikum Foscarnet zurückgegriffen werden. Foscarnet ist ein selektiver Inhibitor viraler Enzyme (durch Blockade der Pyrophosphatbindungsstelle der DNA-Polymerase) und kann so die Replikation und Virusvermehrung unterbrechen.

Eine Kortison-Gabe kann bei kritisch erhöhtem Hirndruck als Ultima Ratio erwogen werden, bislang existieren keine Ergebnisse zur generellen Wirksamkeit einer ergänzenden GlukokortikoidTherapie.

\section{(3)}

Fragen zur Lernkontrolle

- Welche Besonderheit besteht beim Herpes-simplex-Virus gegenüber anderen Herpesviren?

- Welche Faktoren können (mutmaßlich) für eine Herpes-Enzephalitis prädisponieren?

- Welchen klassischen Verlauf nimmt eine Herpes-Enzephalitis und wie lassen sich die unterschiedlichen Phasen pathophysiologisch erklären?

- Welche therapeutischen Optionen bestehen bei Herpes-Enzephalitis und auf welcher Grundlage wirken die Therapeutika? 


\subsection{Limbische Enzephalitis und Autoimmunenzephalitis}

\section{S. Knauss}

\section{- - Zum Einstieg}

Limbische Enzephalitiden (LE) sind eine Gruppe entzündlicher Erkrankungen des ZNS, die überwiegend das limbische System betreffen und lebensbedrohlich sein können. Etwa 60\% der Fälle sind mit Neoplasien assoziiert (paraneoplastische LE). Sie werden von den nicht-paraneoplastischen limbischen Enzephalitiden unterschieden. Ein grundsätzliches Verständnis der Pathomechanismen der unterschiedlichen Entitäten ist wichtig, da sich Diagnostik und Therapie in Abhängigkeit von der zugrundeliegenden Ätiologie unterscheiden. Neben der Einteilung paraneoplastisch vs. nichtparaneopastisch können LE auch nach der Lokalisation des Antigens (extrazellulär vs. intrazellulär) eingeteilt werden. In den letzten Jahren konnten neben einer Neoplasie auch zahlreiche weitere Triggerfaktoren dieser Erkrankung, wie eine Infektion des zentralen Nervensystems, identifiziert werden.

Limbische Enzephalitis und Autoimmunenzephalitis

- Heterogene Gruppe entzündlicher ZNSErkrankungen im Bereich des limbischen Systems.

- Bislang keine verbindliche Klassifikation, Unterscheidung hier in

- limbische (paraneoplastische) Enzephalitis,

- Autoimmunenzephalitis (fakultativparaneoplastisch, z. B. NMADR-Enzephalitis, LGI1-Enzephalitis),

- weitere (z. B. infolge einer ZNS-Infektion).

- Klinik der autoimmunen limbischen Enzephalitis: Subakuter Beginn (schnelle Progression innerhalb von weniger als 3 Monaten), Gedächtnisstörung (insbesondere Arbeits- und Kurzzeitgedächtnis), psychiatrische Symptome, Wesenveränderungen, epileptische Anfälle.

- Diagnostik:

- MRT: bilaterale Auffälligkeiten der medialen Temporallappen in T2-gewichteten FLAIR-Sequenzen,
- Liquor: Pleozytose (>5 Zellen/ $\mu \mathrm{l})$,

- EEG: epileptische oder Slow-WaveAktivität im Bereich der Temporallappen, Ausschluss von Differenzialdiagnosen.

- Therapie: Je nach Grunderkrankung; immunsuppressive/-modulatorische Therapie, Tumortherapie nach onkologischer Maßgabe.

- Prognose: Sehr variabel, je nach Grunderkrankung. Prognoseentscheidend ist der möglichst frühe Therapiebeginn.

\section{Limbische Enzephalitiden}

Die limbische Enzephalitis (LE) ist eine Entzündung des Gehirns, die hauptsächlich Strukturen betrifft, die zum limbischen System gehören. Ihre Ätiologie kann vielfältig sein. Die Ursachen einer limbischen Enzephalitis umfassen infektiöse (z. B. im Rahmen einer Herpes-simplex-Enzephalitis, s. $>$ Abschn. 2.3), aber auch paraneoplastische und nicht-paraneoplastische autoimmune Prozesse.

\subsubsection{Grundlagen/Nomenklatur}

Klassische paraneoplastische limbische Enzephalitiden treten häufig in Verbindung mit Tumorerkrankungen auf, ohne dass sie direkt durch den Tumor, dessen Metastasen, metabolische oder therapiebedingte Ursachen erklärbar wären. Sie sind typischerweise mit Antikörpern gegen intrazelluläre Zielantigene assoziiert. Die Antikörper sind mutmaßlich nicht direkt pathogenetisch relevant. Als primär ursächlich für die neuronale Schädigung wird ein T-Zell-vermittelter Prozess angenommen (Bien et al. 2012).

Im Gegensatz dazu scheinen bei den 2007 erstmals beschriebenen und nur fakultativ paraneoplastischen Autoimmunenzephalitiden mit Antikörpern gegen neuronale Oberflächenantigene die Antikörper eine entscheidende pathogenetische Rolle zu spielen (Dalmau et al. 2008).

Die klassische Trennung zwischen paraneoplastischen und den neuen fakultativ paraneoplastischen Enzephalitiden, häufig synonym als Autoimmunenzephalitiden bezeichnet, ist haupt- 
sächlich historischer Natur. Auch therapeutisch relevanter ist eine Unterscheidung nach pathophysiologischer Relevanz der Antikörper. In Abhängigkeit vom Antikörpertypen ist bei frühzeitigem Therapiebeginn unter Umständen ein sehr gutes Therapieansprechen zu erwarten (Graus et al. 2009).

In diesem Beitrag wird aus Konventionsgründen eine Trennung in klassische paraneoplastische limbische Enzephalitis und Autoimmunenzephalitis beibehalten. Insbesondere die Autoimmunenzephalitiden mit Antikörpern gegen neuronale Oberflächenantigene stellen ein sich rasch entwickelndes neues Feld der Neurologie dar. Jährlich werden neue Subentitäten beschrieben, und für viele ist der genaue Pathomechanismus unbekannt. Es sollen daher einige Grundprinzipien der Pathophysiologie für die häufigsten autoimmunen Entitäten dargestellt werden.

\section{Differenzialdiagnose der autoimmunen} und paraneoplastischen limbischen

\section{Enzephalitis}

- Infektiös:

- HSV, VZV, HHV6, Lues, HIV, Morbus Whipple, Creutzfeld-Jakob-Krankheit

- Rheumatologisch:

- Lupus erythematodes, SjögrenSyndrom, Sarkoidose

- Neoplastisch:

- Gliome

- Metabolisch:

- Wernicke-Korsakow-Syndrom, hepatische Enzephalopathie, septische Enzephalopathie

- Vaskulär:

- ischämisch, z. B. Verschluss der Percheron-Arterie mit bithalamischen Infarkten

\subsubsection{Das limbische System}

Das limbische System ist eine unscharfe Beschreibung von kortikalen und subkortikalen Strukturen und deren Verbindungen, denen insbesondere eine Bedeutung für komplexe assoziative Funktionen (Emotionen, Gedächtnis, Affekt, Antrieb) und die Regulation vegetativer Funktionen zugeschrieben werden. Der zuerst von MacLean ver- wendete Begriff geht auf Paul Brocas Beschreibung des „grand lobe limbique“ (lat. Limbus: Gürtel) zurück, der den Gyrus cinguli und den Gyrus parahippocampalis als Gürtel aneinanderliegender Rindenfelder beschrieb. Da keine eindeutige Definition des limbischen Systems existiert, ist der Begriff weiterhin umstritten, hat sich jedoch als Konzept integrativer Aspekte der beteiligten Regionen und aus didaktischen Gründen durchgesetzt. Regelmäßig dazu gezählt werden:

- der Hippocampus mit seinen Faserverbindungen,

- Gyrus parahippocampalis (mit Area entorhinalis, -perirhinalis, -presubicularis und -parahippocampalis caudalis),

- Gyrus cinguli,

- telenzephale Kerngebiete (Area septalis, Ncl. accumbens, Corpus amygdaloideum),

- thalamische Kerngebiete (Ncll. anteriores),

- hypothalamische Kerngebiete (Corpus mamillare).

Insbesondere die Verbindungen zwischen diesen Strukturen (z. B. Papez-Neuronenkreis) sind von entscheidender Bedeutung für die physiologische Funktion des limbischen Systems. Störungen in diesem System sind als Bestandteil zahlreicher neurologischer Erkrankungen beschrieben (z. B. Korsakow-Syndrom mit amnestischen Konfabulationen bei Schädigung der Corpora mammillaria, Alzheimer-Demenz bei neurodegenerativem hippocampalen Neuronenuntergang, Temporallappenepilepsie bei Hippocampussklerose oder Schizophrenie bei Verminderung der glutamatergen Neurone des Gyrus parahippocampalis und Hippocampus). Eine akute oder subakute Funktionseinschränkung von Strukturen des limbischen Systems kann zum Bild der limbischen Enzephalitis führen.

\section{Papez-Neuronenkreis}

Der sogenannte Papez-Neuronenkreis ist einer der wichtigsten Schaltkreise des limbischen Systems. Er wurde von James Papez 1937 beschrieben und als Grundlage der Emotionsregulation postuliert (Papez 1937). Wie heute bekannt ist, sind die tatsächlichen Verschaltungen der beteiligten Hirnstrukturen weitaus komplexer, sodass auch der hier dargestellte Schaltkreis eher als didaktisches Konzept dient.

Ausgehend vom Ammonshorn und dem Subiculum des Hippocampus führt er über den Fornix postcommissuralis zum Corpus mammillare. Von dort zieht er über mammillothalamische Bahnen zu anterioren Thalamuskernen und zum Gyrus cinguli. Über das Cingulum und Presubiculum 
erreicht er schließlich die Area entorhinalis. Von dort schließt sich der Kreis zum Subiculum und Hippocampus. Alkoholtoxisch und im Rahmen von Polioenzephalitiden kann es zu Schädigungen insbesondere der Corpora mammillaria und damit zu Unterbrechungen dieses Schaltkreises kommen. Klinische Folge ist das sog. Korsakow-Syndrom mit amnestischen Konfabulationen.

\subsubsection{Entstehungsmechanismus immunvermittelter Enzephalitiden}

Die Pathogenese der einzelnen Unterformen der immunvermittelten Enzephalitiden unterscheiden sich deutlich voneinander. Trotzdem sind die Grundmechanismen für die Entwicklung einer antineuronalen Immunreaktion in beiden Fällen ähnlich.

\subsubsection{Paraneoplastische limbische Enzephalitis}

Im Falle der klassischen paraneoplastischen limbischen Enzephalitis wird angenommen, dass die ektope Präsentation neuronaler Antigene ein wichtiger Trigger für eine epitopspezifische Autoimmunität darstellt. Eine den Tumor umgebende Entzündungsreaktion könnte dabei im lymphatischen System eine Immunreaktion induzieren, die sich nicht nur gegen die Antigene des Tumors selbst, sondern auch gegen neuronale Strukturen richtet. Die häufigsten im Zusammenhang mit einer klassischen paraneoplastischen limbischen Enzephalitis gefundenen Antikörper sind Anti-Hu, Anti-Ma/Ta und Anti-CRMP5/ CV2, die sich allesamt gegen intrazelluläre neuronale Antigene richten (•Tab. 2.4).

Die Namen der Antikörper beziehen sich dabei häufig auf die Initialen der Patienten, bei denen sie zuerst gefunden wurden. Die häufigsten assoziierten Tumoren sind kleinzellige Lungentumoren für Anti-Hu und -CRMP5/CV2 bzw. Hoden- und Keimzelltumoren für Anti-Ma/Ta.

Für die assoziierten Tumoren konnte eine ektope Expression der jeweiligen Antigene nachgewiesen werden (Albert et al. 1998). Ein Grund für die Induktion der Immunreaktion gegen diese Tumorantigene könnte daher in der körpereigenen Tumorabwehr liegen. Für zahlreiche Fälle konnte gezeigt werden, dass das Auftreten eines paraneoplastischen Syndroms, wie z. B. der limbischen Enzephalitis, mit einem längeren Überleben oder sogar einer Regression des Tumors einher- geht (Keime-Guibert et al. 1999; Darnell und DeAngelis 1993). Dies vermag womöglich auch zu erklären, warum sich in einer Mehrzahl der Fälle die Tumoren bei Auftreten paraneoplastischer Syndrome noch in einem frühen Stadium befinden oder erst Monate oder Jahre später in Erscheinung treten. Es ist jedoch unklar, ob bereits das Auftreten der Antikörper oder erst eine klinisch relevante Immunreaktion - im Sinne eines paraneoplastischen Syndroms - mit einer relevanten Tumorsuppression einhergeht (Monstad et al. 2004). Diese Diskrepanz ist insbesondere pathophysiologisch interessant, da für die klassischen paraneoplastischen Syndrome ein T-Zell-vermittelter Effekt angenommen wird (s. unten).

$>$ Die häufigsten Antikörper bei einer paraneoplastischen limbischen Enzephalitis sind Anti-Hu, -YO, -Ri und -Ma2/Ta.

\subsubsection{Autoimmunenzephalitis}

Im Gegensatz zur klassischen paraneoplastischen limbischen Enzephalitis wird bei den limbischen Enzephalitiden mit Antikörpern gegen neuronale Oberflächenantigene ein direkter Effekt durch die Antikörper angenommen (s. unten). Auch für diese Gruppe der Autoimmunenzephalitiden ist jedoch die ektope Expression von neuronalen Antigenen durch Tumoren ein wichtiger Triggerfaktor.

Die NMDAR-Enzephalitis, die mit Abstand am häufigsten vorkommende Autoimmunenzephalitis, ist bei erwachsenen Frauen in ca. 50\% der Fälle mit einem Ovarialteratom assoziiert. Ovarialteratome enthalten regelhaft neuronales Gewebe mit Expression von NMDAR-Untereinheiten (Tabata et al. 2014).

Zahlreiche Fallbeschreibungen legen zudem die Vermutung nahe, dass generell die Exposition von neuronalen Antigenen in Zusammenhang mit einer Entzündungsreaktion zur Bildung von antineuronalen Antikörpern führen kann. Die Herpes-simplex-Enzephalitis kann beispielsweise selbst eine limbische Enzephalitis mit NMDARezeptor-Antikörpern triggern (s. - Abschn. 2.3). Als Auslöser wird eine Exposition neuronaler Antigene durch virusinduzierte Zerstörung neuronalen Gewebes angenommen. Ähnliches konnte für eine ZNS-Infektion mit Varicella-zoster-Viren, im Verlauf einer schubförmig remittierenden multiplen Sklerose, Glioblastomen und bei Zerstörung peripheren Nervengewebes beobachtet werden (Prüß 2016). 
- Tab. 2.4 Häufige und gut charakterisierte paraneoplastische Antikörper. Der häufigste mit dem Antikörper assoziierte Tumor ist fett gedruckt hervorgehoben

\begin{tabular}{|c|c|c|c|}
\hline Antikörper & Art des Antigens & Klinische Präsentation & Tumorassoziation \\
\hline $\mathrm{Hu}$ (ANNA-1) & $\begin{array}{l}\text { Antigene in neuronalen } \\
\text { Zellkernen des zentralen } \\
\text { und peripheren Nerven- } \\
\text { systems }\end{array}$ & $\begin{array}{l}\text { Enzephalomyelitis, Hirnstamm- } \\
\text { enzephalitis, limbische Enzepha- } \\
\text { litis, zerebelläre Ataxie, Denny- } \\
\text { Brown-Syndrom, gastrointestinale } \\
\text { Pseudoobstruktion, autonome } \\
\text { Neuropathie, Opsoklonus- } \\
\text { Myoklonus-Syndrom (OMS) }\end{array}$ & $\begin{array}{l}\text { SCLC, [„small cell lung } \\
\text { cancer" (kleinzelliges } \\
\text { Bronchialkarzinom)], } \\
\text { Prostatakarzinom, Neuro- } \\
\text { blastom, Thymom }\end{array}$ \\
\hline Ri (ANNA-2) & $\begin{array}{l}\text { Antigene in neuronalen } \\
\text { Zellkernen des zentralen } \\
\text { Nervensystems }\end{array}$ & $\begin{array}{l}\text { OMS, zerebelläre Ataxie, } \\
\text { Encephalomyelitis }\end{array}$ & $\begin{array}{l}\text { Mamma-, Ovarialkarzinom, } \\
\text { SCLC, Medulloblastom }\end{array}$ \\
\hline Yo (PCA-1) & $\begin{array}{l}\text { „Yo-Antigen“ in Purkinje- } \\
\text { Zellen des Kleinhirns }\end{array}$ & zerebelläre Ataxie & $\begin{array}{l}\text { Gynäkologische Tumoren } \\
\text { (Ovarial-, Mamma-, Endo- } \\
\text { metriumkarzinom) }\end{array}$ \\
\hline CV2/CRMP5 & $\begin{array}{l}\text { Antigen ist das intrazelluläre } \\
\text { „collapsing response media- } \\
\text { tor protein 5“, das vor allem } \\
\text { im Kortex und im Kleinhirn } \\
\text { exprimiert wird }\end{array}$ & $\begin{array}{l}\text { Encephalomyelitis, limbische } \\
\text { Enzephalitis, zerebelläre Ataxie, } \\
\text { Neuropathie }\end{array}$ & SCLC, Thymom \\
\hline Ma-1 & $\begin{array}{l}\text { Antigen in Nucleoli, v. a. von } \\
\text { Neuronen des Kleinhirns }\end{array}$ & $\begin{array}{l}\text { Hirnstammenzephalitis, LE und } \\
\text { Neuropathie }\end{array}$ & $\begin{array}{l}\text { Mammakarzinom, Bronchial- } \\
\text { karzinom, Kolonkarzinom }\end{array}$ \\
\hline $\mathrm{Ma}-2 / \mathrm{Ta}$ & $\begin{array}{l}\text { Antigen in Nucleoli, v. a. von } \\
\text { Neuronen des Kleinhirns }\end{array}$ & Hirnstammenzephalitis und LE & Keimzelltumoren \\
\hline $\operatorname{Tr}$ (DNER) & $\begin{array}{l}\text { Antigen ist der Delta/notch- } \\
\text { like epidermal growth factor- } \\
\text { related receptor }\end{array}$ & Zerebelläre Ataxie & $\begin{array}{l}\text { Hodgkin-Lymphom, } \\
\text { Non-Hodgkin-Lymphom }\end{array}$ \\
\hline
\end{tabular}

Allen diesen Konstellationen gemeinsam ist die Exposition von neuronalen Proteinen, die ansonsten dem Immunsystem nicht zugänglich sind. Das saisonale Häufigkeitsmuster des Auftretens von Autoimmunenzephalitiden bei Kindern mit einem Peak in den warmen Monaten von April bis September ist zudem eine interessante Beobachtung, die weitere Umweltfaktoren für die Entwicklung einer Autoimmunenzephalitis nahelegt. Denkbar wäre eine saisonale Verbreitung von Infektionserregern als Ursache. Die genauen Mechanismen und mögliche Suszeptibilitätsfaktoren, die in einigen Fällen zur Bildung von antineuronalen Antikörpern und zum klinischen Bild einer autoimmunen limbischen Enzephalitis führen, sind jedoch weiterhin nicht gut verstanden.

\subsubsection{Grundprinzipien der Patho- physiologie unterschiedlicher Enzephalitiden}

Insbesondere auf der Grundlage histologischer und funktioneller Untersuchungen konnte in den letzten Jahren das Verständnis der Pathomechanismen der autoimmunen und paraneoplastischen limbischen Enzephalitis deutlich erweitert werden. Vor allem die Lokalisation des Zielantigens der Antikörper scheint dabei eine wichtige Rolle zu spielen.

$>$ Die klassische paraneoplastische limbische Enzephalitis ist häufig mit Antikörpern gegen intrazelluläre Zielantigene assoziiert, wohingegen die Gruppe der Autoimmunenzephalitiden typischerweise Antikörper gegen neuronale Oberflächenantigene zeigt. 

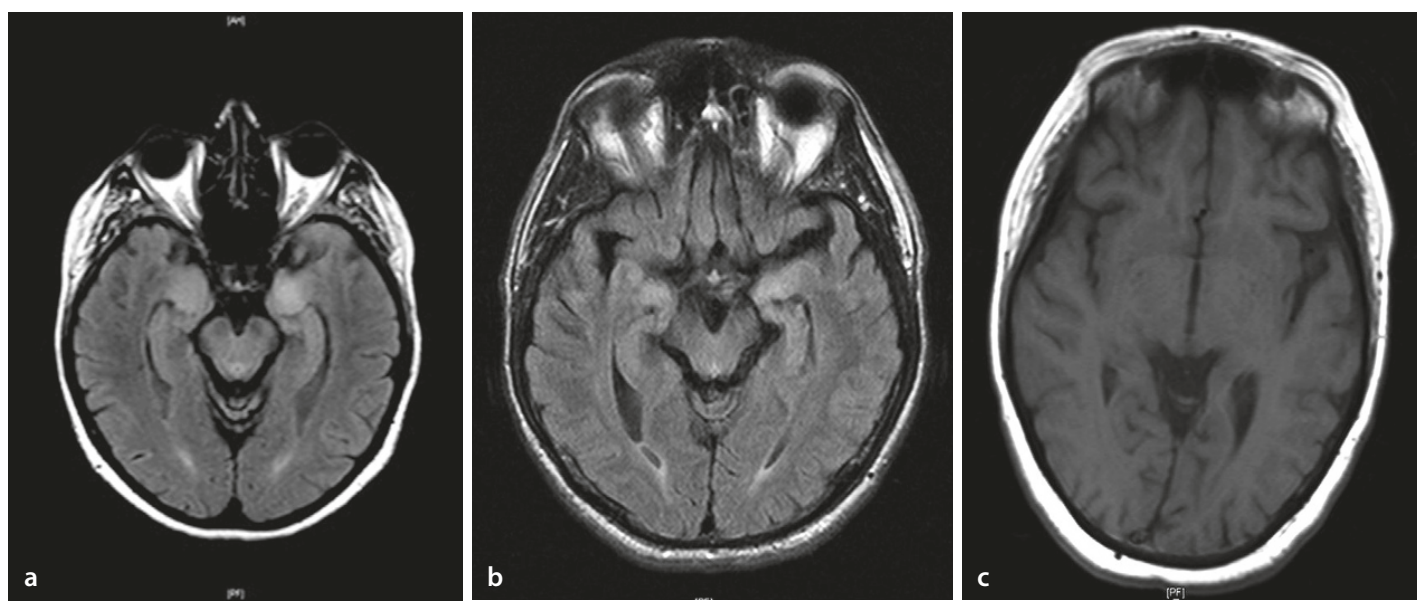

- Abb. 2.17 MRT-Bildgebung bei unterschiedlichen limbischen Enzephalitiden. a Bei einer Anti-Hu-assoziierten paraneoplastischen Enzephalitis kommt es typischerweise zu einer hyperintensen Signalveränderung der Hippocampi beidseits. $\mathbf{b}$ Auch bei der LGI1-Enzephalitis sind im Stadium

\subsubsection{Paraneoplastische LE}

Mit Ausnahme von Antikörpern gegen die Glutamat-Dehydrogenase (GAD) und Amphiphysin konnte für praktisch keinen Antikörper gegen intrazelluläre Antigene eine direkte Pathogenität im Tiermodell oder im Menschen gezeigt werden.

Histologische Untersuchungen legen vielmehr einen zytotoxischen T-Zell-vermittelten Effektormechanismus nahe. Der zum Teil deutliche Neuronenverlust und die erhöhte Dichte eingewanderter T-Zellen in Biopsie- und Autopsiematerial von Patienten mit paraneoplastischen LE gaben erste Hinweise auf eine inflammatorische neuronale Schädigung. Durch die Darstellung der direkten Assoziation von aktivierten zytotoxischen T-Zellen (definiert durch die Expression von CD107a und Granzym-B) mit neuronalen Strukturen wurde der Verdacht auf einen durch zytotoxische T-Zellen vermittelten Neuronenverlust weiter erhärtet. Auch die erhöhte Rate von zytotoxischen T-Zellen (CD8/CD3 Ratio) im Hirngewebe von Patienten mit einer paraneoplastischen limbischen Enzephalitis würde zu diesem Schädigungsmechanismus passen (Bien et al. 2012; Albert et al. 1998).

Sowohl die Fluordesoxyglukose-Positronenemissionstomographie (FDG-PET) als auch die MRT-Bildgebung zeigen in einer Mehrzahl der Fälle typische bildgebende Korrelate einer Ent- der limbischen Enzephalitis häufig die Hippocampi betroffen. c Bei der NMDAR-Enzephalitis finden sich in 50-75\% der Fälle keine Signalveränderungen in der MRT. (Abbildung von PD Dr. Harald Prüß, Klinik für Neurologie Charité Universitätsmedizin Berlin, mit freundlicher Genehmigung)

zündungsreaktion in wichtigen Strukturen des limbischen Systems (• Abb. 2.17).

Praktisch alle Patienten mit einer LE mit Antikörpern gegen intrazelluläre Antigene zeigen mesiotemporal einen gestörten Glukosemetabolismus in der FDG-PET. Auch im MRT lassen sich in einem Großteil der Fälle meist hyperintense Signalveränderungen in diesen Regionen nachweisen (Baumgartner et al. 2013). Es ist somit davon auszugehen, dass die neurologische Symptomatik direkt durch die inflammatorische Schädigung der Neuronen hervorgerufen wird (Stich und Rauer 2013).

\section{Bei den klassischen paraneoplastischen limbischen Enzephalitiden sind nicht die Antikörper selbst, sondern wahrscheinlich eine zelluläre Immunantwort zytotoxischer T-Zellen für die Symptome verantwortlich.}

\subsubsection{Autoimmunenzephalitis}

Histologische Untersuchungen von Patienten mit einer Autoimmunenzephalitis konnten zeigen, dass das Ausmaß der Infiltration des Hirngewebes durch Entzündungszellen maßgeblich vom jeweiligen Antikörper-Zielantigen abhängig ist. Die Autoimmunenzephalitiden lassen sich hiernach in drei Hauptgruppen aufteilen:

- Neurotransmitter-Rezeptoren (NMDAR, AMPAR, mGluR5, GABAAR, GABABR, GlyR), 
- Tab. 2.5 Übersicht über die wichtigsten Autoimmunenzephalitiden

\begin{tabular}{|c|c|c|c|c|}
\hline Antigen & Art des Antigens & Klinische Präsentation & Tumorassoziation & $\begin{array}{l}\text { Angenommener } \\
\text { Mechanismus }\end{array}$ \\
\hline NMDAR & $\begin{array}{l}\text { lonotroper } \\
\text { Glutamat- } \\
\text { Rezeptor }\end{array}$ & $\begin{array}{l}\text { Enzephalitis mit primär } \\
\text { psychiatrischer Präsen- } \\
\text { tation }\end{array}$ & $\begin{array}{l}\text { Altersabhängig, bei } \\
\text { erwachsenen Frauen in } \\
50 \% \text { Ovarialterartom }\end{array}$ & $\begin{array}{l}\text { Internalisierung der Rezep- } \\
\text { toren mit reduzierter Ober- } \\
\text { flächenexpression }\end{array}$ \\
\hline LGI1 & $\begin{array}{l}\text { Extrazelluläres } \\
\text { VGKC-assoziier- } \\
\text { tes Protein }\end{array}$ & $\begin{array}{l}\text { FBDS, LE mit ausge- } \\
\text { prägter Gedächtnis- } \\
\text { störung }\end{array}$ & $10 \%$, meist Thymom & $\begin{array}{l}\text { Störung der transynapti- } \\
\text { schen Signaltransduktion }\end{array}$ \\
\hline AMPAR & $\begin{array}{l}\text { lonotroper Glut- } \\
\text { amat-Kanal }\end{array}$ & $\begin{array}{l}\text { LE, epileptische } \\
\text { Anfälle, Psychosen }\end{array}$ & $\begin{array}{l}70 \%, \text { v. a. Bronchial- } \\
\text { und Mammakarzinom }\end{array}$ & $\begin{array}{l}\text { Internalisierung der Rezep- } \\
\text { toren }\end{array}$ \\
\hline GABABR & $\begin{array}{l}\text { Metabotroper } \\
\text { GABA-Rezeptor }\end{array}$ & $\begin{array}{l}\text { LE mit häufigen epi- } \\
\text { leptischen Anfällen }\end{array}$ & $\begin{array}{l}\text { 50\% der Fälle Bron- } \\
\text { chialkarzinom, v.a. } \\
\text { SCLC (kleinzelliges } \\
\text { Bronchialkarzinom) }\end{array}$ & $\begin{array}{l}\text { Blockade des Rezeptors } \\
\text { ohne Internalisierung }\end{array}$ \\
\hline mGluR5 & $\begin{array}{l}\text { Metabotroper } \\
\text { Glutamat- } \\
\text { Rezeptor }\end{array}$ & $\begin{array}{l}\text { LE, Ophelia-Syndrom } \\
\text { (Depression, Agitation, } \\
\text { Halluzinationen, } \\
\text { Gedächtnisstörung, } \\
\text { Wesensänderungen) }\end{array}$ & Hodgkin-Lymphom & Unbekannt \\
\hline CASPR2 & $\begin{array}{l}\text { Extrazelluläres } \\
\text { VGKC-assoziier- } \\
\text { tes Protein }\end{array}$ & $\begin{array}{l}\text { LE, zerebelläre Symp- } \\
\text { tomatik, Morvan- } \\
\text { Syndrom (Neuromyo- } \\
\text { tonie + LE) }\end{array}$ & $\begin{array}{l}<10 \% \text { (bei Morvan ca. } \\
40 \% \text { ) dann meist Thy- } \\
\text { mome }\end{array}$ & $\begin{array}{l}\text { Veränderung des Synap- } \\
\text { sengerüsts (Gephyrin) }\end{array}$ \\
\hline GAD & $\begin{array}{l}\text { GABA-syntheti- } \\
\text { sierendes Enzym }\end{array}$ & $\begin{array}{l}\text { LE, zerebelläre Ataxie, } \\
\text { Stiff-Person-Syndrom }\end{array}$ & $\begin{array}{l}\text { Selten paraneoplas- } \\
\text { tisch (Thymom, Mam- } \\
\text { ma-, Kolonkarzinom) }\end{array}$ & Unbekannt \\
\hline
\end{tabular}

\section{- lonenkanaluntereinheiten bzw. Zellad- häsionsmoleküle (LGI1, CASPR2, DPPX, IgLON5) sowie \\ - gliale Strukturen (GFAP).}

Aussagekräftige Studien liegen hauptsächlich für die beiden häufigsten Subtypen mit Antikörpern gegen NMDAR und LGI1 vor, weshalb sie hier vornehmlich behandelt werden. In - Tab. 2.5 sind zudem die wichtigsten Autoimmunenzephalitiden mit ihren jeweiligen Zielantigenen aufgeführt.

(2) Bei der NMDAR- und der LGI1-Enzephalitis führen die Antikörper direkt zu einer Funktionseinschränkung, die zumindest im frühen Stadium prinzipiell reversibel ist. Der wichtigste Prognosefaktor bei der NMDAR- und LGI1-Enzephalitis ist daher die frühzeitige Diagnose mit ausreichend aggressiver Immuntherapie.

\section{- NMDAR-Enzephalitis}

Die NMDA-Rezeptor-Antikörper-assoziierte Autoimmunenzephalitis ist mit Abstand die häufigste und am besten verstandene Erkrankung der Gruppe der Autoimmunenzephalitiden. Bei der NMDAR-Enzephalitis, wie auch bei den meisten anderen Autoimmunenzephalitiden mit Antikörpern gegen extrazelluläre Antigene, sind die Antikörper direkt pathogenetisch relevant und führen z. B. durch eine Internalisierung des Rezeptorkomplexes zu einer synaptischen Funktionsstörung.

Auch bei einer NMDAR-Enzephalitis finden sich Entzündungszellinfiltrate im Hirngewebe (- Abb. 2.18). Sie sind jedoch deutlich weniger stark ausgeprägt als bei anderen Enzephalitiden. Es dominieren Plasmazellinfiltrate, passend zu der für die Autoimmunenzephalitiden typischen, intrathekalen Immunglobulinsynthese (MartinezHernandez et al. 2011). Eine direkte Assoziation 


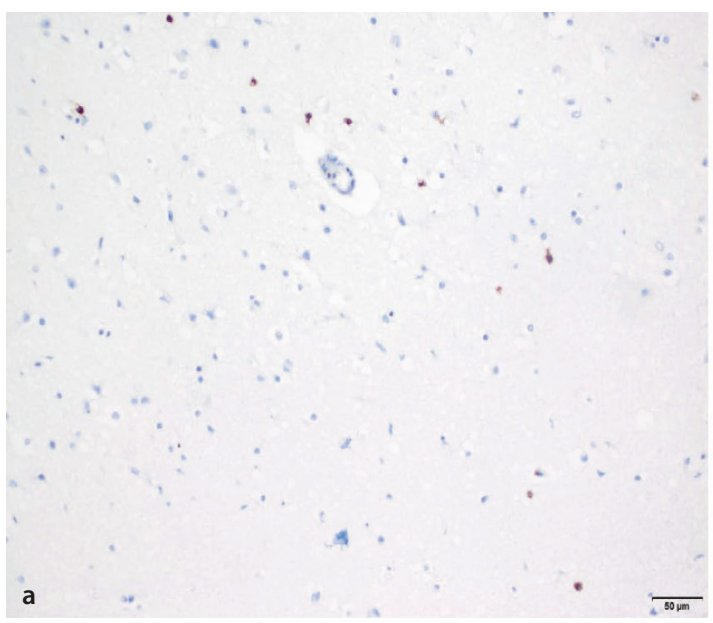

- Abb. 2.18a, b Geringe Infiltration von CD8+-zytotoxischen T Zellen im temporalen Kortex bei NMDAR-Enze-

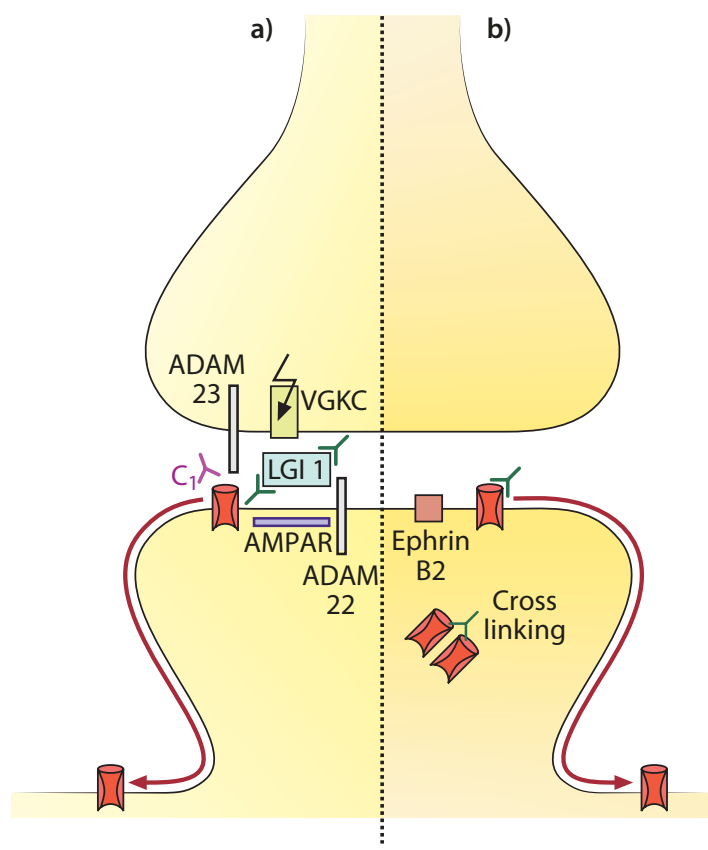

- Abb. 2.19a, b Pathogenität der Antikörper bei a LGI1und b NMDAR-Enzephalitis. a Binden Antikörper an LGI1, kommt es zu einer Störung der transsynaptischen Signaltransduktion der Proteine ADAM22 und ADAM23. Dadurch wird zum einen die Kanalfunktion der VGKC moduliert, zum anderen kommt es zu einer Delokalisation des AMPAR aus der Synapse. b Durch Bindung von Antikörpern an die N1-Untereinheit des NMDA-Rezeptors kommt es, nach einer vorübergehenden Aktivierung des Rezeptors und gestörter Ephrin-B2-Interaktion, zur Dislokation und Kreuzvernetzung ("cross linking") der NMDARezeptoren, die zur Internalisierung des Komplexes führt. Nach Transport ins Lysosom und Endosom wird der Rezeptor-Antikörper-Komplex abgebaut.

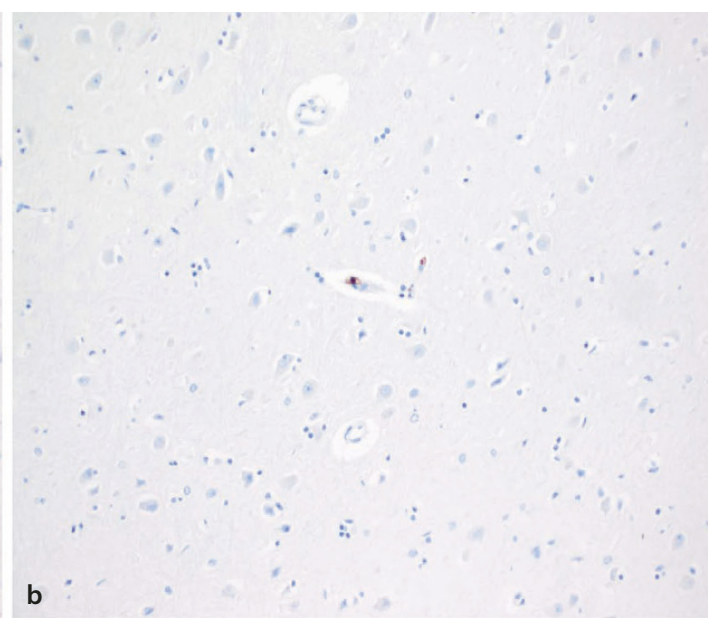

phalitis. (Mit freundlicher Genehmigung des Instituts für Neuropathologie der Charité Universitätsmedizin Berlin)

mit Neuronen und ein Neuronenverlust konnten nicht nachgewiesen werden (Bien et al. 2012).

Hippocampale Strukturen weisen die höchste Dichte an NMDA-Rezeptoren auf. So ist es nicht verwunderlich, dass in diesen Regionen auch eine besonders ausgeprägte Bindung der Antikörper an Neurone gezeigt werden konnte. Eine Komplementaktivierung und damit eine irreversible Schädigung der Nervenzellen durch diese Antikörper scheint jedoch nicht oder zumindest nicht unmittelbar stattzufinden (Martinez-Hernandez et al. 2011).

Es stellt sich also die Frage, wie die Antikörper $\mathrm{zu}$ diesen teilweise schwerwiegenden neurologischen Symptomen führen, ohne eine ausgeprägte neuronale Schädigung zu hinterlassen. Erste Erkenntnisse dazu beruhen auf neuronalen Zellkulturexperimenten mit Patientenliquor: Die Behandlung von Zellkulturen mit Liquor von $\mathrm{Pa}-$ tienten mit einer NMDAR-Enzephalitis führte zu einer selektiven Verminderung der NMDARDichte auf den Dendriten, die nach Auswaschen des Liquors reversibel war (Dalmau et al. 2008). Mittlerweile ist der zugrunde liegende Mechanismus dieser Beobachtung besser verstanden (- Abb. 2.19):

Die Bindung der Antikörper an die NR1Untereinheit des NMDA-Rezeptors scheint u. a. durch eine gestörte Interaktion des Rezeptors mit Ephrin B2 zu einer lateralen Dislokation des Rezeptors aus dem synaptischen Spalt zu führen (Mikasova et al. 2012). Durch eine Kreuzvernetzung („cross-linking“) der Rezeptoren durch den 

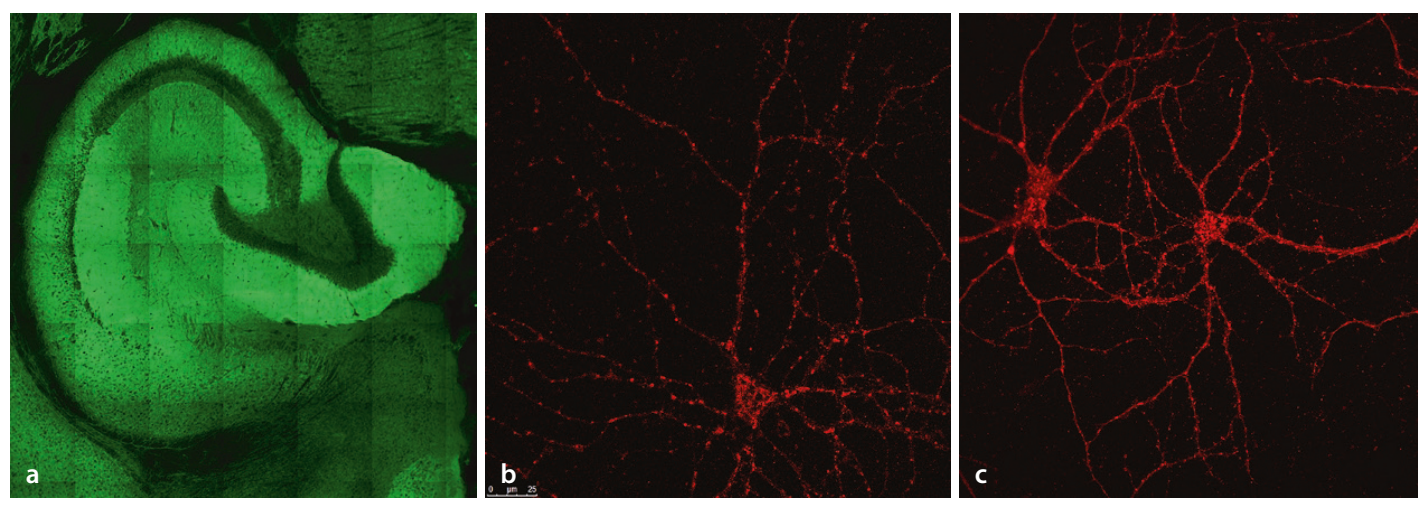

- Abb. 2.20a-c Fluoreszenzmikroskopische Darstellung der Antikörperbindung und Verringerung der Clusterdichte nach NMDAR-Antikörperbehandlung. a NMDAR-Antikörper binden insbesondere an hippocampale Neurone; Neuronen zeigen nach Behandlung mit NMDAR-Antikörpern (b)

Antikörper kommt es zudem zur Internalisierung des Rezeptorkomplexes und damit zu einer $\mathrm{Ab}$ nahme der Rezeptorclusterdichte (• Abb. 2.20). Nach der Internalisierung folgt der Transport und Abbau des Komplexes im Lysosom und Endosom (Moscato et al. 2014).

Die unveränderte Dichte anderer synaptischer Proteine und der Synapse selbst legt eine hohe Selektivität der Antikörper nahe. Zusätzlich scheint bereits die Mutation einer einzelnen Aminosäure in der Proteinstruktur des Rezeptors zum Verlust der Antikörperbindung zu führen.

Die insgesamt gestörte synaptische Signaltransduktion in Strukturen des limbischen Systems führt also zum klinischen Bild der NMDAREnzephalitis. Diese Ergebnisse passen ebenso zu den häufig unauffälligen Befunden der MRT-Bildgebung (• Abb. 2.17). Auch wenn die MRT-Bildgebung unauffällig bleibt, kann sich in der FDGPET das typische Muster eines frontotemporalen Hypermetabolismus und eines okzipitalen Hypometabolismus zeigen. Diese Ergebnisse legen eine über das limbische System hinausgehende Pathologie durch die Antikörper nahe.

\section{Epileptische Anfälle bei NMDAR-Enzephalitis}

Interessanterweise konnte in Untersuchungen von Zellkulturen der NMDAR-Enzephalitis durch Behandlung mit Patientenserum eine Abnahme der Dichte inhibitorischer Synapsen auf hippocampalen exzitatorischen Neuronen gezeigt werden, was als Ursache für die häufig beobachteten epileptischen Anfälle bei NMDAR-Enzephalitis angenommen wird.

Auch unabhängig von klinisch manifesten epileptischen Anfällen lässt sich in vielen Fällen im Elektroenzephalogramm ein typisches Muster nachweisen. Charakteristisch eine geringere Rezeptorclusterdichte im Vergleich zur Behandlung mit Kontrollantikörpern (c). (Abbildung von PD Dr. Harald Prüß, Klinik für Neurologie Charité Universitätsmedizin Berlin, mit freundlicher Genehmigung)

für dieses als „extreme delta brush" bezeichnete Muster ist eine rhythmische Delta-Aktivität $(1-3 \mathrm{~Hz})$ mit aufgelagerten "bursts" rhythmischer Beta-Aktivität $(20-30 \mathrm{~Hz})$. In allen Fällen waren die synaptischen Veränderungen nach Entfernen der Antikörper vollständig regredient und konnten auch in vivo nachgewiesen werden.

\section{- LGI1-Enzepehalitis}

Die zweithäufigste Subentität der Autoimmunenzephalitiden ist die LGI1-Enzephalitis. LGI1 ist ein mit dem makromolekularen Kanalkomplex des spannungsgesteuerten Kaliumkanals (VGKC) assoziiertes Protein, das im gesamten Gehirn, vor allem jedoch im Hippocampus und Neokortex, exprimiert wird. Ursprünglich wurde aufgrund der Ko-Lokalisation angenommen, dass sich die Antikörper gegen den VGKC selbst richten würden.

Einer limbischen Enzephalitis geht regelhaft eine Phase mit - für die LGI1-Enzephalitis pathognomonischen - faziobrachialen dystonen Anfällen (FBDS) voraus. Die Ursache für dieses klinische Bild ist bislang nicht geklärt, es hat sich jedoch gezeigt, dass es in der Regel nicht durch Antikonvulsiva beeinflussbar ist, wohingegen eine Immuntherapie, z. B. mit Steroiden, die Anfallsfrequenz unmittelbar senken kann. Die zweite Phase der limbischen Enzephalitis ist gekennzeichnet durch ein ausgeprägtes und rasch progredientes demenzielles Syndrom, das auch durch aggressive Immuntherapie häufig nur noch unzureichend behandelt werden kann.

Die beiden Stadien der LGI1-Enzephalitis zeigen vermutlich unterschiedliche vorherrschende Schädigungsmechanismen. 
Einerseits scheinen die Antikörper die Funktion des VGKCs und die Dichte von Glutamatrezeptoren vom AMPA-Typ zu modulieren, indem sie die Bindung von LGI1 an die synaptischen, und für eine Zell-Zell-Interaktion wichtigen, Proteine ADAM22 und ADAM23 (• Abb. 2.19) und somit die transsynaptische Signalkaskade stören (Ohkawa et al. 2013). Symptome sind vor allem die im Stadium 1 auftretenden FBDS.

Andererseits führt die Antikörperbindung (im Gegensatz zu Anti-NMDAR) zu einer Aktivierung des Komplementsystems und damit zu einer direkten neuronalen Schädigung (Bien et al. 2012) vor allem in hippocampalen und parahippocampalen Strukturen. Klinisches Korrelat ist die im Stadium 2 auftretende limbische Enzephalitis.

Dementsprechend unterscheiden sich auch bildgebende Befunde in diesen beiden Stadien. Während im Stadium der FBDS Auffälligkeiten in der Bildgebung eine Seltenheit sind, zeigt der Großteil der Patienten im Stadium der limbischen Enzephalitis uni- oder bilaterale T2/FLAIRHyperintensitäten im medialen Temporallappen. Im Verlauf kommt es häufig zu einer Hippocampusatrophie als Korrelat des Neuronenverlustes. Abhängig vom Krankheitsstadium kommt es auch zu einer veränderten Darstellung des Glukosemetabolismus im Temporallappen und den Basalganglien in der FDG-PET (Heine et al. 2015). Bei der LGI1-Enzephalitis scheinen also sowohl eine direkte Funktionseinschränkung durch die Antikörperbindung als auch eine sekundäre neuronale Schädigung durch Komplementaktivierung eine Rolle zu spielen.

\subsubsection{Klinische und therapeutische Implikationen}

Die frühzeitige Diagnose und ätiologische Zuordnung einer limbischen Enzephalitis sind für die Therapieentscheidung und damit für die Prognose essenziell. Neben klinischer Untersuchung und Bildgebung nimmt die Antikörperdiagnostik aus Liquor und Serum eine Schlüsselrolle ein. Um eine unnötige Verzögerung des Therapiebeginns zu vermeiden, muss jedoch häufig vor allem anhand des klinischen Bildes und nach Ausschluss von Differenzialdiagnosen eine Therapieentscheidung getroffen werden. Sowohl bei Verdacht auf eine klassische paraneoplastische LE als auch bei Hinweisen auf eine Autoimmunenzephalitis sollte so früh wie möglich mit einer effektiven Immuntherapie begonnen werden.

Paraneoplastische limbische Enzephalitiden sind, insbesondere bei assoziierten Anti-Hu-Antikörpern, häufig von anderen charakteristischen paraneoplastischen neurologischen Syndromen begleitet (-Tab. 2.4), die einen Schlüssel zur richtigen Diagnose darstellen können. Trotz der, auf den ersten Blick sehr breit gefächerten Symptomatik, zeigen auch Autoimmunenzephalitiden häufig einen sehr typischen Verlauf.

Die NMDAR-Enzephalitis beispielsweise zeigt ein charakteristisches Syndrom, das sich nur mit einer schweren, auch über das limbische System hinausgehenden, zerebralen Affektion erklären lässt: Nach einem Prodromalstadium mit subfebrilen Temperaturen oder Kopfschmerzen kommt es typischerweise zu einem Syndrom mit Wesensveränderungen, Wahn und Halluzinationen, gefolgt von typischen perioralen Dyskinesien, Vigilanzveränderungen, epileptischen Anfällen und vegetativen Störungen bis hin zur Hypoventilation, die eine intensivmedizinische Behandlung notwendig machen.

Auch die LGI1-Enzephalitis zeigt ein charakteristisches klinisches Bild: In der Frühphase oft übersehen oder falsch zugeordnet werden die eigentlich für dieses Krankheitsbild pathognomonischen FBDS (s. oben). Die hierauf folgende limbische Enzephalitis ist insbesondere durch ausgeprägte Gedächtnisstörungen, aber auch psychiatrische Auffälligkeiten, epileptische Anfälle und Hyponatriämie gekennzeichnet. Die Ursache für die Hyponatriämie ist bislang nicht eindeutig geklärt. Aufgrund des hohen Vorkommens von LGI1 im Hypothalamus ist eine hypothalamische Ursache - im Sinne einer exzessiven ADH-Ausschüttung - jedoch denkbar.

\subsubsection{Prognostische Bedeutung der Therapie}

Das pathophysiologische Verständnis - insbesondere der Unterschiede - zwischen den klassischen paraneoplastischen limbischen Enzephalitiden (mit zumeist intrazellulären onkoneuralen Antikörpern) und der neuen Gruppe der Autoimmunenzephalitiden (mit Antikörpern gegen neuronale Oberflächenantigene) ist bei häufig zunächst ähnlicher klinischer Präsentation für die Wahl des richtigen langfristigen Therapiekonzepts entscheidend. Während bei den paraneoplastischen LE die Tumorsuche absolute Priorität hat, da ein 
Ansprechen auf eine Immuntherapie in der Regel nicht zu erwarten ist, steht bei den Autoimmunenzephalitiden die Immuntherapie im Vordergrund.

Die neurologische Symptomatik der paraneoplastischen limbischen Enzephalitis wird durch eine inflammatorische neuronale Schädigung hervorgerufen und ist somit zumindest teilweise irreversibel. Selbst bei vollständiger Entfernung des assoziierten Malignoms beträgt die mittlere Überlebensdauer bei einem Anti-Hu-Syndrom lediglich 6-16 Monate (Orange et al. 2012).

Im Gegensatz dazu ist die Funktionseinschränkung bei einem Großteil der Autoimmunenzephalitiden direkt durch die Bindung der Antikörper an neuronale Zielstrukturen verursacht und somit bei frühem Therapiebeginn prinzipiell reversibel. Bei frühem Therapiebeginn und Ansprechen auf die Erstlinientherapie zeigen 97\% der Patienten mit NMDAR-Enzephalitis ein gutes Endergebnis nach zwei Jahren.

\section{GAD-Enzephalitis}

Enzephalitiden mit Antikörpern gegen Glutamat-Dehydrogenase (GAD) nehmen eine interessante Sonderstellung ein. Zwar handelt es sich bei GAD um ein intrazelluläres Antigen, In-vitro- und In-vivo-Experimente mit gereinigtem IgG von Patienten mit GAD-Antikörpern deuten jedoch auch auf eine direkte Pathogenität der Antikörper hin.

Neben der limbischen Enzephalitis finden sich GAD-Antikörper auch im Zusammenhang mit schwer beherrschbaren Temporallappenepilepsien, dem Stiff-person-Syndrom, zerebellären Ataxien und Diabetes mellitus Typ 1. In seltenen Fällen kommt ein assoziierter Tumor vor. GAD ist ein an der Synthese von GABA, dem wichtigsten inhibitorischen Neurotransmitter, beteiligtes Enzym mit zwei Isoformen GAD 65 und GAD 67. Meist richten sich die Antikörper gegen GAD 65, das sich vor allem präsynaptisch findet. Obwohl GAD 65 intrazellulär liegt, wird angenommen, dass es während der synaptischen Vesikelfreisetzung zu einer kurzfristigen Antigen-Antikörper-Interaktion kommt. In-vitroStudien an Hirnschnitten deuten auf eine verminderte inhibitorische synaptische Signaltransmission hin. Allerdings konnte dieser Effekt nur bei Antikörpern von Patienten mit zerebellärer Ataxie und nicht bei solchen mit limbischer Enzephalitis beobachtet werden. Eine mögliche Erklärung hierfür wäre eine unterschiedliche Epitopspezifität, die auch die unterschiedlichen klinischen Präsentationen erklären könnte. Passend zu diesen Befunden ist auch das schlechte Therapieansprechen von Patienten mit limbischer Enzephalitis und Anti-GAD 65 im Gegensatz zu einem 50\%igen Therapieansprechen bei GAD 65-assoziierter zerebellärer Ataxie.

Eine direkte pathogenetische Relevanz der GAD 65-Antikörper wird daher hauptsächlich für die GAD 65-assoziierte zerebelläre Ataxie angenommen. Die genaue Rolle der Anti-GAD 65-Antikörper bleibt jedoch weiterhin ungeklärt.
Fragen zur Lernkontrolle

- Welche wichtigen grundsätzlichen Unterscheidungsmerkmale existieren zwischen limbischen Enzepahlitiden?

- Welcher Pathomechanismus wird als Ursache der Symptome einer paraneoplastischen Enzephalitis in erster Linie vermutet?

- Welche Besonderheiten sollte man in der zerebralen Bildgebung bedenken?

- Was sind typische Zielstrukturen der Antikörper einer Autoimmunenzephalitis?

\section{Literatur}

\section{Literatur zu $>$ Abschn. 2.1}

Andlauer TFM, Buck D, Antony G et al. (2016) Novel multiple sclerosis susceptibility loci implicated in epigenetic regulation. Sci Adv 2: (6): e1501678

Axisa P-P, Hafler DA (2016) Multiple sclerosis. Curr Opin Neurol 29: (3): 345-353

Beecham AH, Patsopoulos NA et al. (2013) International Multiple Sclerosis Genetics Consortium (IMSGC) Analysis of immune-related loci identifies 48 new susceptibility variants for multiple sclerosis. Nat Genet 45 (11): 1353-1360

Berer K, Gerdes LA, Cekanaviciute E et al. (2017) Gut microbiota from multiple sclerosis patients enables spontaneous autoimmune encephalomyelitis in mice. Proceedings of the National Academy of Sciences. 114 (40): 10719-10724

Geraldes R, Ciccarelli O, Barkhof F et al., on behalf of the Magnims study group (2018) The current role of MRI in differentiating multiple sclerosis from its imaging mimics. Nature Rev Neurol 14: 188-213 (https://www. nature.com/articles/nrneurol.2018.14\#f1)

Goodin DS (2016) The epidemiology of multiple sclerosis: insights to a causal cascade. Handb Clin Neurol 138: 173-206

Haase S, Haghikia A, Gold R et al. (2018) Dietary fatty acids and susceptibility to multiple sclerosis. Mult Scler. 24 (1): 12-16

Havla J, Warnke C, Derfuss T, Kappos L, Hartung HP, Hohlfeld R (2016) Interdisciplinary Risk Management in the Treatment of Multiple Sclerosis. Dtsch Ärztebl Int 113 (51-52): 879-886

Hohlfeld R, Dornmair K, Meinl E, Wekerle H (2016a) The search for the target antigens of multiple sclerosis, part 1: autoreactive CD4+ T lymphocytes as pathogenic effectors and therapeutic targets. Lancet Neurol 15 (2): 198-209

Hohlfeld R, Dornmair K, Meinl E, Wekerle H (2016b). The search for the target antigens of multiple sclerosis, part 2: CD8+T cells, B cells, and antibodies in the focus of reverse-translational research. Lancet Neurol 15 (3): 317-331

Hohlfeld R, Wekerle H (2015) Multiple sclerosis and microbiota. From genome to metagenome? Nervenarzt 86 (8): 925-933 
Jarius S, Eichhorn P, Franciotta D et al. (2017) The MRZ reaction as a highly specific marker of multiple sclerosis: re-evaluation and structured review of the literature. J Neurol 264 (3): 453-466

Jarius S, Ruprecht K, Kleiter I et al. (2016) MOG-IgG in NMO and related disorders: a multicenter study of 50 patients. Part 2: Epidemiology, clinical presentation, radiological and laboratory features, treatment responses, and long-term outcome. J Neuroinflammation 13 (1): 280

Jarius S, Eichhorn P, Franciotta D et al. (2017) The MRZ reaction as a highly specific marker of multiple sclerosis: re-evaluation and structured review of the literature. J Neurol 264 (3): 453-466. doi:10.1007/ s00415-016-8360-4

Kalincik T, Guttmann CR, Krasensky J et al. (2013) Multiple sclerosis susceptibility loci do not alter clinical and MRI outcomes in clinically isolated syndrome. Genes Immun 14: 244-248

Kip M, Schönfelder T, Bleß HH (Hrsg) (2016) Weißbuch Multiple Sklerose. Versorgungssituation in Deutschland. Springer, Berlin Heidelberg New York

Kurtzke JF (1983) Rating neurologic impairment in multiple sclerosis: an expanded disability status scale (EDSS). Neurology 33 (11): 1444-1452

Lehmann-Horn K, Wang S-Z, Sagan SA, Zamvil SS, Büdingen von HC (2016) B cell repertoire expansion occurs in meningeal ectopic lymphoid tissue. $\mathrm{JCl}$ Insight 1 (20)

Lennon VA, Wingerchuk DM, Kryzer TJ et al. (2004) A serum autoantibody marker of neuromyelitis optica: distinction from multiple sclerosis. Lancet 364 (9451): 2106-2112. doi: 10.1016/S0140-6736 (04) 17551-X

Linn J, Wiesmann M, Brückmann H (Hrsg) (2011) Atlas der klinischen Neuroradiologie des Gehirns. Springer, Berlin Heidelberg New York, S 379

Lucchinetti CF, Brück W, Parisi J, Scheithauer B, Rodriguez M, Lassmann H (2000) Heterogeneity of multiple sclerosis lesions: implications for the pathogenesis of demyelination. Ann Neurol 47: 707-717

McDonald WI, Compston A, Edan G et al. (2001) Recommended diagnostic criteria for multiple sclerosis: guidelines from the International Panel on the diagnosis of multiple sclerosis. Ann Neurol 50 (1): 121-127

Mentis A-FA, Dardiotis E, Grigoriadis N, Petinaki E, Hadjigeorgiou GM (2017) Viruses and endogenous retroviruses in multiple sclerosis: From correlation to causation. Acta Neurol Scand 136 (6): 606-616

Montalban X, Hauser SL, Kappos L et al. (2017) Ocrelizumab versus Placebo in Primary Progressive Multiple Sclerosis. N Engl J Med 376 (3): 209-220

Ontaneda D, Thompson AJ, Fox RJ, Cohen JA (2017) Progressive multiple sclerosis: prospects for disease therapy, repair, and restoration of function. Lancet 389 (10076): 1357-1366

Paulus W, Schröder JM (Hrsg) (2012) Pathologie/Neuropathologie. Springer, Berlin Heidelberg New York

Petzold A, Balcer LJ, Calabresi PA et al. (2017) Retinal layer segmentation in multiple sclerosis: a systematic review and meta-analysis. Lancet Neurol 16 (10): 797-812
Polman CH, O'Connor PW, Havrdova E et al. (2006) A randomized, placebo-controlled trial of natalizumab for relapsing multiple sclerosis. N Engl J Med 354 (9): 899-910

Polman CH, Reingold SC, Banwell B et al. (2011) Diagnostic criteria for multiple sclerosis: 2010 revisions to the McDonald criteria. Ann Neurol 69 (2): 292-302

Reich DS, Lucchinetti CF, Calabresi PA (2018) Multiple sclerosis. Longo DL (ed) N Engl J Med 378 (2): 169-180

Schumacher A-M, Mahler C, Kerschensteiner M (2017) Pathologie und Pathogenese der progredienten Multiplen Sklerose: Konzepte und Kontroversen. Aktuelle Neurologie 44 (07): 476-488

Thompson AJ, Banwell BL, Barkhof F et al. (2018) Diagnosis of multiple sclerosis: 2017 revisions of the McDonald criteria. Lancet Neurol 17 (2): 162-173

Tischner D, Reichardt HM (2007) Glucocorticoids in the control of neuroinflammation. Mol Cell Endocrinol 15;275 (1-2): 62-70

Warnke C, Menge T, Hartung HP et al. (2010) Natalizumab and progressive multifocal leukoencephalopathy: what are the causal factors and can it be avoided? Arch Neurol 67 (8): 923-930

Warnke C, Kieseier BC, Hartung HP (2013) Biotherapeutics for the treatment of multiple sclerosis: hopes and hazards. J Neural Transm (Vienna) 120 Suppl 1 (S1): $55-60$

Warnke C, Olsson T, Hartung HP (2015) PML: The dark side of immunotherapy in multiple sclerosis. Trends Pharmacol Sci 36 (12): 799-801

Warnke C, Wattjes MP, Adams O et al. (2016) Progressive multifocal leukoencephalopathy. Nervenarzt 87 (12): 1300-1304

\section{Literatur zu $>$ Abschn. 2.2}

Al Bekairy AM, Al Harbi S, Alkatheri AM et al. (2014) Bacterial meningitis: An update review. Afr J Pharm Pharmacol 8: (18): 469-478

Armulik A, Abramsson A, Betsholtz C (2005) Endothelial/ pericyte interactions. Circ Res 97: 512-523

Banerjee A, Kim B, Carmona E et al. (2011) Bacterial Pili exploit integrin machinery to promote immune activation and efficient blood-brain barrier penetration. Nat. Commun 2: 462

Barichello T, Pereira J, Savi G et al. (2011) A kinetic study of the cytokine/chemokines levels and disruption of blood-brain barrier in infant rats after pneumococcal meningitis. J. Neuroimmunol 233: (1-2): 12-17

Borrow R, Abad R, Trotter C et al. (2013) Effectiveness of meningococcal serogroup $C$ vaccine programmes. Vaccine 31: 4477-4486

Brouwer MC, Tunkel AR, van de Beek D (2010) Epidemiology, diagnosis and antimicrobial treatment of acute bacterial meningitis. Clin Microbiol Rev 23: (3): 467-492

Brouwer M, McIntyre P, Prasad K, van de Beek D (2015) Corticosteroids for acute bacterial meningitis, Cochrane. Database. Syst. Rev 9: CD004405

Carmignoto G, Gomez-Gonzalo M (2010) The contribution of astrocyte signalling to neurovascular coupling. Brain Res Rev 63: 138-148. 
Castelblanco RL, Lee M, Hasbun R (2014) Epidemiolgy of bacterial meningitis in the USA from 1997 to 2010: a population-based observational study. Lancet Infect Dis 14: 813-819

Collins S, Vickers A, Ladhani SN et al. (2016) Clinical and molecular epidemiology of childhood invasive nontypeable Haemophilus influenzae disease in England and Wales. Pediatr Infect Dis J 35: (3): e7684

Coureuil M, Join-Lambert OF, Lécuyer H, Bourdoulous S, Marullo S, Nassif X (2012) Mechanism of meningeal invasion by Neisseria meningitidis. Virulence 3 (2): 164-172. doi: 10.4161/viru.18639

Coureuil M, Lécuyer H, Bourdoulous S, Nassif X (2017) A journey into the brain: insight into how bacterial pathogens cross blood-brain barriers. Nat Rev Microbiol 15 (3): 149-159. doi: 10.1038/nrmicro.2016.178

Daneman R (2012) The blood-brain barrier in health and disease. Ann Neurol 72: 648-672

De Gans J, van de Beek D (2002) Dexamethason in adults with bacterial meningitis. New Engl J Med 347: (20): 1549-1556

European Centre for Disease Prevention and Control (2014) Annual Epidemiological Report. Vaccine-preventable diseases - invasive bacterial diseases. Stockholn: ECDC; 2015

European Centre for Disease Prevention and Control (2016) Annual epidemiological report 2016 - Invasive pneumococcal disease. [Internet]. ECDC, Stockholm

Haj-Yasein N, Vindedal G, Eilert-Olsen M et al. (2011) Glialconditional deletion of aquaporin-4 (Aqp4) reduces blood-brain water uptake and confers barrier function on perivascular astrocyte endfeet. Proc Natl Acad Sci 108: 17815-17820

Heckenberg S, Brouwer M, van der Ende A, van de Beek D (2012) Adjunctive dexamethasone in adults with meningococcal meningitis, Neurology 79: 1563-1569

Htar MT, Christopoulou D, Schmitt HJ (2015) Pneumococcal serotype evolution in Western Europe. BMC Infect Dis 15: 419

Kim KS (2006) Microbial translocation of the blood-brain barrier. Int J Parasitol 36: 607-614

Kim KS (2008) Mechanisms of microbial traversal of the blood-brain barrier. Nat Rev Microbiol 6: 625-634

Kim S, Turnbull J, Guimond S (2011) Extracellular matrix and cell signalling: the dynamic cooperation of integrin, proteoglycan and growth factor receptor. J. Endocrinol 209: (2): 139-151

Koedel U, Pfister HW (1999) Oxidative stress in bacterial meningitis. Brain Pathol 9: 57-67

Nau R, Gerber J (2003) Neuronale Schäden bei der bakteriellen Meningitis - Entstehungsmechanismen und mögliche Konsequenzen für die Behandlung. Neuroforum 1/03

Pfister HW, Borasio G, Dirnagl U et al. (1992) Cerebrovascular complications of bacterial meningitis in adults. Neurology 42: 1497-1504

Prevention and Control of Meningococcal Diseases: Recommendations of the advisory committee on immunization practices (ACIP). Recommendations and reports. Prepared by Cohn AC, McNeil JR, Clark TA et al. 22 March 2013/62: (RR02): 1-2
Puig C, Grau I, Marti S et al. (2014) Clinical and Molecular epidemiology of Haemophilus influenzae causing invasive disease in adult patients. PloS one 9: (11): e112711

RKI - Robert Koch-Institut (2016) Epidemiologisches Bulletin, Ausgabe 43/2016. DOI 10.17886/EpiBull2016-064.2

Van Sorge N, Doran K (2012) Defense at the border: the blood-brain barrier versus bacterial foreigners. Future Microbiol 7: (3): 383-394

Vogel U, Taha M-K, Vazquez J et al. (2013) Predicted strain coverage of a meningococcal multicomponent vaccine (4CMenB) in Europe: a qualitative and quantitative assessment. Lancet Infect Dis 13: (5): 416-425

\section{Literatur zu $>$ Abschn. 2.3}

Armangue T, Leypoldt F, Málaga I, Raspall-Chaure M, Marti I et al. (2014) Herpes simplex virus encephalitis is a trigger of brain autoimmunity. Ann Neurol 75 (2): 317-23

Bradshaw MJ, Venkatesan A (2016) Herpes simplex virus-1 encephalitis in adults: Pathophysiology, diagnosis, management. Neurotherapeutics 13: 493-508

DeBiasi RL, Kleinschmidt-DeMasters BK, Richardson-Burns S, Tyler KL (2002) Central Nervous System Apoptosis in Human Herpes Simplex Virus and Cytomegalovirus Encephalitis. The J Infectious Diseases 186: 1547-57

Hacohen Y, Deiva K, Pettingill P, Waters P, Siddiqui A, Chretien P, Menson E, Lin JP, Tardieu M, Vincent A, Lim MJ (2014) N-methyl-D-aspartate receptor antibodies in post-herpes simplex virus encephalitis neurological relapse. Mov Disord 29 (1): 90-6.

Linn J, Wiesmann M, Brückmann H (Hrsg) (2011) Atlas der klinischen Neuroradiologie des Gehirns. Springer, Berlin Heidelberg New York

Martinez-Torres F, Menon S, Pritsch M, Victor N, Jenetzky E, Jensen K, Schielke E, Schmutzhard E, de Gans J, Chung $\mathrm{CH}$, Luntz S, Hacke W, Meyding-Lamadé U, GACHE Investigators (2008) Protocol for German trial of Acyclovir and corticosteroids in Herpes-simplexvirus-encephalitis (GACHE): a multicenter, multinational, randomized, double-blind, placebo-controlled German, Austrian and Dutch trial. BMC Neurol 29;8: 40

Meyding-Lamadé U et al. (2015) DGN-Leitlinie „Virale Meningoenzephalitis". https://www.dgn.org/images/ red_leitlinien/LL_2014/PDFs_Download/030100_ DGN_LL_virale_meningoenzephalitis.pdf

Nosadini M, Mohammad SS, Corazalla F, Ruga EM, Kothur K, Perilongo G, Frigo AC, Toldo I, Dale RC, Sartori S (2017) Herpes simplex virus-induced anti-N-methyl-D-aspartate receptor encephalitis: a systematic literature review with analysis of 43 cases. Dev Med Child Neurol 59: 796-805

Prüss H, Finke C, Höltje M, Hofmann J, Klingbeil C, Probst C, Borowski K, Ahnert-Hilger G, Harms L, Schwab JM, Ploner CJ, Komorowski L, Stoecker W, Dalmau J, Wandinger KP (2012) N-methyl-D-aspartate receptor antibodies in herpes simplex encephalitis. Ann Neurol 72 (6): 902-11

Rabinstein AA (2017) Herpes Virus Encephalitis in Adults. Current knowledge and old myths Neurol Clin 35: 695-705 
Sköldenberg B, Aurelius E, Hjalmarsson A, Sabri F, Forsgren $M$, Andersson B, Linde A, Strannegård O, Studahl M, Hagberg L, Rosengren L (2005) Incidence and pathogenesis of clinical relapse after herpes simplex encephalitis in adults. J Neurol 253 (2): 163-70

Smith G (2012) Herpesvirus Transport to the nervous system and back again. Annu Rev Microbiol 66: 1-28

Suerbaum S et al. (2016) Medizinische Mikrobiologie und Infektiologie, 2. Aufl. Springer, Berlin Heidelberg New York

Whitley R, Kimberlin DW, Prober CG (2007) Pathogenesis and disease. In: rvin A, Campidelli-Fiume G, Mocarski E, Moore PS, Roizman B,Whitley R (eds) Human herpesviruses: biology, therapy and immunoprophylaxis. Cambridge University Press, Cambridge, pp 589-601

Wildemann B, Ehrhart K, Storch-Hagenlocher B, MeydingLamadé U, Steinvorth S, Hacke W, Haas J (1997) Quantitation of Herpes Simplex Virus Type 1 DNA in cells of cerebrospinal fluid of patients with herpes simplex virus encephalitis. Neurology 48: 1341-1346

Zhang SY, Casanova JL (2015) Inborn errors underlying herpes simplex encephalitis: From TLR3 to IRF3. Exp Med 212 (9): 1342-1343

Zhang SY, Jouanguy E, Ugolini S et al. (2007) TLR3 deficiency in patients with herpes simplex encephalitis. Science 317: 1522-1527

\section{Literatur zu $>$ Abschn. 2.4}

Albert ML et al. (1998) Tumor-specific killer cells in paraneoplastic cerebellar degeneration. Nature Med 4 (11): 1321-1324

BaumgartnerA et al. (2013) Cerebral FDG-PET and MRI findings in autoimmune limbic encephalitis: correlation with autoantibody types. J Neurol 260 (11): 2744-2753

Bien CG et al. (2012) Immunopathology of autoantibodyassociated encephalitides: clues for pathogenesis. Brain 135 (5): 1622-1638

Dalmau J, Gleichman AJ, Hughes EG, Rossi JE, Peng X, Lai M, Dessain SK, Rosenfeld MR, Balice-Gordon R, Lynch DR (2008) Anti-NMDA-receptor encephalitis: case series and analysis of the effects of antibodies. Lancet Neurol 7 (12): 1091-1098

Darnell RB., DeAngelis LM (1993) Regression of small-cell lung carcinoma in patients with paraneoplastic neuronal antibodies. Lancet 341 (8836): 21-22

Finke, C et al. (2012) N-methyl- D-aspartate receptor antibodies in herpes simplex encephalitis. Ann Neurol 72 (6): 902-911

Graus F et al. (2016) A clinical approach to diagnosis of autoimmune encephalitis. Lancet 15 (4): 391-404

Graus F, Saiz A, Dalmau, J (2009) Antibodies and neuronal autoimmune disorders of the CNS. J Neurol 257 (4): 509-517

Heine J et al. (2015) Imaging of autoimmune encephalitisRelevance for clinical practice and hippocampal function. Neuroscience 309: 68-83. doi: 10.1016/j.neuroscience.2015.05.037

Keime-Guibert F et al. (1999) Clinical outcome of patients with anti-Hu-associated encephalomyelitis after treatment of the tumor. Neurology 53 (8): 1719-1719
Martinez-Hernandez E et al. (2011) Analysis of complement and plasma cells in the brain of patients with antiNMDAR encephalitis. Neurology 77 (6): 589-593

Mikasova L et al. (2012) Disrupted surface cross-talk between NMDA and Ephrin-B2 receptors in anti-NMDA encephalitis. Brain 135 (5): 1606-1621

Monstad SE et al. (2004) Hu and voltage-gated calcium channel (VGCC) antibodies related to the prognosis of small-cell lung cancer. J Clin Oncol 22 (5): 795-800

Moscato EH et al. (2014) Acute mechanisms underlying antibody effects in anti-N-methyl-D-aspartate receptor encephalitis. Ann Neurol 76 (1): 108-119

Ohkawa T et al. (2013) Autoantibodies to Epilepsy-Related LGI1 in Limbic Encephalitis Neutralize LGI1-ADAM22 Interaction and Reduce Synaptic AMPA Receptors. J Neuroscience 33 (46): 18161-18174

Orange D et al. (2012) Cellular Immune Suppression in Paraneoplastic Neurologic Syndromes Targeting Intracellular Antigens. Arch Neurol 69 (9): 1-9

Papez JW (1937) A Proposed Mechanism Of Emotion. Arch Neurol Psychiat 38 (4), p.725

Prüß, H (2016) Pathophysiologie und Prognosefaktoren der Autoimmunenzephalitiden. Fortschr Neurol. Psychiat 84 (05), p.264

Stich O, Rauer S (2013) Paraneoplastic neurological syndromes. Nervenarzt 84 (4): 455-460

Tabata E et al. (2014) Immunopathological Significance of Ovarian Teratoma in Patients with Anti-N-Methyl-DAspartate Receptor Encephalitis. Eur Neurol 71 (1-2): 42-48 